University of Rhode Island

DigitalCommons@URI

Open Access Dissertations

2017

\title{
Encouraging Energy Efficiancy: Pricing, Education, and Framing
}

Carrie A. Gill

University of Rhode Island, cannegill@gmail.com

Follow this and additional works at: https://digitalcommons.uri.edu/oa_diss

\section{Recommended Citation}

Gill, Carrie A., "Encouraging Energy Efficiancy: Pricing, Education, and Framing" (2017). Open Access Dissertations. Paper 581.

https://digitalcommons.uri.edu/oa_diss/581

This Dissertation is brought to you for free and open access by DigitalCommons@URI. It has been accepted for inclusion in Open Access Dissertations by an authorized administrator of DigitalCommons@URI. For more information, please contact digitalcommons-group@uri.edu. 
ENCOURAGING ENERGY EFFICIENCY:

PRICING, EDUCATION, AND FRAMING

BY

CARRIE A. GILL

\begin{abstract}
A DISSERTATION SUBMITTED IN PARTIAL FULFILLMENT OF THE REQUIREMENTS FOR THE DEGREE OF DOCTOR OF PHILOSOPHY

IN
\end{abstract}

ENVIRONMENTAL AND NATURAL RESOURCE ECONOMICS

UNIVERSITY OF RHODE ISLAND 


\title{
DOCTOR OF PHILOSOPHY DISSERTATION
}

\author{
OF
}

CARRIE A. GILL

APPROVED:

Dissertation Committee:

Major Professor Corey Lang

Emi Uchida

Stephen Atlas

Nasser H. Zawia

UNIVERSITY OF RHODE ISLAND 


\begin{abstract}
Encouraging Energy Efficiency: Pricing, Education, and Framing

By

Carrie A. Gill

Doctor of Philosophy of Environmental and Natural Resource Economics

University of Rhode Island
\end{abstract}

The US residential sector consumed over 20 quadrillion Btu of energy in 2015, costing households billions of dollars in energy bills in addition to negative environmental and health externalities from conventional energy generation. Reducing energy consumption and promoting energy efficiency are critical for controlling costs, minimizing negative environmental impacts, and ensuring security of energy supply. Regulators and policy makers rely on a suite of strategies to promote energy efficiency and conservation. These strategies vary in degree of control over individual freedom of choice, effectiveness and impact, and political and practical feasibility. In this dissertation, I investigate the effects of three strategies to promote energy efficiency.

In the first manuscript, I examine the effects of a time-varying residential electricity rate structure. One challenge of promoting energy efficiency is that the true marginal costs of electricity are not passed onto the majority of consumers who are charged a flat rate for electricity. I exploit quasi-random assignment of TOU rates and use a regression discontinuity framework to identify the causal effects of TOU pricing on four outcomes over the twelve months following treatment for high-use households. Though microeconomic theory predicts households shift consumption from peak to off- 
peak hours, I find only suggestive evidence that this is the case. I find a decrease in level of peak consumption six to eight months following treatment along with a decrease in total consumption, suggesting energy conservation rather than load deferment and possibly indicating spillover effects of energy conservation into off-peak hours. I find evidence for decreases in electricity bill amounts, consistent with both more favorable marginal prices for households with already-low peak proportion and decreased consumption.

In the second manuscript, I evaluate the effectiveness of in-school energy education lessons. Despite the prevalence of such education, there is little empirical evidence to support the efficacy of these programs on tangible outcomes outside of school. Using a differences-in-differences approach, I find evidence for short-term reductions on the order of eight percent in electricity use the day of a lesson regarding reducing phantom electric loads, with evidence of deferment in electricity use rather than reduction. I find no effect of lessons on energy pathways or wind energy on the days of the lessons. Findings show that energy education is potentially a valuable tool for encouraging energy efficiency and conservation, though the timing of lessons and curriculum content are critical to optimize treatment effects.

In the third manuscript, I explore two facets of choice architecture that can encourage more energy-efficient behavior intentions. One challenge of promoting energy-efficient behavior change is status quo bias: limiting energy use often requires sacrificing convenience and comfort now and in the future. Using experimental data, I explore what temporal frame (e.g. daily, monthly, or yearly) minimizes status quo bias and encourages energy-efficient choices. Results suggest individuals are most willing to 
adopt energy-efficient behaviors when the cost savings are framed on a monthly basis, relative to daily and yearly frames. I investigate whether cognitive fluency - the perceived ease of processing information - could be an underlying mechanism. I find suggestive evidence that individuals are indeed most fluent with energy costs framed on a monthly basis, possibly because most individuals receive monthly energy bills. When individuals are faced with energy costs in relatively disfluent frames (daily and yearly), I find that energy efficiency intentions are greatest when given a context for total energy spending in a matching frame. 


\section{ACKNOWLEDGEMENTS}

Completing a dissertation is a team effort, and I want to thank everyone who has provided support, advice, encouragement, and laughter along the way. First and foremost, I am grateful for my advisor, Corey Lang. You consistently set the bar high and expected the most from me, all while providing the best guidance and support throughout my time at URI. You've given me opportunities I would have never had. I could not have done this without you. Thank you for your support both in research and in life! I'm also grateful to Stephen Atlas for welcoming me into MAPLab and getting me involved with interdisciplinary research. Your patience, enthusiasm, and constant encouragement have kept me going! Lastly, thank you to Emi Uchida and David Bidwell for uncountable helpful conversations about research in progress, research ideas, and life in general. Thank you!

I'd also like to thank the faculty in the Department of Environmental and Natural Resource Economics. You have all at one time or another provided encouragement, sympathy, and insight needed to get through this process. A special thank you to Judy Palmer, Denise Foley, and Ben Morris for your extreme patience with my inability to fill out simple forms and multitude of room reservation requests. Your wonderful and caring personalities have brightened many of my days! Thank you!

Thank you to Lisa Sarubbi and the team at United Illuminating for providing excellent research opportunities, support, and patience throughout this process!

I am grateful to my classmates for helpful conversations, diversions, and advice.

Thank you in particular to Kyle Montanio, Andrew Boslett, Nate Merrill, Edson Okwelum, Pam Booth, Mike Weir, Pat Prendergast, and Kristina DiSanto. You have all 
been role models and great friends throughout this process! Thank you to fellow MAPLab members, especially Jim Blair - I always look forward to coffee, bagels, and discussion with you all!

Thank you to the colleagues and friends I've worked with on municipal energy management this past year. Thanks in particular to Simona Trandafir for getting me involved with this effort, Kristina DiSanto, Rachel Sholly, and Becca Trietch, Ilene Mason and Jerry Drummond, Kaylyn Keane and Kate Venturini, and Lindsey, Joe, Mary, Ryan, and Alex. It has been such a pleasure working with you all and I'm so excited to continue working together!!

Thank you to my friends for your constant support. Karina, you've been an inspiration for me from college to grad school and beyond. Thank you for always being there for me! Lisa, I've valued your friendship since we were kids. Thanks for all the laughs throughout the years! Team five - Lisa, Andrea, and Mat - you all taught me how to be part of a team. I look forward to years of sharing GSO lost and found emails!

A big, big thank you to the URI women's ultimate team! You've gotten me through the toughest days and always showed true spirit, perseverance, and kindness. I've tried to incorporate our FEARLESS attitude into every aspect of my life! Thank you especially to all the captains and players I've worked so closely with. I look forward to continued friendship and years of coaching in the future!!

Most importantly, thank you to my amazing parents Bruce and Colleen Gill. You've been so patient and encouraging throughout this process and you are the kindest, nicest people I know - you two are my role models! I love you both so much! :) Thank you!! 


\section{PREFACE}

This dissertation is written in three-manuscript form. The first manuscript is coauthored with Corey Lang. It is being prepared for submission to the Journal of Environmental Economics and Management. The second manuscript is also co-authored with Corey Lang. It is being prepared for submission to the Journal of the Association of Environmental and Resource Economists. The third manuscript is co-authored with Stephen Atlas and David Hardisty. It is being prepared for submission to the Journal of Public Policy and Marketing.

Manuscript 1: The effects of mandatory time-of-use pricing on high-consuming households using a regression discontinuity framework

Manuscript 2: Learn to conserve? The effects of in-school energy education on at-home electricity consumption

Manuscript 3: Matching costs to context: Status quo bias, temporal framing, and household energy decisions 


\section{TABLE OF CONTENTS}

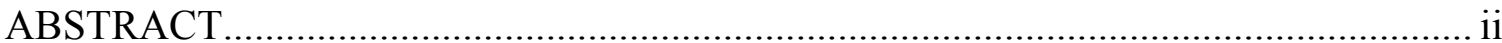

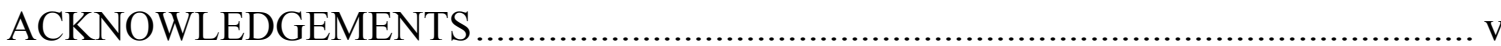

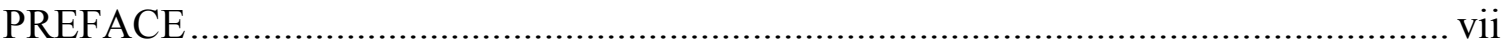

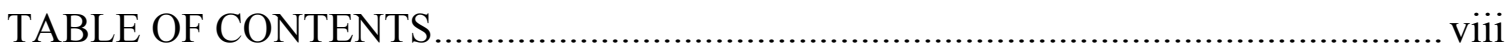

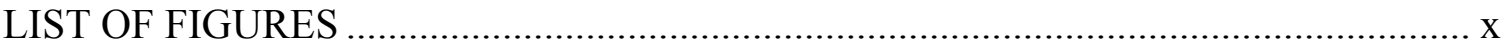

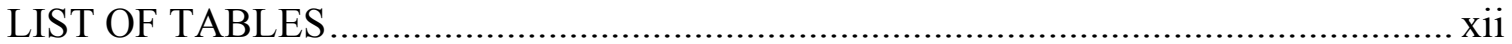

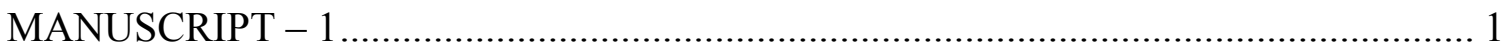

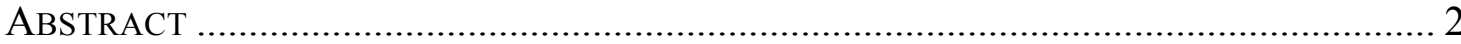

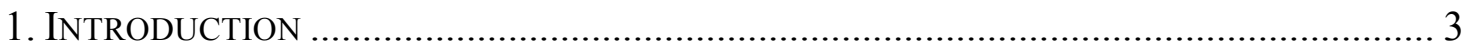

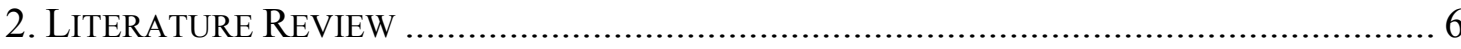

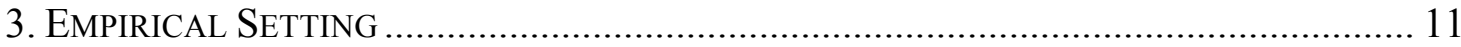

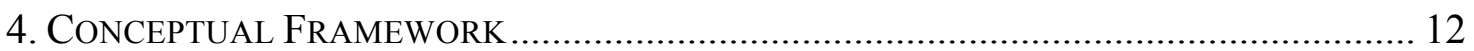

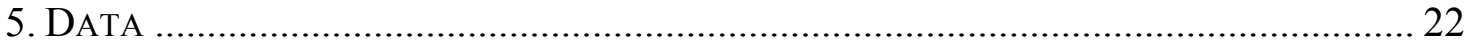

6. REGRESSION DiSCONTINUITY METHOD …............................................................... 25

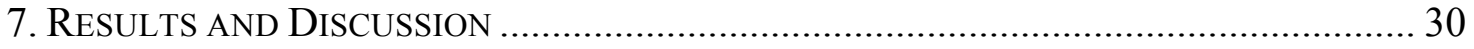

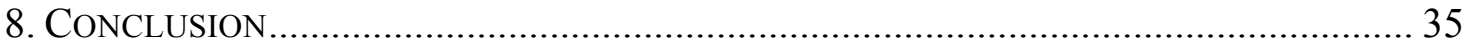

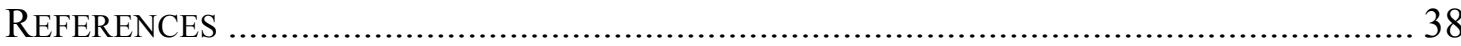

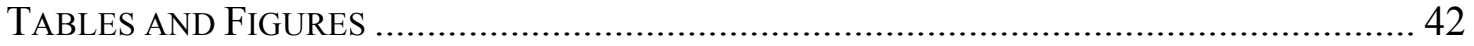

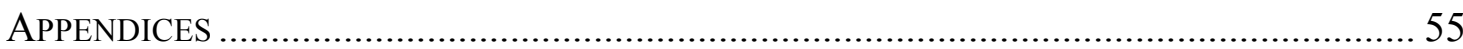

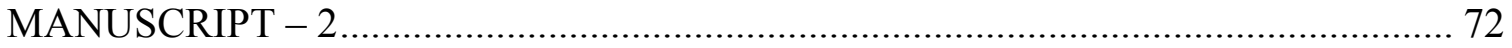

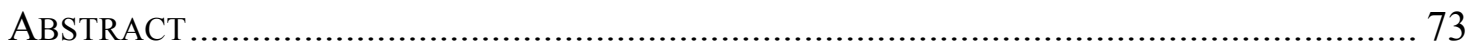

viii 
1. INTRODUCTION

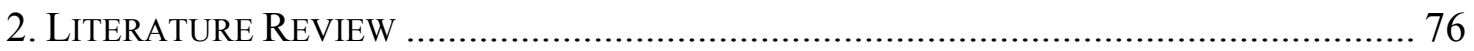

3. BACKGROUND ON EESMARTS ENERGY LESSONS....................................................... 82

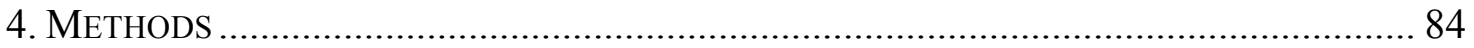

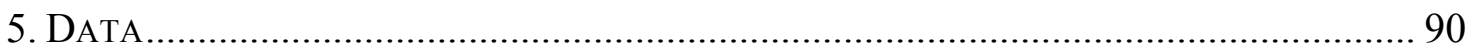

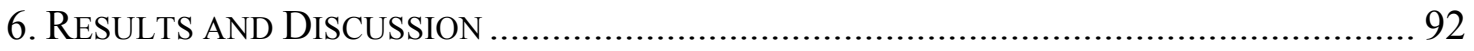

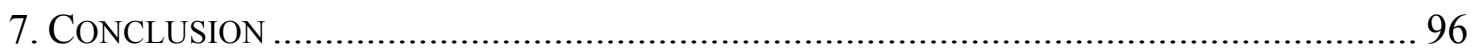

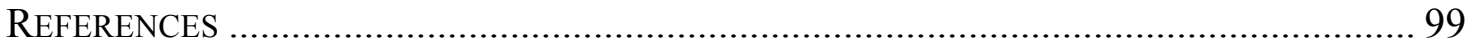

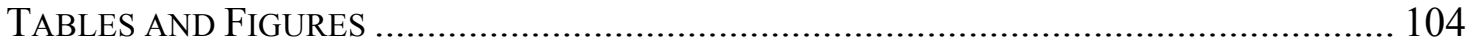

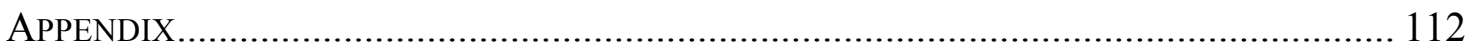

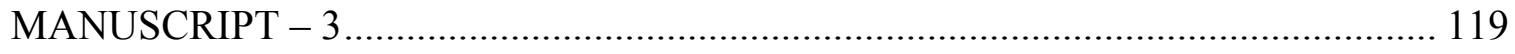

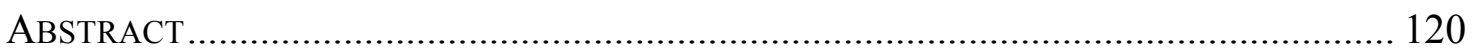

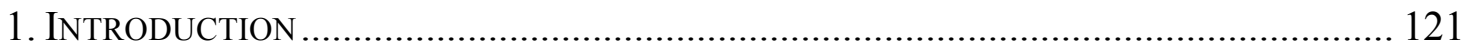

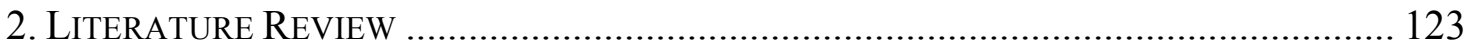

3. CONCEPTUAL UnDERPINNINGS AND HyPotHESES ............................................... 127

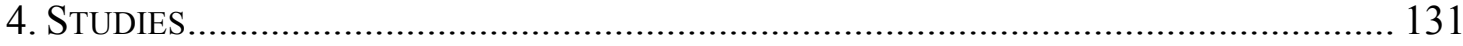

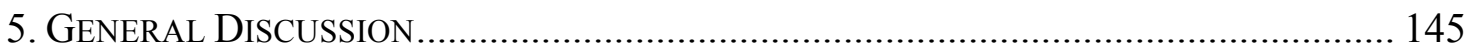

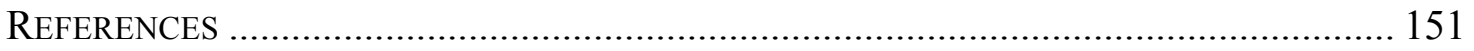

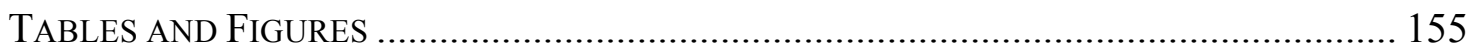

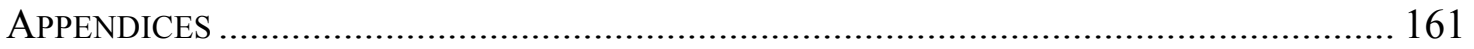




\section{LIST OF FIGURES}

\section{Manuscript 1}

Figure 1. Optimized Consumption Bundles for Break-Even Peak Proportion

Figure 2. Optimized Consumption Bundles for Low and High Peak

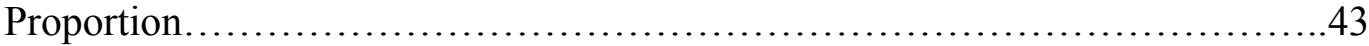

Figure 3. Daily Load over Sample Period......................................44

Figure 4. Number of Households that Incur Rate Changes each Month...........45

Figure 5. Average Load Profile..............................................46

Figure 6. Variation in Monthly Peak Proportion..............................47

Figure 7. Regression Discontinuity Framework...............................48

Figure 8. McCrary Density Plot.............................................49

Figure 1C. Rate of Exceedance in Event Time.................................63

Figure 2C. Mean Load in Event Time.........................................65

Figure 3C. Distribution of Treatment Effects................................70

\section{Manuscript 2}

Figure 1. Electricity consumption....................................... 104

Figure 2 . Electricity consumption...................................... 105

Figure 3. Treatment effect over time for lesson 1 on phantom power...........107

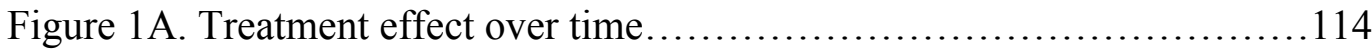




\section{Manuscript 3}

Figure 1. Energy efficient behavior intentions by status quo condition and cost

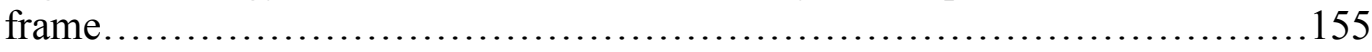

Figure 2. Fluency by cost frame......................................... 156

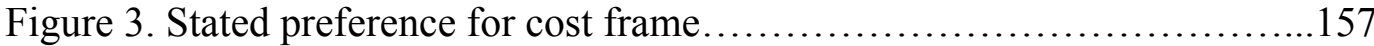

Figure 4. Energy meter context and cost sticker............................158

Figure 5. Energy efficient behavior intention cost frame and total expenditure

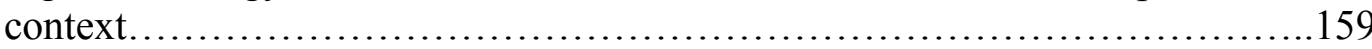

Figure 1A. Energy efficient behavior intention averaged across five scenarios by status quo condition and cost frame..................................... 167 


\section{LIST OF TABLES}

\section{Manuscript 1}

Table 1. Flat Rate and TOU Pricing Schedules..............................50

Table 2. Balance of Observable Characteristics...........................51

Table 3. Average Treatment Effect across Models..........................52

Table 4. Treatment Effect on Outcome Measure in Future Months...............53

Table 5. Falsification Tests..............................................5 54

Table 1A. Treatment Effect in Future Months across Specifications .............55

Table 2A. Treatment Effect in Future Months across Specifications .............56

Table 3A. Treatment Effect in Future Months across Specifications ............57

Table 4A. Treatment Effect in Future Months across Specifications .............58

Table 5A. Treatment Effect on Outcome Measures in Future Months.............59

Table 1C. Main Results of Panel Data Method...............................69

Table 2C. Excluding the pre-rate change spike in electricity, peak proportion.......................................................... 71

\section{Manuscript 2}

Table 1. Treatment Effect of Lesson 1..................................... 108

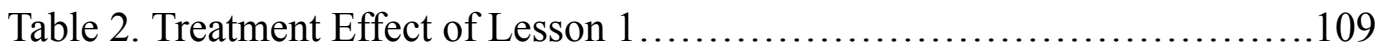

Table 3. Treatment Effect of Lessons 1, 2, 3............................110 
Table 4. Heterogeneity in Treatment Effect of Lesson 1 111

Table 1A. Treatment Effect of Lesson 1....................................113

Table 2A. Treatment Effect of Lesson 2...................................115

Table 3A. Treatment Effect of Lesson 3...................................116

Table 4A. Heterogeneity in Treatment Effect of Lesson 2.....................117

Table 5A. Heterogeneity in Treatment Effect of Lesson 3.....................118

\section{Manuscript 3}

Table 1. Stated Preferences for Cost Frames...................................160 
Manuscript - $\mathbf{1}$
Being prepared for submission to the Journal of Environmental Economics and Management

The effects of mandatory time-of-use electricity pricing on high-consuming households using a regression discontinuity framework

Carrie Gill and Corey Lang

Environmental and Natural Resource Economics, University of Rhode Island 


\begin{abstract}
Time-varying electricity rates are one way to encourage the optimal level of electricity consumption by passing along the marginal cost of electricity generation to consumers. Time of use (TOU) pricing is a coarse variant of real-time pricing, charging consumers a higher rate during hours of peak demand and a lower rate during off-peak hours. Because of marginal costs set to appease regulatory concerns about increasing electricity bills, such a rate structure gives rise not only to substitution between on- and off-peak consumption, but also produces income effects through decreased electricity bills. We exploit quasi-random assignment of TOU rates and use a regression discontinuity framework to identify the causal effects of TOU pricing on four outcomes over the twelve months following treatment for high-use households. Though microeconomic theory predicts households shift consumption from peak to off-peak hours, we find only suggestive evidence that this is the case. We find a decrease in level of peak consumption six to eight months following treatment along with a decrease in total consumption, suggesting energy conservation rather than load deferment and possibly indicating spillover effects of energy conservation into off-peak hours. We find evidence for decreases in electricity bill amounts, consistent with both more favorable marginal prices for households with already-low peak proportion and decreased consumption.
\end{abstract}

Keywords: Time-of-Use Pricing; Electricity; Energy Conservation; Regression Discontinuity 


\section{Introduction}

One challenge of promoting residential energy efficiency is that the true costs of electricity are not passed onto the consumer. Most consumers face either a flat rate or inclining block rate pricing schedule, where rates are independent of total demand for electricity (FERC 2012). However, since electricity cannot be stored and must be generated in real time to meet demand, times of peak demand cause additional electricity generation facilities to come on board (Borenstein 2013). These additional facilities generate electricity that is often purchased at a higher wholesale cost either because the facilities are less efficient or because the producers have market power to increase marginal prices (Borenstein 2013, EIA 2014). Growing peak demand exacerbates the challenge of producing adequate supplies of electricity to meet varying demand throughout the year (NERC 2013). In regions where peak demand is met through the use of fossil fuel-based generation, reducing peak demand and variability can decrease emissions of greenhouse gases and pollutants (Holland and Mansur 2004). Because these costs are hidden to consumers, consumers have no incentive to reduce their electricity consumption (Borenstein 2002, 2005; Joskow and Wolfram 2012).

Dynamic, real-time pricing, which translates the actual cost of electricity generation at any given time to the consumer, represents the opposite end of the spectrum from flat rate pricing. However, real-time pricing comes with regulatory and political concerns, including difficulty for the consumer to understand and adjust to time-varying prices (see Alexander 2010 for a review). Time-of-use (TOU) pricing is a coarse form of real-time pricing. Under a time-of-use pricing scheme, consumers pay a higher rate during pre-determined hours of peak demand and a lower rate during off-peak hours. 
While over two million residents are enrolled in some form of TOU pricing (FERC 2012), nearly all time-varying pricing schemes are optional for residential consumers, and may have either opt-in or opt-out defaults (e.g. Cappers et al. 2016, Hydro One 2008, Idaho Power Company 2006, Charles River Associates 2005, Strapp et al. 2007, Hammerstrom et al 2007, Navigant 2008, Hartway 1999). As utility regulators move toward time-varying pricing, it is critical to understand the effects on consumption and cost to the consumer across a variety of settings.

One strategy to enact TOU pricing is to mandate certain households into the rate structure based on some criteria. We exploit a unique empirical setting in Connecticut, where households who exceed a threshold of $2,000 \mathrm{kWh}$ in a single billing period are mandated into TOU pricing and may not switch back to flat rate pricing. Because households cannot precisely control their electricity consumption, exceeding this threshold may be considered as-good-as-random assignment of TOU pricing to high-use households. Therefore, this particular empirical setting lends itself very well to a regression discontinuity framework, allowing for identification of the causal effect of TOU pricing on several outcomes specifically for high-use households.

We employ this framework to estimate local average treatment effects of exceeding this threshold - and being treated with TOU pricing - on proportion of consumption during peak hours, level of peak consumption, level of total consumption, and total electricity bill cost from one to twelve months following the exceedance. Though microeconomic theory predicts households would shift consumption from peak to off-peak hours, we only find suggestive evidence that this is the case. We find a decrease in level of peak consumption six to eight months following treatment along with 
a decrease in total consumption, possibly indicating spillover effects of energy conservation into off-peak hours. Lastly, we find evidence for decreases in electricity bill amounts, consistent with both more favorable marginal prices for households with already-low peak proportion and decreased consumption.

We make several important contributes to the literature. Generally, this research provides another point in the important conversation of how to appropriately encourage energy conservation through price incentives. Specifically, we investigate the causal effect of TOU pricing for the segment of high-consuming households, which has been overlooked in the literature. Furthermore, this research addresses a critical gap regarding the effectiveness of mandatory enrollment based on some criteria. There are several ways in which utility providers may enact TOU pricing, all with potential benefits and concerns. One option is to allow consumers to opt into TOU pricing. This option has traditionally had a low rate of uptake, with only certain consumers opting in (see for example Matsukawa 2001 or Aigner and Ghali 1989). For example, consumers who have flexibility to shift their usage throughout the day and could save money or who are environmentally concerned and view TOU pricing as a commitment device to reduce energy may be more inclined to opt into a time-varying rate structure. Utility providers could instead default consumers into TOU pricing and allow them to opt-out. This would capture another subset of consumers that are rather indifferent to the rate change (Cappers et al. 2016). If these consumers are engaged enough to be aware of the rate change, they may have some flexibility to shift load and either maintain the same energy expenditure or reduce their costs. However, if these indifferent consumers are also disengaged or fail to opt-out for other reasons, they may face higher electricity costs. A 
third method of deploying TOU pricing is mandatory enrollment (Jessoe et al. 2014). Concerns over consumer welfare prevent across-the-board mandatory enrollment in TOU pricing (Alexander 2010). However, the compromise is to enroll only the highest-use customers into TOU pricing, allowing others to opt in as they prefer, may present relatively low regulatory risk.

The paper is structured as follows. We review the literature on energy efficiency generally and TOU pricing specifically in Section 2 and describe the empirical setting in Section 3. We lay out our conceptual framework and corresponding hypotheses in Section 4. We describe the data in Section 5 and regression discontinuity method in Section 6. We present results and discussion in Section 7 and conclude with directions for future research and policy implications in Section 8 .

\section{Literature Review}

Utility providers face the challenge of providing just enough electricity to meet demand at any given time (Borenstein 2013). Each electricity generation plant can only generate electricity up to some capacity, before additional facilities must be brought on board to meet increased in demand. To prevent the occurrence of blackouts and brownouts, when utility providers triage who receives electricity, excess facilities are built that can generate additional electricity only during times of peak demand. However, the most efficient electricity generation facilities that can supply electricity at the lowest marginal cost are utilized first. Then during times of peak demand, additional, lessefficient facilities are brought online. Higher marginal costs from the less-efficient facilities and relatively inelastic demand for electricity result in a large wholesale price. 
Under a time-invariant pricing scheme, these higher costs are seen only by the utility provider and not by the consumer. This lack of information about marginal costs results in over-consumption by consumers, who face a rate lower than the true marginal cost of generation during hours of peak demand in their flat rate tariffs (Borenstein 2005, Joskow and Wolfram 2012). ${ }^{1}$

To address the problem of high demand from households during times of high peak total demand, utility providers and others have pushed for behavior change and demand response programs. There has been a growing movement for using concepts from psychology and behavioral economics to encourage energy efficiency (Allcott 2014, Gillingham and Palmer 2014, Allcott and Mullainathan 2010). One well-known example is the peer comparison on energy bills, which leverage social norms to encourage conservation (Allcott 2011). Demand response programs can include programmable thermostats, direct load control, and other technologies that can limit the amount of energy usage either by schedule or directly from the utility during hours of peak demand. These programs have been found to be relatively effective in reducing electricity consumption and shifting load demand, especially when paired with time-varying pricing schemes (see Newsham and Bowker 2010 and Faruqui and Sergici 2009 for reviews), though there is some evidence of strategic behavior to counteract direct load control technology (e.g. Lang and Okwelum 2014).

Time-varying electricity prices offer another way to encourage efficiency, where consumers face costs that more closely reflect actual marginal costs. On the opposite side of the spectrum from flat rate pricing is dynamic real-time pricing, which changes with

\footnotetext{
${ }^{1}$ There could also be under-consumption when consumers face marginal prices that are higher than the true marginal costs of electricity.
} 
the fluctuations of marginal rates on the wholesale electricity market. One study of realtime pricing finds consumers respond to real-time pricing by reducing demand during peak hours (Allcott 2011). In between flat rate and real-time pricing lie several course variants. Time-of-use (TOU) pricing, peak time rebates (PTR), and critical peak pricing (CPP) are three such schemes that either charge consumers a pre-determined premium to use electricity during pre-set hours of peak demand (TOU and CPP) or rebate consumers for reducing usage during hours of peak demand (PTR). If consumers are aware of the rates and can modify their energy consumption behavior, then they can better control their electricity usage and bills. However, if consumers are either unaware, do not understand, or are unwilling or unmotivated to change their behavior, time-varying rates may result in increased bills for consumers. Indeed, the literature has generally found that coupling time-varying pricing programs with salient information about marginal costs and electricity consumption (e.g. in-home displays (Jessoe and Rapson 2014) or glowing orbs (Allcott 2011)) or technology that enables increased control over consumption is more effective (Newsham and Bowker 2010).

Prior research has explored the effects of coarse time-varying pricing schemes on residential electricity consumption, generally finding small reductions in electricity consumption due to TOU pricing, varying in both magnitude and significance (see Faruqui and Sergici (2009) and Newsham and Bowker (2010) for reviews). In a metaanalysis of TOU pricing programs, Faruqui and Sergici (2010) find a three percent reduction in peak electricity load. Programs that couple TOU pricing with an enabling technology, such as a programmable thermostat that allows residents to set back the temperature when they are out of the home or during peak hours, tend to result in the 
largest reductions (Newsham and Bowker 2010). Similarly, TOU pricing schedules coupled with critical peak pricing, days when there is an additional premium for electricity, result in larger electricity load reductions (Faruqui and Sergici 2010). Much of the recent literature studies programs in which participation is voluntary and open to all households (e.g. Cappers et al. 2016, Hydro One 2008, Idaho Power Company 2006, Charles River Associates 2005, Strapp et al. 2007, Hammerstrom et al 2007, Navigant 2008, Hartway 1999).

A recent randomized control trial in California compared voluntary (opt-in) TOU enrollment to default (opt-out) TOU enrollment (Cappers et al 2016). Given the option to opt-in, 19.5 percent of households chose TOU pricing over their default inclining block rate schedule. However, only two percent of households actively opted-out of TOU pricing when it was the default pricing schedule. The households in each group also had differential energy savings, with households who actively opted into TOU pricing having roughly three times larger energy reductions than those who were defaulted in. This is evidence of a subset of consumers who are relatively disengaged from their energy pricing and/or unwilling or unable to change their demand. But while the average percustomer energy savings were lower in the default TOU enrollment scenario, estimated benefits dwarfed those of an opt-in enrollment scenario due to increased participation. While studies of voluntary and default TOU pricing are critical to understanding the efficacy of time-varying pricing on demand, self-selection may bias the magnitudes of estimated effects (Aigner and Ghali 1989). The effects of mandatory enrollment in timevarying pricing for high-use consumers have been largely overlooked. Moreover, the specific effects of mandatory enrollment for high-use consumers is important, as these 
consumers are responsible for a significant amount of total electricity consumption and demand during peak hours.

Jessoe, Rapson, and Smith (2014) investigated the effects of a preliminary iteration of the TOU pricing program in this paper, finding reductions in total electricity usage. Our analysis extends their study in several ways. First, we use higher resolution data and are able to observe preferences for peak and off-peak electricity consumption under flat rate prices. Second, the threshold for being mandated onto TOU pricing is 2,000 kWh for all households in our sample, while the threshold starts quite a bit higher at 4,000 $\mathrm{kWh}$ and then drops to $3,000 \mathrm{kWh}$ for the households in Jessoe, Rapson, and Smith's analysis. Third, there are a couple nuances due to the newness of the TOU pricing program that we do not face in our analysis, including a long time lag between exceeding the threshold and switching rates (households that exceeded as early as November 2006 were not switched to TOU rates until February 2008) and implementation glitches that failed to switch some households that actually exceeded the threshold.

Jessoe and Rapson (2015) explore a mandatory TOU pricing program for highuse consumers, but in the Commercial and Industrial (C\&I) sector. In this program, C\&I consumers who exceeded a certain consumption threshold within one billing period were mandated to TOU pricing and not allowed the option to switch to a different pricing schedule. For these consumers, the threshold started at $300 \mathrm{~kW}$ on June 1, 2008 and decreased by $100 \mathrm{~kW}$ each of the subsequent two years. Each time the threshold decreased, a number of C\&I consumers exceeded the threshold and were mandated into TOU pricing. The authors use a regression discontinuity design to estimate the effects of 
TOU pricing on future consumption for the set of firms that exceeded the June 1, 2010 threshold, and find no significant change in electricity consumption due to TOU pricing. This empirical setting is very similar to the setting that residential consumers face in this study.

\section{Empirical Setting}

The United Illuminating Company (UI) services consumers in the greater New Haven area, Connecticut. On January 1, 2009, under the direction of the Public Utility Regulatory Authority, UI imposed a mandatory TOU pricing schedule for residential consumers who exceed $2000 \mathrm{kWh}$ in a single monthly billing period. Once a household exceeds this threshold, the household is notified and switched from a flat rate to TOU pricing within six months. It is important to note that households do not see an immediate rate change. For the households in our dataset, it typically took two monthly bills before they were switched to TOU rates (mean $=2.1$ bills, standard deviation $=0.5$ bills). Households are prohibited from switching back to flat rate pricing, with exceptions made for households containing a person with a serious medical condition who have a letter from a physician, houses undergoing repairs related to a storm, exceedances due to malfunction appliances with evidence of repair or replacement, and households that may have received an incorrect utility bill. However, all of these exceptions require that electricity rates were consistently below 20 percent of the threshold for the prior 24 months, and any reversals that are approved are a one-time only exception (UI 2016).

Table 1 presents rates for flat rate and TOU standard generation pricing schedules January 2013-2016 for standard service generation. Due to factors like demand and losses 
in transmission and distribution, utility providers distinguish between summer and winter rates, with summer rates typically being higher. Charges under flat rate pricing are independent of the time of day, in contrast to TOU pricing, which charges a higher rate during hours of peak demand. On-peak hours are defined as noon - 8pm Monday through Friday. All other times, including Saturday and Sunday and holidays, constitute off-peak hours.

[Table 1 about here]

Flat rate tariffs range from $\$ 0.18$ - $\$ 0.25$ per kilowatt-hour $(\mathrm{kWh})$. Under TOU pricing, off-peak rates ranged from $\$ 0.14-\$ 0.20$ per $\mathrm{kWh}$ while on-peak rates ranged from $\$ 0.27$ - $\$ 0.37$ per kWh. TOU rates during on-peak hours were 1.7-2.4 times higher than off-peak rates over this time period. The proportion of consumption occurring during peak hours required for the total cost to be identical under both rate structures is given for both summer and winter months. This proportion varies between 0.29-0.31. A household that consumes more during peak hours than this proportion would face higher total costs under TOU pricing than under flat rate pricing, while households with a lower peak proportion would face lower electricity bills. We discuss distribution of peak proportion along with data in Section 5.

\section{Conceptual Framework}

Let $p_{o}^{T}<p_{o}^{F}=p_{p}^{F}<p_{p}^{T}$ be prices for peak $p_{p}$ and off-peak $p_{o}$ usage under flat rate $p^{F}$ and TOU $p^{T}$ price structures and $Q_{T}=Q_{p}+Q_{o}$ be total consumption of energy 
during peak and off-peak hours. The consumer's problem is to maximize utility over $Q_{p}$, $Q_{o}$ subject to a budget constraint:

$$
\max _{Q_{p}, Q_{o}} U\left(Q_{p}, Q_{o}\right) \text { s.t. } p_{p} Q_{p}+p_{o} Q_{o} \leq B
$$

where $B$ is the amount budgeted for electricity. Assume, for illustrative purposes, that utility is described by a Cobb Douglas utility function:

$$
U\left(Q_{p}, Q_{o}\right)=Q_{p}{ }^{\alpha} Q_{o}{ }^{1-\alpha}
$$

where $\alpha \in(0,1)$. When the household is billed under flat rate pricing, they do not have to discriminate when to consumer energy due to a price differential. Therefore, we can think of the household as revealing information about their true preferences for consumption during peak and off-peak hours. Define $\theta \equiv Q_{p} / Q_{T}$ as the proportion of peak consumption and let $\theta^{0}$ represent a consumer's initial preferences for peak and offpeak consumption under flat rate pricing. We can solve the utility maximization problem to gain insight into this preference parameter:

$$
\mathcal{L}=Q_{p}{ }^{\alpha} Q_{o}{ }^{1-\alpha}+\lambda\left(B-p_{p} Q_{p}+p_{o} Q_{o}\right)
$$

The first order conditions are

$$
\begin{aligned}
& \frac{\partial \mathcal{L}}{\partial Q_{p}}=\alpha Q_{p}{ }^{\alpha-1} Q_{o}{ }^{1-\alpha}-\lambda p_{p}=0 \\
& \frac{\partial \mathcal{L}}{\partial Q_{o}}=(1-\alpha) Q_{p}{ }^{\alpha} Q_{o}{ }^{-\alpha}-\lambda p_{f}=0
\end{aligned}
$$




$$
\frac{\partial \mathcal{L}}{\partial \lambda}=B-p_{p} Q_{p}+p_{o} Q_{o}=0
$$

Using the first two conditions, we can solve each for $\lambda$ and set them equal to each other to solve for $\alpha$ :

$$
\begin{aligned}
& \frac{\alpha Q_{p}{ }^{\alpha-1} Q_{o}{ }^{1-\alpha}}{p_{p}}=\frac{(1-\alpha) Q_{p}{ }^{\alpha} Q_{o}{ }^{-\alpha}}{p_{o}} \\
& \frac{\alpha}{(1-\alpha)}=\frac{Q_{p}}{Q_{o}} \cdot \frac{p_{p}}{p_{o}} \\
& \alpha=\frac{\rho Q_{p}}{Q_{o}+\rho Q_{p}}
\end{aligned}
$$

where we define $\rho$ as the ratio of peak to off-peak prices, $\rho \equiv p_{p} / p_{o}$. In the case of flat rate pricing, $p_{p}=p_{o} \Rightarrow \rho=1$ and $\alpha=Q_{p} / Q_{T}=\theta^{0}$. In other words, $\alpha$ is the proportion of usage during peak hours relative to total consumption. A household reveals their preferences under flat rate pricing, which gives us critical information about the shape of the household's utility function. By knowing a single parameter $\alpha$, we can make inferences about a household's preferences for consumption under changing prices.

We want to understand how consumption patterns change following a switch to TOU pricing along four dimensions: peak proportion, peak usage, total usage, and bill amount. To do so, it is necessary to solve the utility maximization problem for demand. Again using the first order conditions, we solve:

$$
Q_{o}=\frac{1-\alpha}{\alpha} \rho Q_{p}
$$




$$
\begin{aligned}
& Q_{o}=\frac{B}{p_{o}}-\rho Q_{p} \\
& Q_{p}^{*}=\frac{\alpha B}{p_{p}} \\
& Q_{o}^{*}=\frac{(1-\alpha) B}{p_{o}}
\end{aligned}
$$

We now have all the necessary calculations to formulate hypotheses of expected behavior under utility maximization. First consider change in peak proportion when a household is treated with TOU pricing. Recall that $\theta^{0}=\alpha$ is the household's initial peak proportion and let $\theta^{\prime}$ be peak proportion under TOU rates. The change in peak proportion is given by:

$$
\begin{aligned}
& \Delta \theta \equiv \theta^{\prime}-\theta^{0} \\
& \Delta \theta=\frac{Q_{p}^{T}}{Q_{o}^{T}+Q_{p}^{T}}-\alpha \\
& \Delta \theta=\frac{\frac{\alpha B}{p_{p}}}{\frac{(1-\alpha) B}{p_{o}}+\frac{\alpha B}{p_{p}}}-\alpha \\
& \Delta \theta=\alpha\left[\frac{p_{o}}{(1-\alpha) p_{p}+\alpha p_{o}}-1\right]
\end{aligned}
$$

Under a TOU pricing scheme where $p_{o}<p_{p}$, we know that $\Delta \theta<0$, indicating a decrease in the proportion of electricity used during peak hours. Using $p_{o}=0.15, p_{p}=$ 
0.30 ), there is a maximum change at $\alpha=0.59$, but for typical preferences peak proportion decreases linearly as $\alpha$ increases.

We can also infer how peak usage will change. It is convenient to normalize $\Delta Q_{p}$ by peak consumption under flat rate prices. Using optimized demand derivations,

$$
\begin{gathered}
\frac{\Delta Q_{p}}{Q_{p}^{F}}=\frac{Q_{p}^{T}-Q_{p}^{F}}{Q_{p}^{F}} \\
\frac{\Delta Q_{p}}{Q_{p}^{F}}=\frac{\frac{\alpha B}{p_{p}}-\frac{\alpha B}{p_{f}}}{\frac{\alpha B}{p_{f}}} \\
\frac{\Delta Q_{p}}{Q_{p}^{F}}=\frac{p_{f}-p_{p}}{p_{p}}
\end{gathered}
$$

So the percentage change in peak usage is a function of flat rate prices and peak prices under TOU, and is independent of preferences for peak proportion. For $p_{o}=0.15, p_{p}=$ 0.30 , households would reduce peak usage by 33 percent. We can conduct a similar inference for total consumption.

$$
\begin{aligned}
& \frac{\Delta Q_{T}}{Q_{T}^{F}}=\frac{Q_{T}^{T}-Q_{T}^{F}}{Q_{T}^{F}} \\
& \frac{\Delta Q_{T}}{Q_{T}^{F}}=\frac{\frac{\alpha B}{p_{p}}+\frac{(1-\alpha) B}{p_{o}}-\frac{\alpha B}{p_{f}}-\frac{(1-\alpha) B}{p_{f}}}{\frac{\alpha B}{p_{f}}+\frac{(1-\alpha) B}{p_{f}}} \\
& \frac{\Delta Q_{T}}{Q_{T}^{F}}=\left(\frac{p_{f}-p_{o}}{p_{o}}\right)-\left(\frac{1}{p_{o}}-\frac{1}{p_{p}}\right) p_{f} \alpha
\end{aligned}
$$


In other words, the percentage change in total load increases for small values of $\alpha$ and decreases linearly with $\alpha$. To illustrate this result using $p_{o}=0.15, p_{p}=0.30, p_{f}=0.20$, households who use less than half their total electricity consumption during peak hours (representing typical real-world preferences) are expected to increase total load. This result is largely due to income effects. For customers who consume a peak proportion less than some value of $\alpha$, the TOU price structure is designed such that most households will not see an increase in bills even in the absence of change in consumption patterns. Therefore, many households who change nothing would actually see bills decrease. However, Walras's law states that households will adjust consumption to spend exactly their electricity budgets. Therefore, deriving changes to bill amounts using this micro theory framework lead to no change to bill amount for households with any value of $\alpha$.

We can further explore how total consumption changes due to substitution and income effects. We use a Slutsky decomposition to find interim demand for peak and offpeak consumption holding buying power constant. In other words, the household can still afford the original consumption bundle preferred under flat rates using TOU prices:

$$
B^{S}=p_{p} Q_{p}^{F}+p_{o} Q_{o}^{F}
$$

Consistent with prior findings, micro theory predicts households shift away from peak consumption, and the substitution effects dominate income effects for households using less than two-thirds of their electricity during peak hours. On the other hand, income and substitution effects both work to increase off-peak consumption for households with peak proportion preferences less than $\alpha=0.33$. For households with preferences for more 
peak consumption relative to total, a negative income effect attenuates a positive substitution effect for off-peak usage.

This level of $\alpha$ represents the break-even peak proportion; a household with preferences for this peak proportion would see identical bills under both flat rate and TOU pricing. More generally, we can solve for $\alpha$ in terms of prices by setting total costs under each rate structure equal to each other:

$$
\begin{aligned}
& T C^{F}=T C^{T} \\
& p_{f} Q_{T}=p_{p} \alpha Q_{T}+p_{o}(1-\alpha) Q_{T} \\
& \alpha_{b e}=\frac{p_{f}-p_{o}}{p_{p}-p_{o}}
\end{aligned}
$$

As the difference between peak and off-peak prices increases, the break-even level of $\alpha$ decreases. As mentioned previously, one regulatory concern is that households would be worse off from a change in rate structure. Therefore, prices are set such that most households have preferences for peak proportion that fall below this break-even point. It is important to note, however, that households with preferences toward peak proportion greater than $\alpha_{b e}$ are still predicted to increase total consumption, as the substitution effect toward off-peak consumption dominates all other effects. More specifically, households with preferences for peak proportion less than $\alpha_{b e}\left(p_{p} / p_{f}\right)$ are predicted to increase total consumption. 
Using average winter rates for $2013-2016,{ }^{2}$ the break-even proportion is equal to one-third. In other words, households that consume one third of total electricity during peak hours see no change in their electricity bill when they are switched from flat rate pricing to TOU pricing. We illustrate this in Figure 1, which plots a consumer's budget constraint under flat rate pricing and indifference curve between peak consumption on the horizontal axis and off-peak consumption on the vertical axis. We use the break-even peak proportion to determine the shape of the utility function and corresponding indifference curves. The resulting optimal consumption bundle under flat rate pricing is represented at point 0 . After rates change according to the TOU rate schedule, the consumer's budget constraint shifts, allowing the consumer to increase utility by shifting load from peak hours to off-peak hours, as seen by the higher indifference curve. Lower total costs also result in a wealth increase, allowing for an increase in total consumption given the assumption that the household's budget for electricity remains fixed. The optimal consumption bundle under TOU pricing is represented at point 1.

[Figure 1 about here]

Note that any consumption bundle that lies along the same ray from the origin contains the same proportion of peak to off-peak consumption. Since bundle 1 lies to the left of the ray from the origin to bundle 0 , peak proportion will decrease when the household switches from flat rate pricing to TOU pricing. This intuitive result holds for all levels of peak proportion and is the basis for our first hypothesis. We test for changes in peak proportion in each of the first twelve months after exceeding the threshold and being switched to TOU pricing.

${ }^{2} p_{\text {flat }}=\$ 0.20 / k W h ; p_{\text {peak }}=\$ 0.30 / k W h ; p_{\text {off }}=\$ 0.15 / k W h$ 
Figure 2 illustrates two additional scenarios for peak proportions below and above $\alpha_{b e}$. Note that all households with true preference for peak proportion less than $\alpha_{b e}$ (i.e. with optimal consumption bundles laying on the budget constraint to the left of point 0 ) are structural "winners" in terms of decreased total costs under TOU pricing. Panel A of Figure 2 shows optimized consumption bundles for a households with a revealed preference for peak proportion $\alpha=0.1$. In the absence of any change in usage patterns, such a household could maintain flat-rate electricity consumption patterns a see a decrease in their bill amounts. However, micro theory predicts that these households would strategize by substituting consumption from peak to off-peak hours. The difference in slopes of the rays from the origin to each optimized bundle shows only a small decrease in peak proportion. There is also an income effect, which allows the household to move to a higher utility and increase total consumption. While utility providers and regulators motivate TOU pricing as a way to decrease peak consumption and shift load to off-peak hours, increases in total consumption would attenuate predicted benefits of electricity conservation. In addition to testing for changes in peak proportion, we also investigate effects of TOU pricing on level of peak consumption and total consumption.

Panel B of Figure 2 illustrates changes to optimal consumption for a household with a preference for higher peak proportion than $\alpha_{b e}$. All households with preferences greater than $\alpha_{b e}$ are structural "losers". In other words, these households would face increased electricity bills if they make no changes to their peak and off-peak consumption patterns. In order to stay within the budget constraint, these households must shift to a lower utility. In this lower utility, peak proportion and total consumption both must decrease. 
[Figure 2 about here]

Several assumptions must hold for predictions of this conceptual framework to be realized. First, the rate changes must be salient to the household and the household must understand the consequences of the TOU marginal prices. In our empirical setting, households who exceed $1,750 \mathrm{kWh}$ in a single billing cycle are sent a letter alerting them to the mandatory rate change policy if they exceed the threshold. Households who exceed the threshold are sent another letter notifying them that their rates will change within the next billing cycle. ${ }^{3}$ However the timing between high consumption and receiving a letter may not be immediate and, while we can assume households receive the letters, we cannot observe whether decision makers within the household pay attention to the letter or understand the consequences. Second, households must be able to shift load to offpeak hours, engage in energy conservation behaviors, or invest in energy efficient capital improvements. It is possible, though, that some households may not be able to make these changes despite understanding the consequences of the rate change. Third, households must be motivated to make these changes. Finally, we make the assumption that households have a fixed budget for electricity and strive to maintain that budget rather than reallocating savings achieved under TOU pricing to other goods or increasing budget to maintain the same levels of peak and total consumption as under flat rate prices.

One regulatory concern with mandating TOU rate structures is placing a burden on households that are limited in their ability to adjust consumption patterns, a burden that could disproportionately impact some socioeconomic populations. Therefore, TOU

\footnotetext{
${ }^{3}$ Both letters are included in Appendix B.
} 
marginal prices are set in such a way that a majority of households would face lower electricity bills without changes to consumption. As we alluded to previously, these income effects may have the unintended consequence of increasing total consumption. We test for changes in electricity bill amount for the twelve bills following treatment to address this question.

\section{Data}

We obtained 15-minute interval electricity load data from April 30, 2013 to October 1, 2016 for all households who were mandated into TOU pricing due to exceeding the 2000 kWh threshold from November 2013 to September $2015,{ }^{4}$ as well as for all households that consume at least $1500 \mathrm{kWh}$ during the timeframes we use in the analysis (we describe these timeframes in the methods section). We exclude households that exceed the threshold but are not switched into TOU rates within six months, as this may be an indicator of households that qualify for an exemption from the mandatory rate change, and therefore arguably fundamentally different in their energy usage patterns. This leaves us with a final dataset of 7358 households, 1974 of which were mandatorily and irreversibly enrolled in TOU pricing.

Figure 3 gives a sense for seasonal variation in total electricity consumption. We plot daily consumption over the sample period, smoothed using a 7-day moving average. Electricity consumption spikes in both the cold winter months and hot summer months, ostensibly due to heating and cooling loads. These peaks in average electricity use also correspond to the occurrence of households exceeding the threshold. Figure 4 illustrates

\footnotetext{
${ }^{4}$ i.e. We have data for households that switch rates during this timeframe that also have six months of data on flat rate pricing and twelve months of data following the rate change.
} 
the number of households that exceed $2,000 \mathrm{kWh}$ and that switch from flat rate to TOU pricing each month. The frequency of rate changes intuitively lags the seasonal peaks in electricity consumption, as households are more likely to exceed in the cold winter months and hot summer months. On average, rate changes occur 2.1 billing cycles following exceedance, with the majority of households being switch within the first couple billings cycles.

[Figure 3 about here]

[Figure 4 about here]

Under TOU pricing, marginal electricity prices are higher during noon-8pm on weekdays. Figure 5 shows an average load profile. Consumption is lowest overnight when most individuals are sleeping, peaks slightly in the morning hours when most individuals are getting up and getting ready for a traditionally scheduled work day, increases during afternoon hours, and peaks in the late afternoon and early evening when many individuals are getting home from work. The shaded gray area indicates peak hours. Since preferences for peak proportion of consumption affect predictions for effects on total consumption and electricity bill amounts, it is important to understand the trends and variation in peak proportion as well. Panel A of Figure 6 shows average peak proportion each month. Average peak proportion is relatively stable throughout the year, with only a slight shift to peak consumption during summer months (likely due to electricity-run air conditioning).

[Figure 5 about here]

[Figure 6 about here] 
Panel B illustrates variation in peak proportion across households. Peak proportion is normally distributed with mean and median equal to $0.26(s d=0.037)$, indicating that 26 percent of electricity is consumed during peak hours. Within our data, monthly trends account for 24 percent of variation in peak proportion while household habits account for another 35 percent of variation. Together, 58 percent of variation in peak proportion is explained by month of sample and household. It is also important to note that 96 percent of the sample consume less than $\alpha_{\text {break-even }}$. This leads to two important observations. First, regulators seem to have set the TOU marginal prices appropriately to ensure the majority of households do not face increases in electricity bills. Second, that the majority of houses stand to benefit from a rate change provides further motivation for our investigation of whether income effects lead to unintended increases in total consumption.

We unfortunately do not have data on what kind of enabling technology (e.g. programmable thermostats) or feedback displays (e.g. in-home energy displays) the households have. Prior research has shown that these technologies are somewhat critical to achieving energy reductions with TOU pricing (e.g. Newsham and Bowker 2010, Baatz 2017).

We aggregate consumption data to the bill-level for our analysis. Specifically, we calculate total consumption in each billing period, peak consumption, peak proportion, and bill amount. We additionally match household electricity data to assessor data to understand balance in observable characteristics between treatment and control groups. 


\section{Regression Discontinuity Method}

In our empirical setting, households that exceed the (arbitrary) threshold of 2000 $\mathrm{kWh}$ in a single billing period are then treated with TOU pricing, while those failing to exceed the threshold are not treated (they remain on flat rate pricing). A household becomes treated when they exceed the threshold for the first time. We make the necessary and plausible assumption that households are unable to precisely control their exact level of electricity consumption. For even just one decision-maker, precise control of cumulative consumption over a billing cycle would be nearly impossible without instant feedback from an in home display or smart meter (and awareness of and desire to receive and act on this feedback). Furthermore, many households are likely to have more than one agent responsible for making energy-related decisions in the household. ${ }^{5}$ Therefore, there is stochasticity in whether a household exceeds the threshold and, in a neighborhood around the threshold, treatment status can be assumed to be as good as random. The regression discontinuity $(\mathrm{RD})$ design improves inference by effectively comparing observations in this neighborhood, exploiting this quasi-random treatment assignment to identify a causal effect of TOU pricing among plausibly similar households (Imbens and Lemieux 2007). In our case, we estimate the local average treatment effect of exceeding the threshold on (i) proportion of consumption during peak hours, (ii) level of peak consumption, (iii) total consumption, and (iv) total cost on electricity bills in one to twelve billing periods.

\footnotetext{
${ }^{5}$ Another source of exogenous variation is assignment to one of 17 billing cycles. Each billing cycle covers roughly 31 days of electricity use, but billing file dates are spread throughout the month (e.g. the December 2013 bill for households on billing cycle 1 covers 11/4/2013 - 12/4/2013 while billing cycle 17 covers $11 / 27 / 2013$ - 12/27/2013). Since there are differences in the days covered (including associated weather, proportion of weekend and week days, holidays, etc.), some households would exceed the threshold under some billing cycles but fall short of the threshold under others. We discuss potential ways to exploit this variation to identify causal effects and related directions for future research in the conclusion.
} 
Each household is exogenously assigned to one of 17 billing cycles that determine start and end dates of each bill throughout the sample period. We group all households that receive a bill during each calendar month-year to form a cohort, and we apply the $\mathrm{RD}$ approach to each cohort. To illustrate, consider the cohort of households who receive a bill in December 2013. 1,510 households used between 1500 and $1999 \mathrm{kWh}$ during their bills, while 141 households exceeded the $2000 \mathrm{kWh}$ threshold for the first time. RD effectively compares households arbitrarily close to the threshold in terms of our three outcomes of interest. Figure 7 illustrates the RD approach. Total consumption in the cohort month is our running variable (horizontal axis), and we plot households with respect to total consumption and some outcome measure in some future month. We control for correlations between total consumption in the cohort month and the outcome variable, allowing for different relationships on either side of the threshold. We then estimate the magnitude of the discontinuity at the threshold, the local average treatment effect. In this particular illustration, suppose the outcome measure is peak consumption. Intuitively, we posit a positive correlation between total consumption and peak consumption, shown by the positive linear fits on either side of the threshold. The magnitude and direction of the discontinuity indicates that exceeding the threshold and being switched to TOU pricing causes a decrease in peak consumption. Such a finding would be consistent with hypotheses derived from our conceptual framework. Empirically, we model these outcomes as:

$$
y_{i t+\tau}=\beta D_{\text {ToUit }}+f\left(D_{\text {Touit }}, y_{i t} ; \boldsymbol{\gamma}\right)+\varepsilon_{i t}
$$

where $y$ is the outcome variable in billing period $t+\tau$ for household $i$, where $\tau$ ranges from one to twelve months and $t$ is equal to the cohort month. The treatment variable is 
$D_{\text {Tovit }}$, an indicator equal to 1 if customer $i$ exceeds the threshold for the first time in their cohort billing cycle and 0 otherwise. The coefficient of interest is $\beta$, which is interpreted at the causal effect of being mandatorily enrolled in TOU pricing from flat rate pricing for households close to the threshold. We use several variations in functional form to control for the running variable on either side of the threshold, including linear, quadratic, cubic, and local-linear ${ }^{6}$, as well as present the average treatment effect estimated from a differences-in-difference model (i.e. comparing mean levels of the outcome measure for treatment and control groups without controlling for total consumption).

We aggregate our RD approach by choosing the six cohort months that have the largest numbers of households that exceed the threshold for the first time: December 2013, January 2014, February 2014, January 2015, February 2015, and August 2015. Households can be assigned to both treatment and control groups for different cohort months. For example, a household may consume $1600 \mathrm{kWh}$ in December 2013, 1900 kWh in January 2014, and 2100 kWh in February 2014. The household would be in the control group for December and January, and in the treatment group in February, and not have any observations in 2015. Since the dependent variable is an outcome in a future month $t+\tau$, we are careful to remove households that eventually are treated from the control group for an analysis of treatment on an outcome in month $t+\tau$ or after. We control for unobservable characteristics of each cohort month with fixed effects. We also acknowledge that the levels of outcome variables may differ systematically by bill cycle. For example, one bill cycle ending in month $t+\tau$ may be several days shorter than

\footnotetext{
${ }^{6}$ Specifically, we use the local linear estimation command by Calonico et al. (2014a, 2014b).
} 
another, or the days in one bill cycle may include a holiday or different distribution of weekend and weekdays. We control for these unobserved differences by including bill cycle fixed effects. Furthermore, we cluster the error term at the household level to allow for correlation within household. Our aggregated model becomes:

$$
y_{i t+\tau}=\beta D_{\text {Tovit }}+f\left(D_{\text {Tovit }}, y_{i t} ; \gamma\right)+\text { cohort }_{i t}+\text { billcycle }_{i}+\varepsilon_{i t}
$$

\subsection{Balance of Observables}

To appropriately apply the RD framework, we must be reasonably convinced that potential outcomes of observations in the neighborhood of the threshold are continuous. In other words, we assume that future peak proportion, level of peak consumption, total consumption and bill amount for households in the neighborhood of the threshold would be continuous in the absence of a change in rate structure. This critical assumption allows us to attribute any discontinuity in future electricity consumption for households who just barely exceeded the threshold (i.e. were treated) relative to households who failed to exceed the threshold (i.e. were not treated) to the rate change rather than to other confounding factors.

Because we cannot observe potential outcomes to test this assumption, we instead test for differences in observable house characteristics and electricity consumption trends. We use the model given in Equation 8 with each characteristic as the dependent variable. We restrict the sample to households that consume within $500 \mathrm{kWh}$ of the threshold throughout the analysis and control flexibly for the running variable using a cubic polynomial fitted to each side of the threshold. Table 2 presents our results. Columns 1-5

test for differences in house characteristics at the threshold. Treated households tend to 
have lower assessed values ( $\$ 38,000$ difference), but treated and control households are statistically indistinguishable in terms of lot size, building area, year built, and number of bedrooms. Columns 6-8 test for differences in baseline consumption characteristics at the threshold. Baseline values use the four billing cycles prior to the cohort month. Differences in these characteristics for households at the threshold are statistically insignificant. These results lend confidence to the strength and appropriateness of the RD empirical framework.

[Table 2 about here]

\subsection{McCrary Density Test}

We also want to ensure that households are not able to strategize their total consumption so as to avoid the mandatory rate change for exceeding the threshold. If households were able to avoid the rate change, it would compromise the as-good-asrandom experimental nature of the RD framework. Such a phenomenon would appear as bunching below the threshold in the density plot of consumption in the cohort months. We conduct a McCrary density test, which estimates a discontinuity in density at the threshold (McCrary 2008). Figure 8 illustrates this. We find no significant discontinuity at the threshold (log difference in density height at the threshold $=0.12$, standard error $=$ 0.15). These results provide further confidence in applying the RD method to our empirical setting.

[Figure 8 about here] 


\section{Results and Discussion}

We first present results for the outcome measure peak proportion six billing cycles following the cohort month in Table 3. By this time, all households that exceeded the threshold in their cohort month are guaranteed to be switched to TOU pricing. We estimate the average treatment effect on either side of the threshold without controlling for the running variable in Column 1. We control for total consumption in the cohort month on either side of the threshold using different functional forms in Columns 2-6, estimating the local average treatment effect. We present the coefficient estimate on an indicator for treatment status (i.e. exceeding $2000 \mathrm{kWh}$ in the cohort month) and omit all other coefficients from the table. The estimated average treatment effect is negative and significant in Column 1, indicating that mean peak proportion is 0.006 less for the treatment group than for the control group six billing periods following initially exceeding the threshold. However, this estimate captures differences between households that may be relatively far from the threshold and plausibly not ideal counterfactuals. Applying the RD framework and controlling more flexibly for total consumption on either side of the threshold, the estimated local average treatment effect decreases in magnitude and statistical difference. This result indicates that there is no statistically distinguishable discontinuity in peak proportion at the threshold.

[Table 3 about here]

We expect the treatment effect to change over time as households adjust to new rates, so we extend our analysis to twelve months after initial exceedance in the cohort month. Table 4 presents our main results across months and outcome measures. Each cell is the coefficient estimate for the treatment indicator for a separate regression of outcome 
$t+\tau$ months later on treatment status (results from twelve regressions are reported in each column). All models control for total consumption on either side of the threshold in the cohort month using a cubic polynomial, include cohort and bill cycle fixed effects, and cluster errors at the household level. ${ }^{7}$

[Table 4 about here]

Column 1 presents the causal effect of treatment on peak proportion. Recall that our microeconomic conceptual framework predicted decreases in peak proportion following the rate change. While coefficient estimates are mostly negative, they are also largely statistically indistinguishable from zero with the exception of peak proportion seven months later. This coefficient is interpreted as a 0.0125 reduction in peak proportion seven months following initially exceeding the threshold and being switched to TOU pricing. Recall that mean peak proportion in our sample is 0.26 , so this reduction indicates a shift of 4 percent of peak consumption to off-peak hours. In sum, the statistical insignificance indicates that we cannot reject the null hypothesis of TOU pricing causing a change in proportion of consumption during peak hours relative to total, and is inconsistent with microeconomic predictions.

One potential explanation for why peak proportion does not change in response to higher peak rates is that households may decrease peak consumption in tandem with offpeak consumption, maintaining the same proportion. Such a case could indicate that either the household is not utility maximizing, or that household preference for peak proportion change, possibly due to spillover effects. For example, if the household

\footnotetext{
${ }^{7}$ Full tables with all model specifications for each outcome measure are available in Appendix A: Tables $1 \mathrm{~A}-4 \mathrm{~A}$.
} 
develops energy efficient habits to decrease rather than defer peak electricity consumption, these habits may also apply to behaviors in off-peak hours. Another possibility is that a household invests in energy-efficiency improvements (e.g. an energy efficient dishwasher, washing machine, or other electronics) in order to decrease peak consumption. Such investments would necessarily also decrease off-peak consumption without changing peak proportion. We can glean inference into whether spillover effects exist in our analysis of peak and total consumption.

Column 2 presents estimated treatment effects on peak consumption while Column 3 presents effects on total consumption. The effects of TOU on these two outcomes follow generally similar patterns. First, results suggest an increase in both peak and total consumption the first month after exceeding the threshold. This increase is a bit counterintuitive. Most households receive a letter during the first month after exceeding the threshold that alerts them to the rate change. With this letter being the only difference between treatment and control households during this month, it is possible that households are responding to the letter. Then the question becomes why consumption increases rather than decreases. We can speculate that households somehow misunderstand the consequences and parameters of TOU pricing as explained in the letter, though this intuitively seems like an unlikely scenario. We estimate small positive effects on consumption turning to negative effects for two to five months after exceedance, though these estimates are statistically insignificant.

We estimate significant reductions in peak and total consumption six to eight months following exceeding the threshold. For six months after exceedance, households enrolled in TOU pricing use $30 \mathrm{kWh}$ less electricity during peak hours and $88 \mathrm{kWh}$ less 
electricity in total. For households in our sample, these reductions represent an eleven percent decrease in peak proportion and nine percent reduction in total consumption. ${ }^{8}$ At six months after exceedance, all treated households have been formally notified and enrolled in TOU pricing. The timing of these reductions align with intuition about when households may respond to their first electricity bills under the new rate structure. However, the effect magnitudes decrease after eight months and become statistically indistinguishable from zero. Interestingly, we estimate a positive, significant increase in both peak and total consumption twelve months following initial exceedance of the threshold, which is admittedly puzzling.

Overall, these results suggest that TOU pricing may cause households to reduce electricity consumption, but these effects may be temporary as households adjust. The effect sizes for reductions in total consumption are larger than the magnitudes of reductions for peak consumption. This indicates two things. First, these results show that households respond to TOU pricing by changing consumption during both peak and offpeak hours, which may partially explain why we fail to find a significant change in peak proportion. Second, the relatively larger magnitudes of reductions in total consumption more than encompass the changes in peak consumption. This finding provides some suggestive evidence of positive spillover effects. Households may respond to TOU pricing by making adjustments that affect their consumption throughout the day, rather than specifically during peak hours. Furthermore, that the effect seems to be temporary and then attenuate suggests that household responses are along the lines of energy efficient behavior modifications, rather than investments in energy efficiency

\footnotetext{
${ }^{8}$ Mean peak load per billing period $=264 \mathrm{kWh}$. Mean total load per billing period $=989 \mathrm{kWh}$.
} 
improvements to appliances, electronics, or infrastructure. These effects can also provide insight into the question of whether income effects cause increases in consumption for the 95 percent of households who face lower electricity bills under TOU pricing without having to adjust usage patterns. Generally negative or insignificant treatment effects point to households reallocating electricity bill savings to other goods rather than to increasing electricity consumption. However, the significant increase in peak and total consumption twelve months following treatment is cause for concern, and motivates the need for additional research to investigate the long-term impacts of TOU rate structures and marginal cost levels.

Finally, we test whether electricity bills change due TOU pricing enrollment. Estimated treatment effects given in Column 4 generally echo the effects on consumption in sign and statistical significance. We find an increase in total cost for the first bill following treatment and then see fairly consistent reductions. Treatment effects are statistically nonzero for six to nine months following treatment, with estimated savings of $\$ 15-22$. This reduction represents an 8-11 percent decrease in monthly electricity bill amounts for these months. These reductions conform to the idea that marginal prices are set such that most households would see either a reduction or no change in bill amount, and provide evidence for the effectiveness of regulatory choices.

\subsection{Falsification Test}

We conduct a falsification test using a false threshold at $1900 \mathrm{kWh}$ in each cohort month. We control for the running variable below the false threshold, between the false and true thresholds, and above the true threshold. Table 5 presents the estimated coefficients on both the false and true treatment indicators, with each panel 
corresponding to one of our four outcome measures and each column corresponding to the number of months following treatment (i.e. each panel-column is its own regression). We expect the coefficients on the false treatment indicators to be consistently statistically insignificant, with the coefficients on the true treatment indicators to generally follow the same pattern in sign, magnitude, and statistical significance as in the main results. Results show only two statistically significant coefficients on the false treatment indicator, and there does not appear to be an obvious pattern that would be cause for concern about application of the RD framework to this particular empirical setting. Furthermore, coefficients on the true treatment indicators generally echo the main results, though statistical significance is slightly diminished. Overall, these results provide support for our empirical method and lend confidence to the robustness of our results.

[Table 5 about here]

\section{Conclusion}

Our research address the question of how TOU electricity rate structures impact the segment of high-consuming households. We exploit a unique empirical setting where households that exceed a consumption threshold within one billing period are mandatorily and irreversibly switched from flat rate pricing to TOU pricing. Imprecise control over consumption and the assumption of potential outcomes across this threshold allow us to estimate the causal local average treatment effect of TOU pricing on four outcome measures in the twelve months following treatment. Microeconomic theory predicts unequal marginal prices would lead to substitution effects that would decrease the proportion of consumption occurring during peak hours, and the way the marginal 
prices are chosen would lead to income effects that could increase total consumption. In contrast, we find only suggestive evidence that peak proportion decreases as a result of TOU pricing. Instead, we find evidence of a short-term decrease in peak and total consumption on the order of ten percent beginning six months after treatment. This level of conservation is consistent with reductions found in prior literature (Newsham and Bowker 2010; Baatz 2017; Jessoe, Rapson, and Smith 2014). The combination of decreased consumption and differential marginal prices leads to expected reductions in electricity bill amounts of $\$ 15-22$. While negative point estimates for effects on consumption and bill amount are generally negative for all months, the statistically significant effects do not persist throughout the study period.

Our findings lead to several interesting observations and directions for future research. First, the combination of results regarding peak proportion and consumption variables suggest that households may be engaging in energy efficient behavior change, at least in the short term. Instead of deferring electricity use to off-peak hours, thereby decreasing peak proportion, households seem to be engaging in energy conservation with spillovers from peak to off-peak hours. This overall decrease, instead of only a decrease during peak hours, may point to the costs of load deferment being higher than the costs of small one-time changes (e.g. replacing incandescent light bulbs with LED bulbs) or habit formation (e.g. turning off lights when leaving a room regardless of the time of day). Decreased consumption also suggests that households may reallocate savings to other goods rather than to additional electricity use.

However, the short-term nature of energy conservation and savings on energy bills, with effects that indicate an increase in consumption twelve months after treatment 
motivate the need for more study to understand how these effects change over time. It is possible that households take longer than twelve months to adjust to the new rate structure, possibly engaging in energy conservation in the short-term but increasing consumption in the long-term due to wealth effects. Since we do not have information on prevalence of enabling technology or feedback displays, we cannot know how salient the change in prices or household usage is to the household. Prior research shows that higher energy reductions may be possible when TOU is coupled with such technology (Newsham and Bowker 2010, Baatz 2017), so evidence of small and insignificant reductions may point to lack of technology or low salience of prices.

We also suspect that the insignificant effects on peak proportion may be masking heterogeneity in response to TOU pricing. Marginal rates are chosen such that the majority of households would see reduced electricity bills under TOU pricing relative to flat rate pricing given no changes to electricity consumption patterns. Preliminary evidence points to significant differences in response between households with belowaverage peak proportion and households with above-average peak proportion, and particularly households near or above the break-even peak proportion. Future research should explore heterogeneity response further.

Finally, our findings generally point to decreases in electricity bill amounts due to switching to TOU pricing. This indicates that regulators are setting rates effectively to avoid distributional concerns about changes to consumer welfare. Future research should seek to understand characteristics of households with high peak proportion under flat rates resulting in bill increases under TOU pricing. 


\section{References}

Alexander, Barbara R. "Dynamic pricing? Not so fast! A residential consumer perspective." The Electricity Journal 23.6 (2010): 39-49.

Aigner, Dennis J., and Khalifa Ghali. "Self-selection in the residential electricity time-ofuse pricing experiments." Journal of Applied Econometrics 4.S1 (1989): S131S144.

Allcott, Hunt. "Rethinking real-time electricity pricing." Resource and energy economics 33.4 (2011): 820-842.

Allcott, Hunt. "Social norms and energy conservation." Journal of Public Economics 95.9 (2011): 1082-1095.

Allcott, Hunt. "Paternalism and energy efficiency: an overview." Annual Review of Economics 8 (2016): 145-176.

Allcott, Hunt, and Sendhil Mullainathan. "Behavior and energy policy." Science 327.5970 (2010): 1204-1205.

Analytics, R. L. W. "AmerenUE Residential TOU Pilot Study Load Research Analysis2005 Program Results." AmerenUE. St Louis, MO (2006). (formerly Puckett and Hennessy)

Baatz, Brendon. (2017). Rate Design Matters: The Intersection of Residential Rate Design and Energy Efficiency. American Council for an Energy-Efficient Economy, Report U1703.

Board, Ontario Energy. "Ontario Energy Board smart price pilot final report." Toronto, ON, July (2007). (formerly Strapp)

Borenstein, Severin. "The long-run efficiency of real-time electricity pricing." The Energy Journal (2005): 93-116.

Borenstein, Severin. "Time-varying retail electricity prices: Theory and practice." Electricity deregulation: choices and challenges (2005): 317-357.

Borenstein, Severin. "Effective and equitable adoption of opt-in residential dynamic electricity pricing." Review of Industrial Organization 42.2 (2013): 127-160.

Borenstein, Severin, Michael Jaske, and Arthur Rosenfeld. "Dynamic pricing, advanced metering, and demand response in electricity markets." Center for the Study of Energy Markets (2002). 
Calonico, Sebastian, Matias D. Cattaneo, and Rocio Titiunik. "Robust data-driven inference in the regression-discontinuity design." Stata Journal 14.4 (2014): 909946.

Calonico, Sebastian, Matias D. Cattaneo, and Rocio Titiunik. "Robust Nonparametric Confidence Intervals for Regression-Discontinuity Designs." Econometrica 82.6 (2014): 2295-2326.

Cappers, Peter., et al. "Time-of-Use as a Default Rate for Residential Customers: Issues and Insights.” Lawrence Berkeley National Laboratory, LBNL-1005704. (2016). https://emp.lbl.gov/sites/all/files/lbnl-1005704_0.pdf

Charles River Associates. Impact Evaluation of the California Statewide Pricing Pilot. (2005).

Energy Information Administration, 2017. FAQs. https://www.eia.gov/tools/faqs/faq.cfm?id= 97\&t=3

Energy Information Administration, 2014. Annual Energy Outlook with Projections 2014.

Government Printing Office. https://www.ferc.gov/legal/staff-reports/12-20-12-demandresponse.pdf

Faruqui, Ahmad, and Sanem Sergici. "Household response to dynamic pricing of electricity: a survey of 15 experiments." Journal of regulatory Economics 38.2 (2010): 193-225.

Federal Energy Regulatory Commission (2012). Assessment of Demand Response and Advanced Metering. https://www.ferc.gov/legal/staff-reports/12-20-12-demandresponse.pdf

Gillingham, Kenneth, and Karen Palmer. "Bridging the energy efficiency gap: Policy insights from economic theory and empirical evidence." Review of Environmental Economics and Policy 8.1 (2014): 18-38.

Hammerstrom, D. J., et al. "Pacific northwest gridwise testbed demonstration projects." Part I. Olympic Peninsula Project 210 (2007).

Hartway, Rob, Snuller Price, and Chi-Keung Woo. "Smart meter, customer choice and profitable time-of-use rate option." Energy 24.10 (1999): 895-903.

Herter, Karen. "Residential implementation of critical-peak pricing of electricity." Energy Policy 35.4 (2007): 2121-2130. 
Holland, Stephen P., and Erin T. Mansur. "Is real-time pricing green? The environmental impacts of electricity demand variance." The Review of Economics and Statistics 90.3 (2008): 550-561.

Hydro One (2008) Hydro One Networks' Time of Use Pricing Pilot Project Results. Report number EB-2007-0086. http://www.ontarioenergyboard.ca/documents/cases/EB-20040205/smartpricepilot/TOU_Pilot_Report_HydroOne_20080513.pdf

Idaho Power Company (2006) Time-of-day and Energy Watch Pilot Programs Final Report.

http://www.puc.idaho.gov/fileroom/cases/elec/IPC/IPCE0502/company/20060329 PILOT\%20PROGRAMS\%20FINAL\%20REPORT.PDF

Imbens, Guido, and Karthik Kalyanaraman. "Optimal bandwidth choice for the regression discontinuity estimator." The Review of economic studies (2011): rdr043.

Imbens, Guido W., and Thomas Lemieux. "Regression discontinuity designs: A guide to practice." Journal of econometrics 142.2 (2008): 615-635.

Jessoe, Katrina, and David Rapson. "Commercial and Industrial Demand Response Under Mandatory Time-of-Use Electricity Pricing." The Journal of Industrial Economics 63.3 (2015): 397-421.

Jessoe, Katrina, and David Rapson. "Knowledge is (less) power: Experimental evidence from residential energy use." The American Economic Review 104.4 (2014): 1417-1438.

Jessoe, Katrina, David Rapson, and Jeremy B. Smith. (2014). "Towards understanding the role of price in residential electricity choices: Evidence from a natural experiment." Journal of Economic Behavior \& Organization 107: 191-208.

Joskow, Paul L., and Catherine D. Wolfram. "Dynamic pricing of electricity." The American Economic Review 102.3 (2012): 381-385.

Lang, Corey, and Edson Okwelum. "The mitigating effect of strategic behavior on the net benefits of a direct load control program." Energy Economics 49 (2015): 141-148.

Matsukawa, Isamu. "Household response to optional peak-load pricing of electricity." Journal of Regulatory Economics 20.3 (2001): 249-267.

McCrary, Justin. "Manipulation of the running variable in the regression discontinuity design: A density test." Journal of econometrics 142.2 (2008): 698-714. 
Navigant Consulting (2008) Evaluation of Time-of-Use Pricing Pilot, Prepared for Newmarket Hydro Ltd.

Newsham, Guy R., and Brent G. Bowker. "The effect of utility time-varying pricing and load control strategies on residential summer peak electricity use: a review." Energy policy 38.7 (2010): 3289-3296.

Nichols, Austin. "rd 2.0: Revised Stata module for regression discontinuity estimation." Available at ideas. repec. org/c/boc/bocode/s456888. html (2011).

North American Electric Reliability Corporation (NERC), 2013. 2013 Summer Reliability Assessment.

http://www.nerc.com/pa/RAPA/ra/Reliability\%20Assessments\%20DL/2013SRA _Final.pdf

Rocky Mountain Institute (2006) Automated Demand Response System Pilot. https://www.smartgrid.gov/files/Aumated_Demd_Response_System_Pilot_Volu me_1_Intro_Exec_Summa.pdf

United Illuminating. (2016) Exceptions to Mandatory Time of Day (TOD). Procedure. 


\section{Tables and Figures}

Figure 1. Optimized Consumption Bundles for Break-Even Peak Proportion

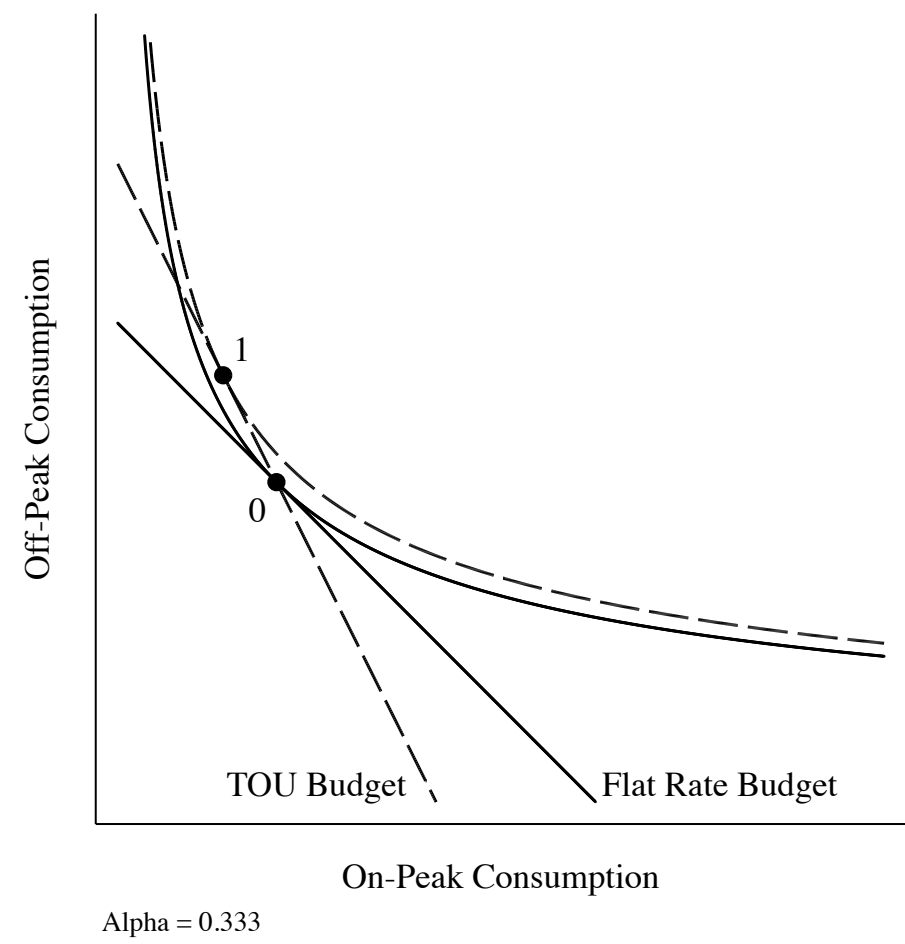

Notes: Figure illustrates budget constraints, indifference curves, and utility-optimized consumption bundles under flat rate pricing (solid) and TOU pricing (dashed). Parameters include flat rate price $=\$ 0.20 / \mathrm{kWh}$, on-peak price $=\$ 0.30 / \mathrm{kWh}$, and off-peak price $=\$ 0.15$, which reflect average prices 2013-2016. We assume a Cobb-Douglas utility function with alpha $=0.333$, which is the break-even peak proportion. 
Figure 2. Optimized Consumption Bundles for Low and High Peak Proportion

Panel A. Low peak proportion

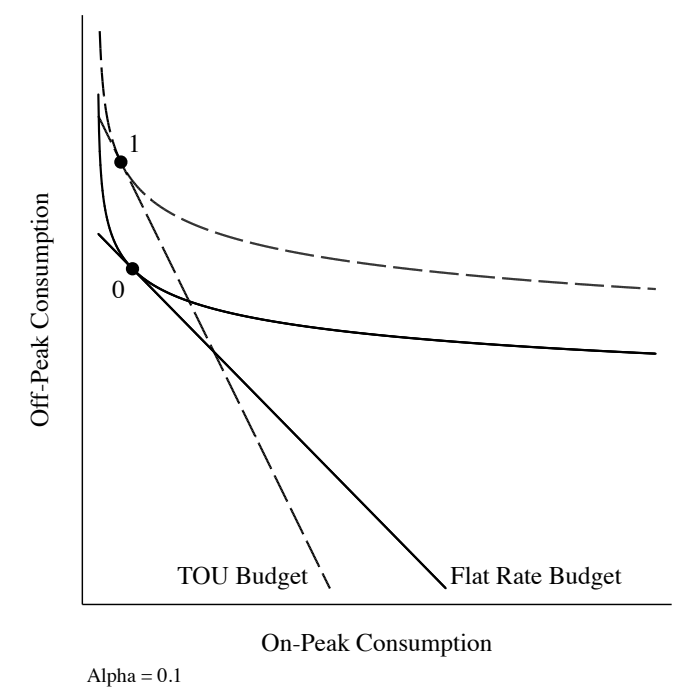

Panel B. High peak proportion

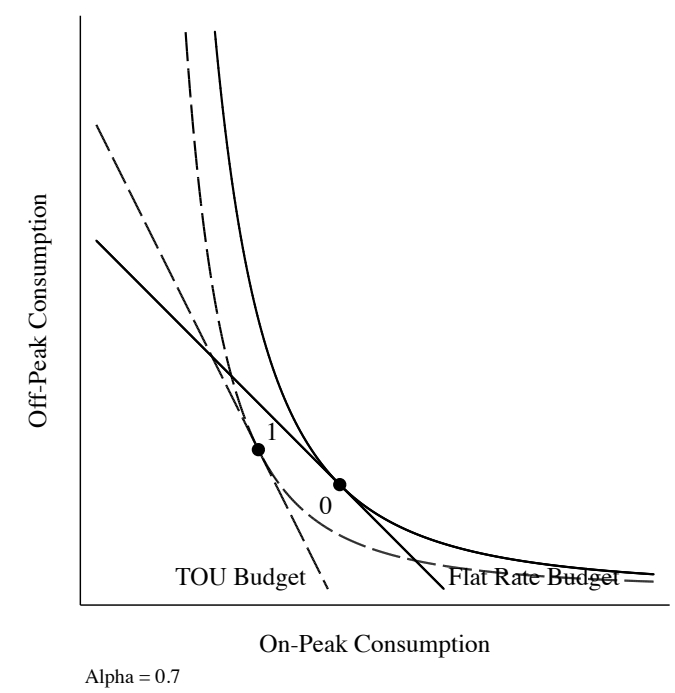

Notes: Figure illustrates budget constraints, indifference curves, and utility-optimized consumption bundles under flat rate pricing (solid) and TOU pricing (dashed). Parameters include flat rate price $=\$ 0.20 / \mathrm{kWh}$, on-peak price $=\$ 0.30 / \mathrm{kWh}$, and off-peak price $=\$ 0.15$, which reflect average prices 2013-2016. We assume a Cobb-Douglas utility function with alpha below (Panel A) and above (Panel B) the break-even peak proportion. 
Figure 3. Daily Load over Sample Period

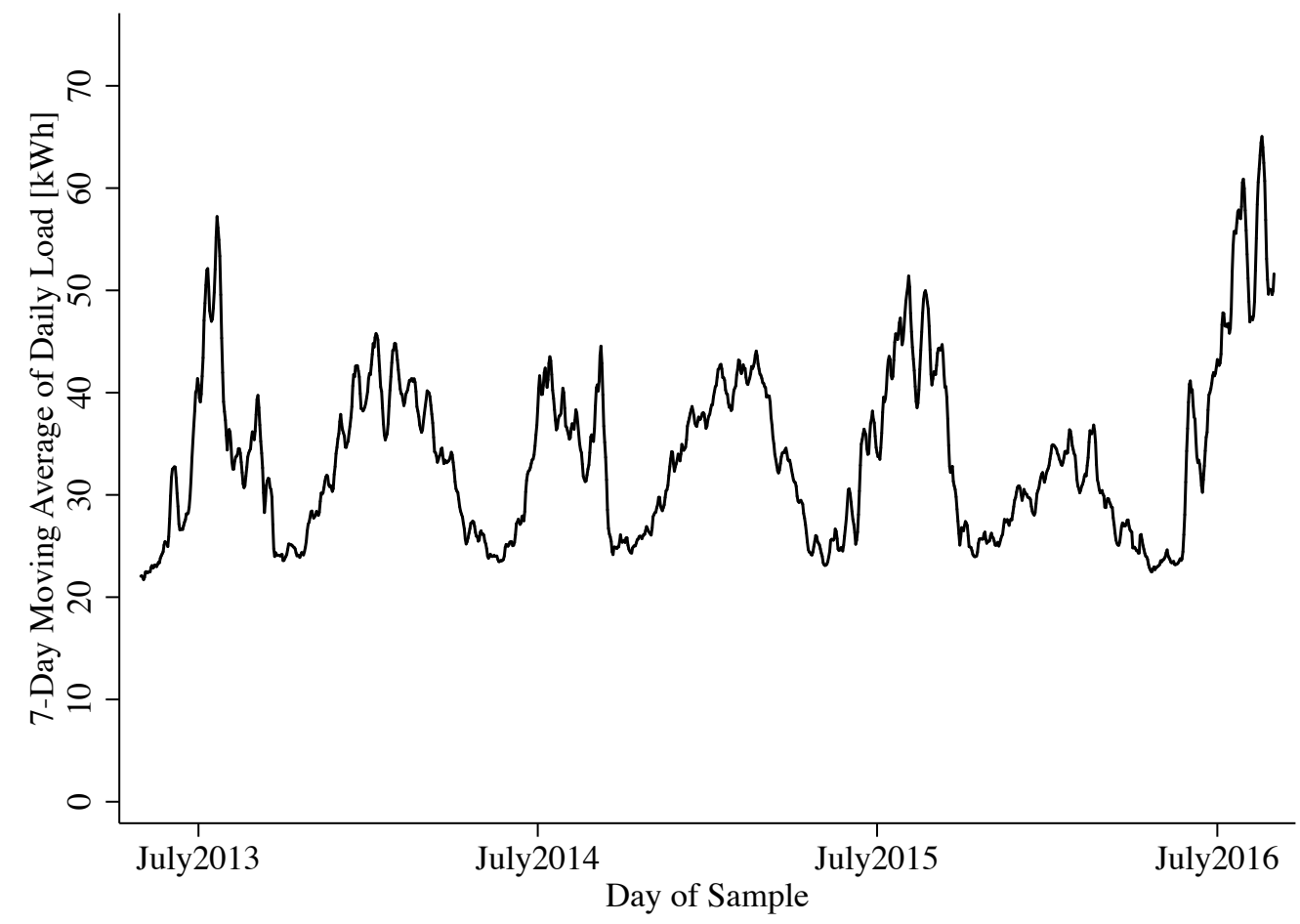

Notes: Figure illustrates daily load over the sample period, smoothed using a 7-day moving average. 
Figure 4. Patterns of Exceedances and Rate Changes

Panel A. Number of Households that Incur Rate Changes each Month

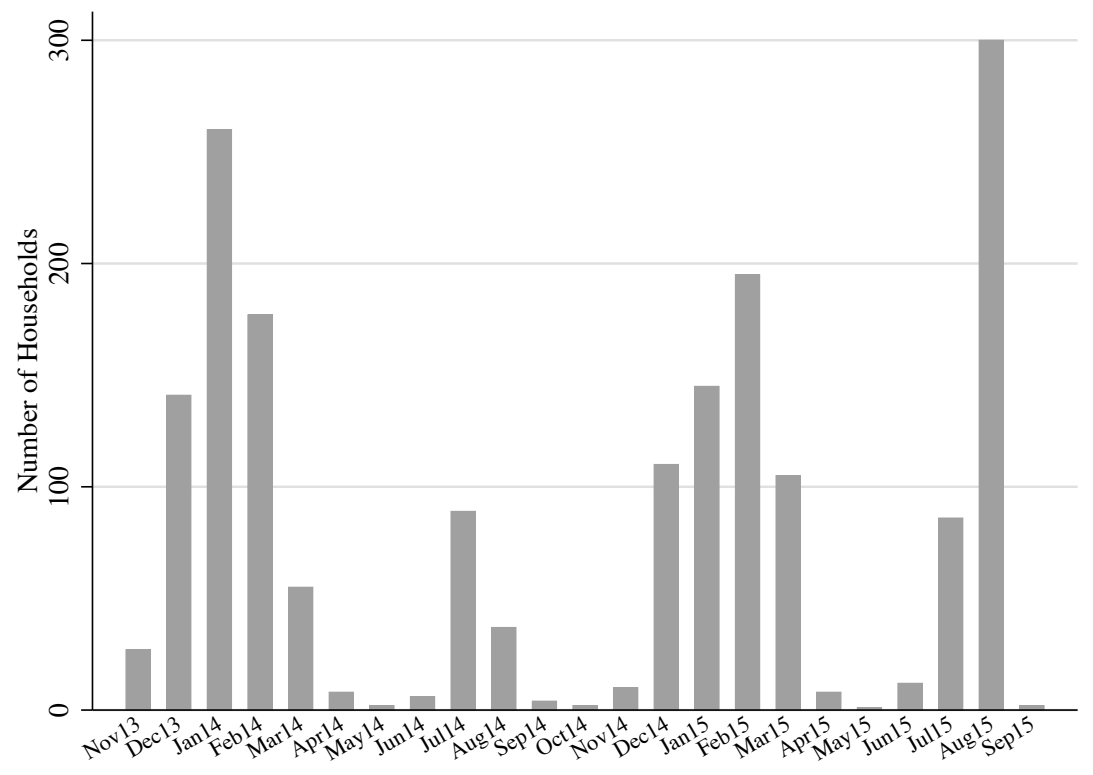

Panel B. Number of Households that Incur Rate Changes each Month

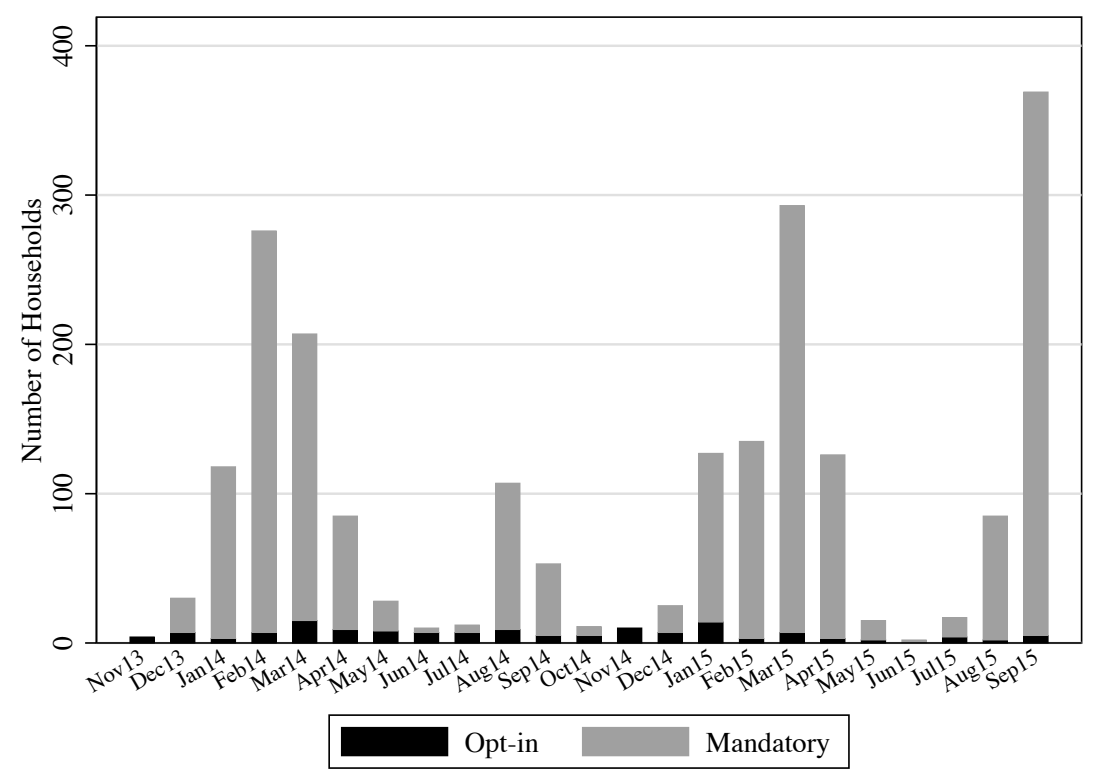

Notes: Figure shows the number of households who exceed 2,000 kWh in a billing period (Panel A) and change rates (Panel B) in each month. Bars are stacked in Panel B, with the gray area representing households who were mandatorily enrolled in TOU pricing and the black area representing households who voluntarily opted into TOU pricing (households who opt-in are removed from the main analysis due to concerns about selection bias). An average of 93 households switch rates per month during Nov 2013 - Sept 2015. 
Figure 5. Average Load Profile

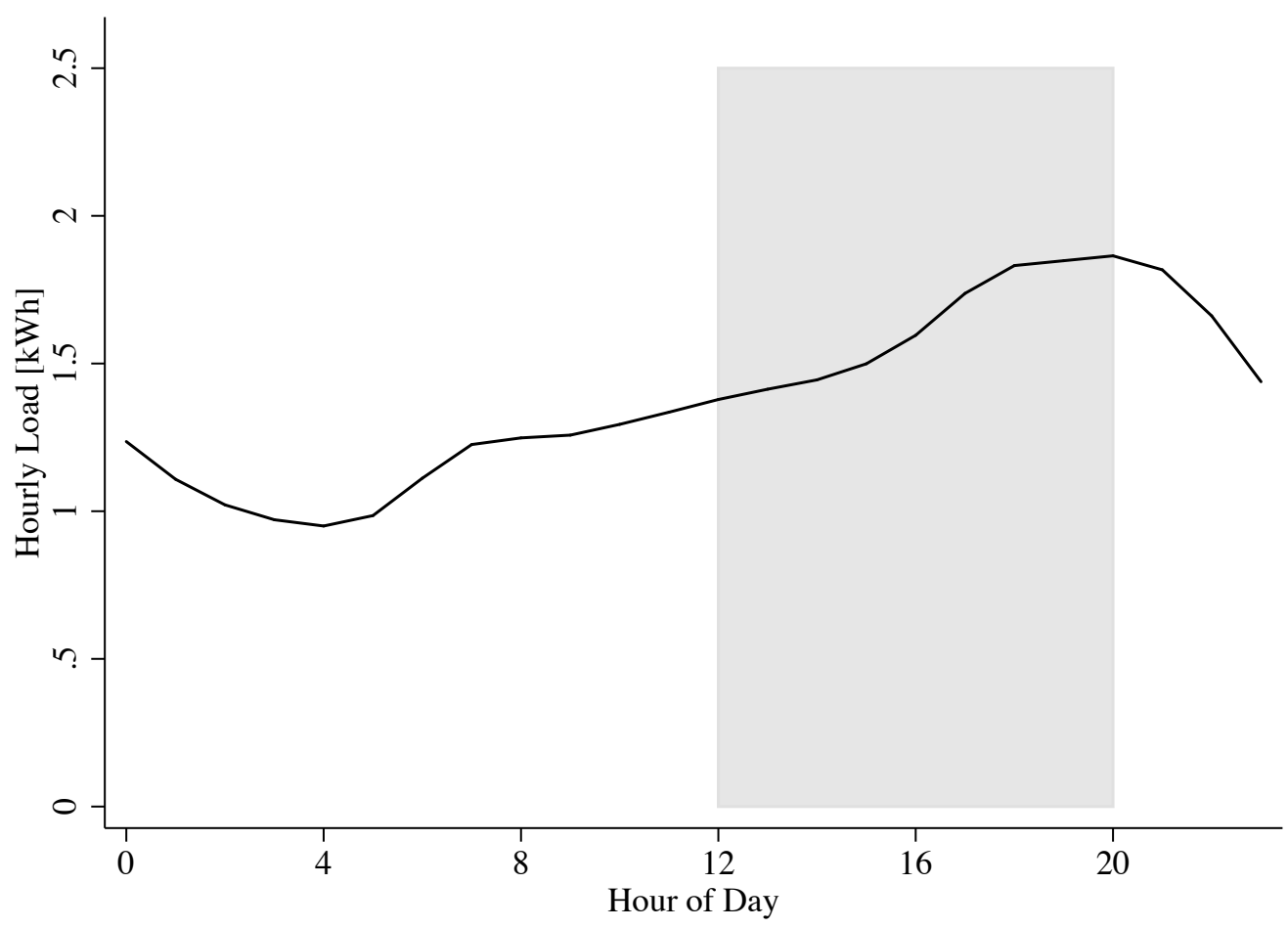

Notes: Figure illustrates daily load over the sample period, smoothed using a 7-day moving average. Gray shaded area indicates peak hours of noon-8pm (weekdays only). 
Figure 6. Variation in Monthly Peak Proportion

Panel A. Peak proportion throughout the year

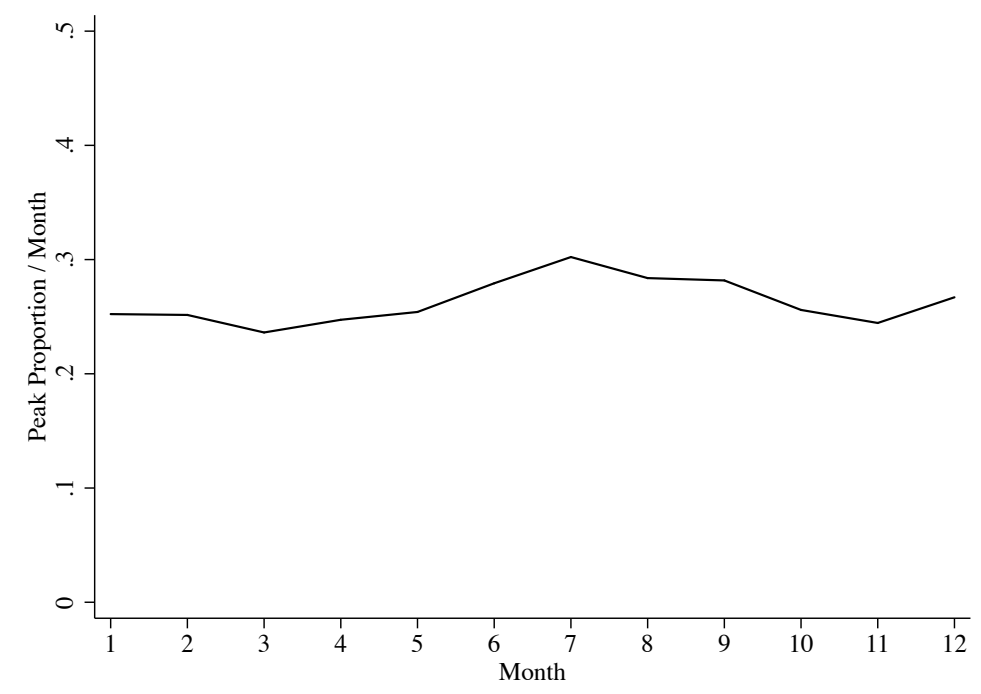

Panel B. Distribution of peak proportion

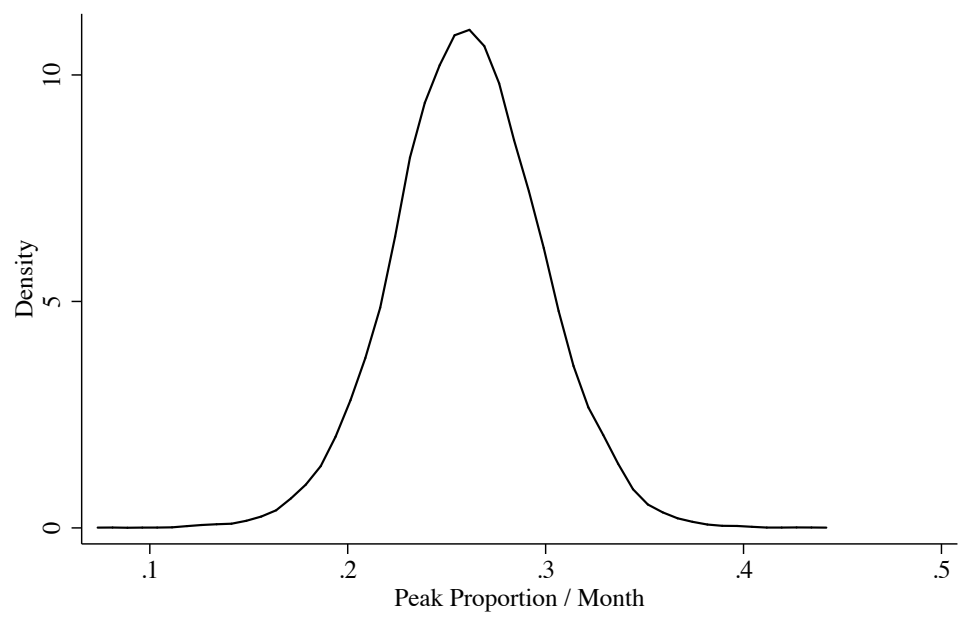

Notes: Figure illustrates trends and variation in monthly peak proportion, defined as the ratio of peak consumption to total consumption over each calendar month. Panel A shows average peak proportion per month. Panel B shows the distribution of peak proportion using a kernel density estimator $($ mean $=0.26)$. 
Figure 7. Regression Discontinuity Framework

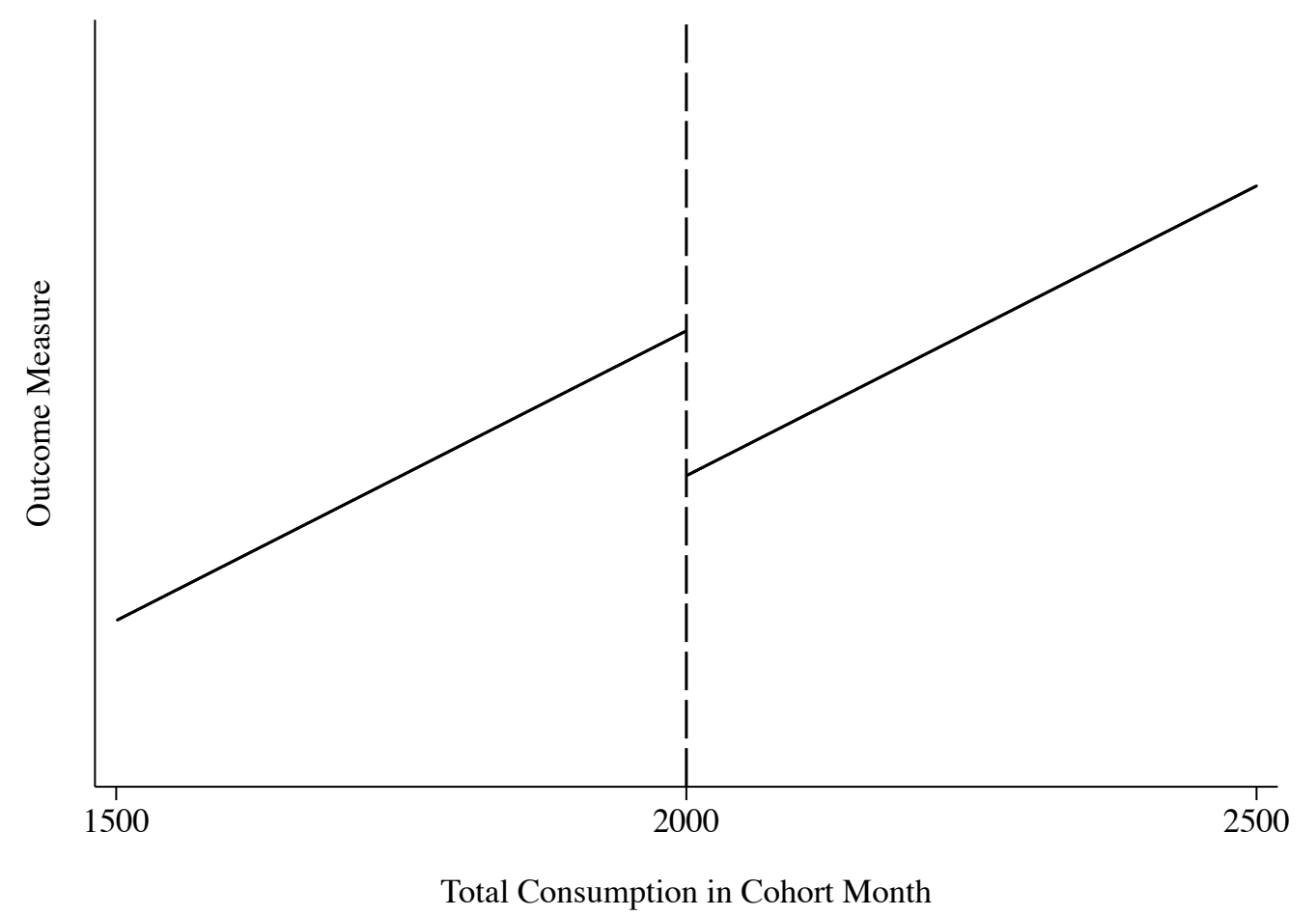

Notes: In our empirical setting, households that have total consumption greater than $2000 \mathrm{kWh}$ in a single billing cycle are treated. This picture illustrates this threshold for a cohort month (i.e. for all households who receive a bill during the month). The outcome measure (peak proportion, peak consumption, total consumption, total cost) is plotted along the vertical axis. We estimate the size of the discontinuity at the threshold. This illustration shows the causal effect of exceeding the threshold would be a decrease in the outcome measure. 
Figure 8. McCrary Density Plot

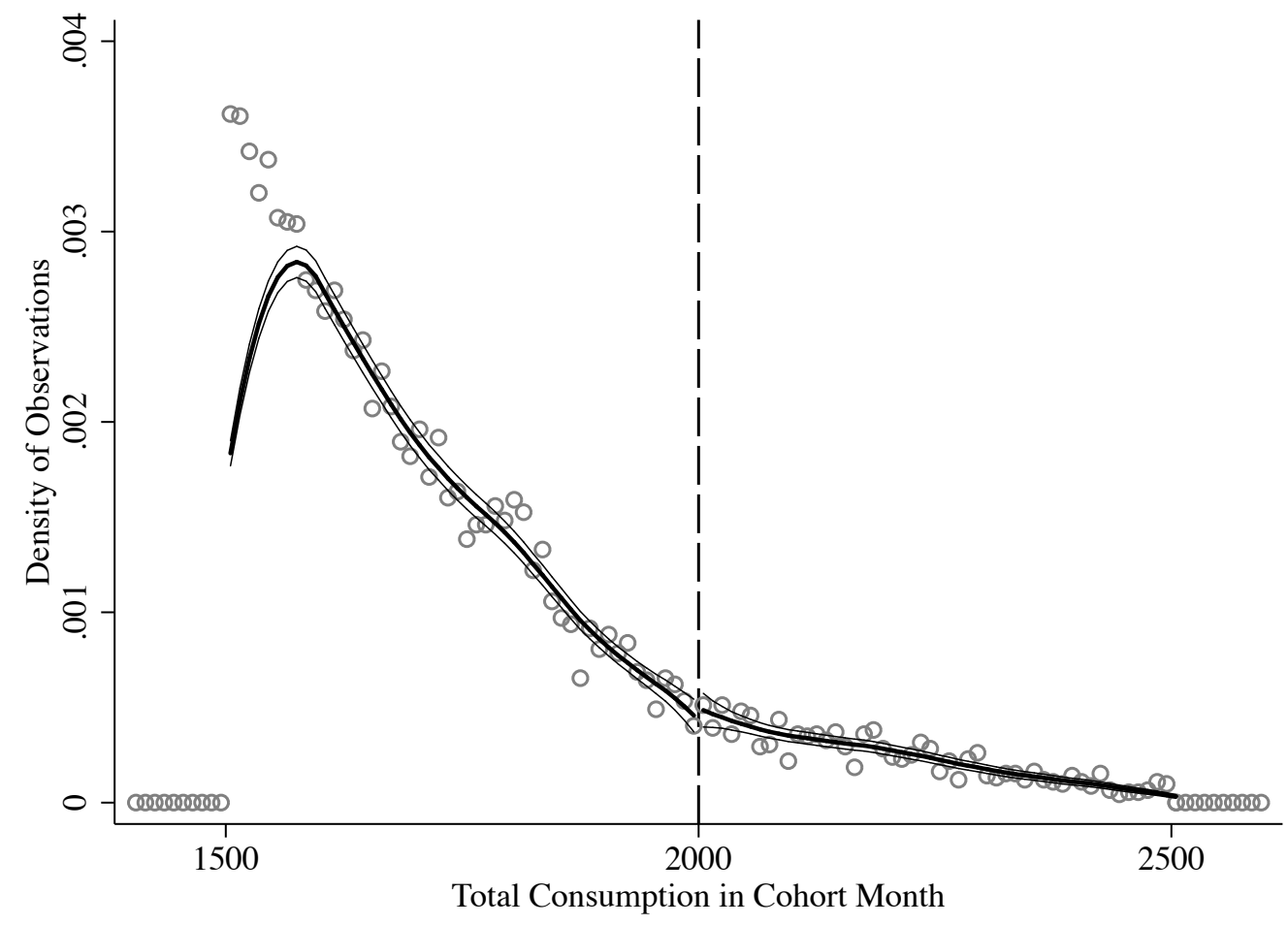

Notes: Figure shows density of observations around the threshold. The log difference in height of density at the threshold $=0.121$ (standard error $=0.150)$. 
Table 1. Flat Rate and TOU Pricing Schedules

\begin{tabular}{|c|c|c|c|c|c|c|c|c|}
\hline \multirow[b]{3}{*}{ Effective Date } & \multicolumn{2}{|c|}{ Flat Rate } & \multicolumn{6}{|c|}{ Time-of-Use Rates } \\
\hline & \multirow[b]{2}{*}{ Summer Rate } & \multirow[b]{2}{*}{ Winter Rate } & \multicolumn{5}{|c|}{ Summer Break } & \multirow{2}{*}{$\begin{array}{c}\text { Winter Break } \\
\text { Even Peak } \\
\text { Proportion }\end{array}$} \\
\hline & & & $\begin{array}{l}\text { Summer On- } \\
\text { Peak Rate }\end{array}$ & $\begin{array}{l}\text { Summer Off- } \\
\text { Peak Rate }\end{array}$ & $\begin{array}{l}\text { Even Peak } \\
\text { Proportion }\end{array}$ & $\begin{array}{l}\text { Winter On- } \\
\text { Peak Rate }\end{array}$ & $\begin{array}{l}\text { Winter Off- } \\
\text { Peak Rate }\end{array}$ & \\
\hline $1 / 1 / 13$ & $\$ 0.187$ & $\$ 0.179$ & $\$ 0.294$ & $\$ 0.139$ & 0.31 & $\$ 0.270$ & $\$ 0.139$ & 0.30 \\
\hline $7 / 1 / 13$ & $\$ 0.192$ & $\$ 0.183$ & $\$ 0.321$ & $\$ 0.139$ & 0.29 & $\$ 0.291$ & $\$ 0.139$ & 0.29 \\
\hline $9 / 5 / 13$ & $\$ 0.199$ & $\$ 0.190$ & $\$ 0.324$ & $\$ 0.143$ & 0.31 & $\$ 0.295$ & $\$ 0.143$ & 0.31 \\
\hline $10 / 1 / 13$ & $\$ 0.201$ & $\$ 0.192$ & $\$ 0.326$ & $\$ 0.145$ & 0.31 & $\$ 0.297$ & $\$ 0.145$ & 0.31 \\
\hline $1 / 1 / 14$ & $\$ 0.196$ & $\$ 0.189$ & $\$ 0.317$ & $\$ 0.147$ & 0.29 & $\$ 0.290$ & $\$ 0.147$ & 0.29 \\
\hline $2 / 1 / 14$ & $\$ 0.197$ & $\$ 0.189$ & $\$ 0.317$ & $\$ 0.147$ & 0.29 & $\$ 0.290$ & $\$ 0.147$ & 0.29 \\
\hline $7 / 1 / 14$ & $\$ 0.201$ & $\$ 0.192$ & $\$ 0.345$ & $\$ 0.144$ & 0.28 & $\$ 0.312$ & $\$ 0.144$ & 0.29 \\
\hline $8 / 14 / 14$ & $\$ 0.208$ & $\$ 0.199$ & $\$ 0.351$ & $\$ 0.150$ & 0.29 & $\$ 0.318$ & $\$ 0.150$ & 0.29 \\
\hline $1 / 1 / 15$ & $\$ 0.249$ & $\$ 0.241$ & $\$ 0.370$ & $\$ 0.195$ & 0.31 & $\$ 0.342$ & $\$ 0.195$ & 0.31 \\
\hline $7 / 1 / 15$ & $\$ 0.201$ & $\$ 0.194$ & $\$ 0.310$ & $\$ 0.153$ & 0.30 & $\$ 0.285$ & $\$ 0.153$ & 0.31 \\
\hline $1 / 1 / 16$ & $\$ 0.211$ & $\$ 0.205$ & $\$ 0.308$ & $\$ 0.168$ & 0.31 & $\$ 0.287$ & $\$ 0.168$ & 0.31 \\
\hline $7 / 1 / 16$ & $\$ 0.195$ & $\$ 0.187$ & $\$ 0.319$ & $\$ 0.141$ & 0.30 & $\$ 0.291$ & $\$ 0.141$ & 0.31 \\
\hline Average & $\$ 0.203$ & $\$ 0.195$ & $\$ 0.325$ & $\$ 0.151$ & 0.30 & $\$ 0.297$ & $\$ 0.151$ & 0.30 \\
\hline $\begin{array}{l}\text { Notes: All rates a } \\
\text { ssessment, com } \\
\text { Dn-peak hours ar } \\
\text { he proportion of } \\
\text { chedule. }\end{array}$ & onsumption $\mathrm{d}$ & $\begin{array}{l}\text { onday - Fride } \\
\text { ring peak ho }\end{array}$ & arges for ge & clude all othe & h that a housel & nd holiday & eak even $p$ & $\begin{array}{l}\text { transmission } \\
\text { ctober - May. } \\
\text { proportion is } \\
\text { der either rate }\end{array}$ \\
\hline
\end{tabular}


Table 2. Balance of Observable Characteristics

\begin{tabular}{|c|c|c|c|c|c|c|c|c|}
\hline Characteristic: & $\begin{array}{c}(1) \\
\text { Lot Size } \\
(0.001 \text { acres }) \\
\end{array}$ & $\begin{array}{c}(2) \\
\text { Assessed } \\
\text { Total House } \\
\text { Value (\$) } \\
\end{array}$ & $\begin{array}{c}\text { (3) } \\
\text { Building Area } \\
\text { (sqft) }\end{array}$ & Year Built & Bedrooms & $\begin{array}{c}\text { Baseline } \\
\text { Consumption }\end{array}$ & $\begin{array}{c}\text { Baseline Peak } \\
\text { Proportion }\end{array}$ & $\begin{array}{c}\text { (8) } \\
\text { Baseline } \\
\text { Total Cost } \\
\end{array}$ \\
\hline Treatment & $\begin{array}{l}-123.2 \\
(137.7)\end{array}$ & $\begin{array}{l}-37,859^{*} \\
(21,747)\end{array}$ & $\begin{array}{l}-92.89 \\
(146.6)\end{array}$ & $\begin{array}{l}-4.138 \\
(4.130)\end{array}$ & $\begin{array}{c}-0.00330 \\
(0.116)\end{array}$ & $\begin{array}{l}-8.426 \\
(30.70)\end{array}$ & $\begin{array}{l}-0.00214 \\
(0.00636)\end{array}$ & $\begin{array}{l}-1.576 \\
(6.385)\end{array}$ \\
\hline Observations & 812 & 1,540 & 956 & 1,254 & 1,197 & 1,335 & 834 & 1,127 \\
\hline
\end{tabular}


Table 3. Average Treatment Effect across Models

\begin{tabular}{|c|c|c|c|c|c|}
\hline $\mathrm{DV}=$ Peak Proportion $(\mathrm{t}+6)$ & Diff-in-Diff & $\begin{array}{c}(2) \\
\text { RD: } \\
\text { Linear }\end{array}$ & $\begin{array}{c}\text { (3) } \\
\text { RD: } \\
\text { Quadratic }\end{array}$ & $\begin{array}{c}\text { (4) } \\
\text { RD: } \\
\text { Cubic } \\
\end{array}$ & $\begin{array}{c}\text { (5) } \\
\text { RD: Local } \\
\text { Linear }\end{array}$ \\
\hline Treatment Indicator & $\begin{array}{c}-0.00670 * * * \\
(0.00169)\end{array}$ & $\begin{array}{l}-0.00560 * \\
(0.00319)\end{array}$ & $\begin{array}{l}-0.00469 \\
(0.00446)\end{array}$ & $\begin{array}{l}-0.00405 \\
(0.00538)\end{array}$ & $\begin{array}{c}0.00101 \\
(0.00739)\end{array}$ \\
\hline Experimental Month FE & $\mathrm{Y}$ & $\mathrm{Y}$ & $\mathrm{Y}$ & $\bar{Y}$ & $\mathrm{~N}$ \\
\hline Bill Cycle FE & $\mathrm{Y}$ & $\mathrm{Y}$ & $\mathrm{Y}$ & $\mathrm{Y}$ & $\mathrm{N}$ \\
\hline Observations & 8,496 & 8,496 & 8,496 & 8,496 & 989 \\
\hline R-squared & 0.0570 & 0.0570 & 0.0575 & 0.0575 & . \\
\hline Adj. R-squared & 0.055 & 0.054 & 0.055 & 0.054 & . \\
\hline
\end{tabular}

Notes: Table presents estimates of treatment effect from several specifications on peak proportion six months following treatment. Columns 1 presents results from a differences in differences model. Columns 2-4 present the local average treatment effect by controlling for the running variable (consumption during the cohort month) using a linear, quadratic, or cubic functional form on either side of the threshold. Column 5 presents a local average treatment effect using robust local-linear RD. Columns 1-4 additionally include fixed effects for cohort month and bill cycle. Standard errors in parentheses are clustered at the household level. *,**, and *** indicate statistical significance at the $10 \%, 5 \%$, and $1 \%$ levels, respectively. 
Table 4. Treatment Effect on Outcome Measures in Future Months

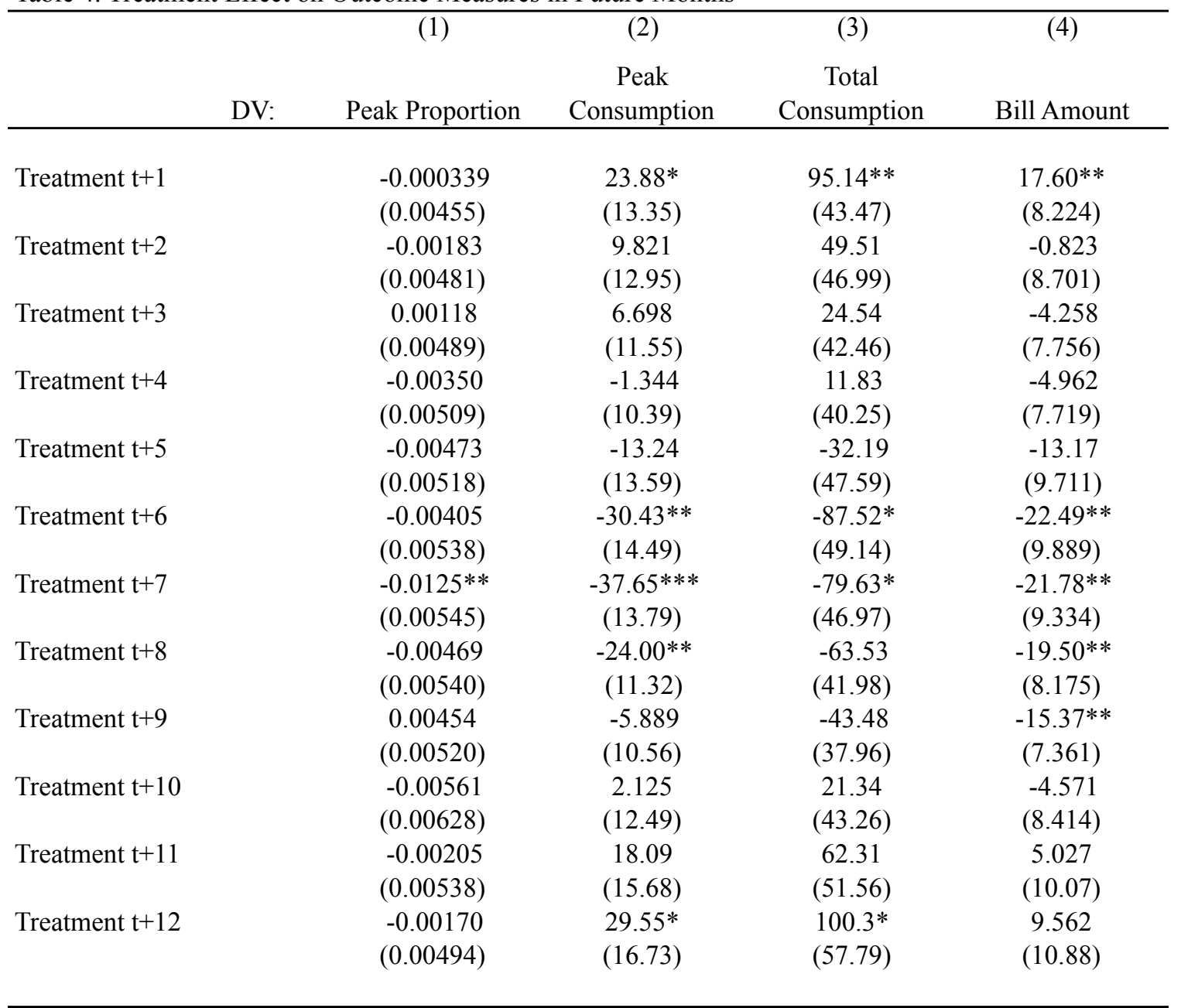

Notes: Table presents local average treatment effects on four outcome measures. Each cell is the treatment effect from one regression, controlling for total consumption during the cohort month using a cubic polynomial on either side of the threshold. Standard errors are shown in parentheses. *, **, and *** indicate statistical significance at the $10 \%, 5 \%$, and $1 \%$ levels, respectively. 
Table 5. Falsification Tests

\begin{tabular}{|c|c|c|c|c|c|c|c|c|c|c|c|c|}
\hline Treatment Effect: & $\begin{array}{c}\text { (1) } \\
1 \text { month later }\end{array}$ & $\begin{array}{c}(2) \\
2 \text { months } \\
\end{array}$ & $\begin{array}{c}\text { (3) } \\
3 \text { months } \\
\end{array}$ & $\begin{array}{c}(4) \\
4 \text { months } \\
\end{array}$ & $\begin{array}{c}(5) \\
5 \text { months }\end{array}$ & $\begin{array}{c}(6) \\
6 \text { months } \\
\end{array}$ & $\begin{array}{c}\text { (7) } \\
7 \text { months }\end{array}$ & $\begin{array}{c}(8) \\
8 \text { months }\end{array}$ & $\begin{array}{c}(9) \\
9 \text { months } \\
\end{array}$ & $\begin{array}{c}(10) \\
10 \text { months }\end{array}$ & $\begin{array}{c}(11) \\
11 \text { months }\end{array}$ & $\begin{array}{c}(12) \\
12 \text { months }\end{array}$ \\
\hline \multicolumn{2}{|c|}{ Panel A: DV = Peak Proportion } & & & & & & & & & & & \\
\hline False Treatment Indicator & $\begin{array}{l}0.00519 \\
(0.0117)\end{array}$ & $\begin{array}{l}0.00843 \\
(0.0114)\end{array}$ & $\begin{array}{c}0.0103 \\
(0.0130)\end{array}$ & $\begin{array}{l}-0.00197 \\
(0.0129)\end{array}$ & $\begin{array}{l}-0.00382 \\
(0.0131)\end{array}$ & $\begin{array}{l}-0.0226 \\
(0.0138)\end{array}$ & $\begin{array}{l}-0.00344 \\
(0.0140)\end{array}$ & $\begin{array}{l}-0.00461 \\
(0.0136)\end{array}$ & $\begin{array}{c}0.000414 \\
(0.0144)\end{array}$ & $\begin{array}{c}0.0198 \\
(0.0143)\end{array}$ & $\begin{array}{c}0.0210 \\
(0.0151)\end{array}$ & $\begin{array}{l}0.00543 \\
(0.0142)\end{array}$ \\
\hline True Treatment Indicator & $\begin{array}{c}5.76 \mathrm{e}-05 \\
(0.00511)\end{array}$ & $\begin{array}{r}-0.00477 \\
(0.00533)\end{array}$ & $\begin{array}{c}0.00220 \\
(0.00571)\end{array}$ & $\begin{array}{c}-0.00285 \\
(0.00581)\end{array}$ & $\begin{array}{r}-0.00356 \\
(0.00594)\end{array}$ & $\begin{array}{c}9.00 \mathrm{e}-06 \\
(0.00610)\end{array}$ & $\begin{array}{c}-0.0129 * * \\
(0.00629)\end{array}$ & $\begin{array}{c}-0.00385 \\
(0.00627)\end{array}$ & $\begin{array}{c}0.00598 \\
(0.00585)\end{array}$ & $\begin{array}{r}-0.00600 \\
(0.00692)\end{array}$ & $\begin{array}{l}-0.000763 \\
(0.00636)\end{array}$ & $\begin{array}{c}0.00139 \\
(0.00595)\end{array}$ \\
\hline \multicolumn{2}{|c|}{ Panel B: DV = Peak Consumption } & & & & & & & & & & & \\
\hline False Treatment Indicator & $\begin{array}{c}11.40 \\
(27.18)\end{array}$ & $\begin{array}{l}-33.15 \\
(27.35)\end{array}$ & $\begin{array}{l}-4.581 \\
(24.84)\end{array}$ & $\begin{array}{l}-17.56 \\
(28.03)\end{array}$ & $\begin{array}{l}-7.349 \\
(35.13)\end{array}$ & $\begin{array}{c}21.26 \\
(36.68)\end{array}$ & $\begin{array}{c}40.14 \\
(33.88)\end{array}$ & $\begin{array}{c}9.133 \\
(26.80)\end{array}$ & $\begin{array}{c}2.566 \\
(23.97)\end{array}$ & $\begin{array}{c}30.58 \\
(27.40)\end{array}$ & $\begin{array}{c}11.79 \\
(32.70)\end{array}$ & $\begin{array}{c}27.32 \\
(37.11)\end{array}$ \\
\hline True Treatment Indicator & $\begin{array}{l}24.76^{*} \\
(14.61)\end{array}$ & $\begin{array}{c}6.926 \\
(14.14)\end{array}$ & $\begin{array}{c}6.086 \\
(12.63)\end{array}$ & $\begin{array}{c}1.392 \\
(11.51)\end{array}$ & $\begin{array}{l}-3.721 \\
(13.74)\end{array}$ & $\begin{array}{r}-25.77 \\
(15.86)\end{array}$ & $\begin{array}{c}-38.01 * * \\
(15.76)\end{array}$ & $\begin{array}{l}-18.78 \\
(12.56)\end{array}$ & $\begin{array}{c}0.958 \\
(11.41)\end{array}$ & $\begin{array}{c}11.16 \\
(13.63)\end{array}$ & $\begin{array}{c}26.14 \\
(16.75)\end{array}$ & $\begin{array}{l}32.51^{*} \\
(17.99)\end{array}$ \\
\hline \multicolumn{2}{|c|}{ Panel C: DV = Total Consumption } & & & & & & & & & & & \\
\hline False Treatment Indicator & $\begin{array}{l}-19.74 \\
(85.46)\end{array}$ & $\begin{array}{c}-189.8^{* *} \\
(96.30)\end{array}$ & $\begin{array}{l}-41.54 \\
(85.96)\end{array}$ & $\begin{array}{l}-53.98 \\
(94.61)\end{array}$ & $\begin{array}{c}14.83 \\
(109.6)\end{array}$ & $\begin{array}{c}168.2 \\
(114.7)\end{array}$ & $\begin{array}{c}149.2 \\
(105.9)\end{array}$ & $\begin{array}{c}39.95 \\
(90.08)\end{array}$ & $\begin{array}{c}0.915 \\
(83.00)\end{array}$ & $\begin{array}{c}41.16 \\
(91.88)\end{array}$ & $\begin{array}{r}-24.49 \\
(102.4)\end{array}$ & $\begin{array}{c}69.55 \\
(116.2)\end{array}$ \\
\hline True Treatment Indicator & $\begin{array}{l}106.0 * * \\
(44.93)\end{array}$ & $\begin{array}{c}52.86 \\
(50.26)\end{array}$ & $\begin{array}{c}19.05 \\
(45.49)\end{array}$ & $\begin{array}{c}21.30 \\
(43.06)\end{array}$ & $\begin{array}{r}-2.550 \\
(46.56)\end{array}$ & $\begin{array}{l}-85.61 \\
(52.47)\end{array}$ & $\begin{array}{r}-71.68 \\
(49.93)\end{array}$ & $\begin{array}{l}-42.25 \\
(43.85)\end{array}$ & $\begin{array}{c}-16.91 \\
(40.98)\end{array}$ & $\begin{array}{c}59.15 \\
(46.32)\end{array}$ & $\begin{array}{c}80.73 \\
(54.50)\end{array}$ & $\begin{array}{c}91.75 \\
(61.51)\end{array}$ \\
\hline \multicolumn{2}{|l|}{ Panel D: DV = Bill Amount } & & & & & & & & & & & \\
\hline False Treatment Indicator & $\begin{array}{c}-2.468 \\
(16.20)\end{array}$ & $\begin{array}{l}-35.45^{*} \\
(18.18)\end{array}$ & $\begin{array}{l}-7.862 \\
(16.24)\end{array}$ & $\begin{array}{c}-14.41 \\
(18.91)\end{array}$ & $\begin{array}{c}5.911 \\
(22.24)\end{array}$ & $\begin{array}{c}32.20 \\
(23.00)\end{array}$ & $\begin{array}{c}30.26 \\
(21.09)\end{array}$ & $\begin{array}{c}10.04 \\
(17.92)\end{array}$ & $\begin{array}{c}0.529 \\
(16.26)\end{array}$ & $\begin{array}{c}8.548 \\
(18.24)\end{array}$ & $\begin{array}{l}-3.274 \\
(20.09)\end{array}$ & $\begin{array}{c}12.60 \\
(22.20)\end{array}$ \\
\hline True Treatment Indicator & $\begin{array}{l}19.52 * * \\
(8.507)\end{array}$ & $\begin{array}{l}-0.353 \\
(9.323)\end{array}$ & $\begin{array}{l}-5.311 \\
(8.346)\end{array}$ & $\begin{array}{l}-3.039 \\
(8.289)\end{array}$ & $\begin{array}{l}-7.704 \\
(9.657)\end{array}$ & $\begin{array}{c}-22.17 * * \\
(10.59)\end{array}$ & $\begin{array}{c}-20.17^{* *} \\
(9.875)\end{array}$ & $\begin{array}{l}-15.27 * \\
(8.534)\end{array}$ & $\begin{array}{l}-10.04 \\
(7.950)\end{array}$ & $\begin{array}{c}3.164 \\
(9.026)\end{array}$ & $\begin{array}{c}8.383 \\
(10.66)\end{array}$ & $\begin{array}{c}8.048 \\
(11.61)\end{array}$ \\
\hline
\end{tabular}

Notes: Table presents results of a falsification test. Each panel-column presents results from one regression that includes a false threshold at $1900 \mathrm{kWh}$ in the cohort month, with cubic control of the running variable interacted with both true treatment indicator and false treatment indicator. Standard errors are shown in parentheses. *, **, and *** indicate statistical significance at the $10 \%, 5 \%$, and $1 \%$ levels, respectively. 


\section{Appendices}

\section{Appendix A: Tables}

Table 1A. Treatment Effect in Future Months Across Specifications

\begin{tabular}{|c|c|c|c|c|c|}
\hline DV = Peak Proportion & Diff-in-Diff & $\begin{array}{c}(2) \\
\text { RD: } \\
\text { Linear }\end{array}$ & RD: Quadratic & $\begin{array}{c}\text { (4) } \\
\text { RD: } \\
\text { Cubic }\end{array}$ & $\begin{array}{c}(5) \\
\text { RD: Local } \\
\text { Linear }\end{array}$ \\
\hline Treatment $\mathrm{t}+1$ & $\begin{array}{l}-0.00256^{*} \\
(0.00131)\end{array}$ & $\begin{array}{c}-0.00224 \\
(0.00247)\end{array}$ & $\begin{array}{c}0.00113 \\
(0.00362)\end{array}$ & $\begin{array}{r}-0.000339 \\
(0.00455)\end{array}$ & $\begin{array}{c}0.00270 \\
(0.00762)\end{array}$ \\
\hline Treatment $\mathrm{t}+2$ & $\begin{array}{c}-0.00358^{* *} \\
(0.00140)\end{array}$ & $\begin{array}{c}-0.00244 \\
(0.00267)\end{array}$ & $\begin{array}{c}0.00322 \\
(0.00389)\end{array}$ & $\begin{array}{l}-0.00183 \\
(0.00481)\end{array}$ & $\begin{array}{l}-0.00472 \\
(0.00562)\end{array}$ \\
\hline Treatment $\mathrm{t}+3$ & $\begin{array}{c}-0.00485 * * * \\
(0.00151)\end{array}$ & $\begin{array}{l}-0.00359 \\
(0.00283)\end{array}$ & $\begin{array}{c}0.00447 \\
(0.00408)\end{array}$ & $\begin{array}{c}0.00118 \\
(0.00489)\end{array}$ & $\begin{array}{c}-0.00137 \\
(0.00501)\end{array}$ \\
\hline Treatment $\mathrm{t}+4$ & $\begin{array}{c}-0.00443 * * * \\
(0.00152)\end{array}$ & $\begin{array}{c}-0.00712^{* *} \\
(0.00290)\end{array}$ & $\begin{array}{c}-0.00212 \\
(0.00417)\end{array}$ & $\begin{array}{l}-0.00350 \\
(0.00509)\end{array}$ & $\begin{array}{l}-0.00481 \\
(0.00623)\end{array}$ \\
\hline Treatment $\mathrm{t}+5$ & $\begin{array}{c}-0.00339 * * \\
(0.00155)\end{array}$ & $\begin{array}{l}-0.00405 \\
(0.00295)\end{array}$ & $\begin{array}{c}-0.00173 \\
(0.00422)\end{array}$ & $\begin{array}{c}-0.00473 \\
(0.00518)\end{array}$ & $\begin{array}{l}-0.0101^{*} \\
(0.00564)\end{array}$ \\
\hline Treatment $\mathrm{t}+6$ & $\begin{array}{c}-0.00670 * * * \\
(0.00169)\end{array}$ & $\begin{array}{l}-0.00560^{*} \\
(0.00319)\end{array}$ & $\begin{array}{l}-0.00469 \\
(0.00446)\end{array}$ & $\begin{array}{l}-0.00405 \\
(0.00538)\end{array}$ & $\begin{array}{c}0.00101 \\
(0.00739)\end{array}$ \\
\hline Treatment $\mathrm{t}+7$ & $\begin{array}{c}-0.00715^{* * *} \\
(0.00173)\end{array}$ & $\begin{array}{c}-0.00792 * * \\
(0.00324)\end{array}$ & $\begin{array}{l}-0.0112 * * \\
(0.00459)\end{array}$ & $\begin{array}{l}-0.0125^{* *} \\
(0.00545)\end{array}$ & $\begin{array}{c}-0.00752 \\
(0.00599)\end{array}$ \\
\hline Treatment $\mathrm{t}+8$ & $\begin{array}{c}-0.00398 * * \\
(0.00170)\end{array}$ & $\begin{array}{l}-0.00106 \\
(0.00319)\end{array}$ & $\begin{array}{c}-0.00203 \\
(0.00448)\end{array}$ & $\begin{array}{l}-0.00469 \\
(0.00540)\end{array}$ & $\begin{array}{l}-3.48 \mathrm{e}-05 \\
(0.00614)\end{array}$ \\
\hline Treatment $\mathrm{t}+9$ & $\begin{array}{l}-0.00321^{*} \\
(0.00165)\end{array}$ & $\begin{array}{c}0.00260 \\
(0.00313)\end{array}$ & $\begin{array}{c}0.00668 \\
(0.00438)\end{array}$ & $\begin{array}{c}0.00454 \\
(0.00520)\end{array}$ & $\begin{array}{c}0.00515 \\
(0.00577)\end{array}$ \\
\hline Treatment $\mathrm{t}+10$ & $\begin{array}{c}-0.00372^{* *} \\
(0.00174)\end{array}$ & $\begin{array}{c}-0.00584^{*} \\
(0.00339)\end{array}$ & $\begin{array}{c}-0.00344 \\
(0.00500)\end{array}$ & $\begin{array}{c}-0.00561 \\
(0.00628)\end{array}$ & $\begin{array}{c}-0.00668 \\
(0.00620)\end{array}$ \\
\hline Treatment $\mathrm{t}+11$ & $\begin{array}{c}-0.00440 * * \\
(0.00175)\end{array}$ & $\begin{array}{l}-0.00217 \\
(0.00324)\end{array}$ & $\begin{array}{c}0.00184 \\
(0.00453)\end{array}$ & $\begin{array}{l}-0.00205 \\
(0.00538)\end{array}$ & $\begin{array}{l}-0.00239 \\
(0.00817)\end{array}$ \\
\hline Treatment $\mathrm{t}+12$ & $\begin{array}{c}-0.00371^{* *} \\
(0.00160)\end{array}$ & $\begin{array}{r}-0.000965 \\
(0.00298)\end{array}$ & $\begin{array}{c}0.00215 \\
(0.00421)\end{array}$ & $\begin{array}{c}-0.00170 \\
(0.00494)\end{array}$ & $\begin{array}{c}-0.00544 \\
(0.00640)\end{array}$ \\
\hline \multicolumn{6}{|c|}{$\begin{array}{l}\text { Notes: Table presents estimated treatment effect on peak proportion, with each row estimating the effect of } \\
\text { treatment on peak proportion in future months. Column } 1 \text { presents results from a differences in differences } \\
\text { model. Columns } 2-4 \text { present the local average treatment effect by controlling for the running variable } \\
\text { (consumption during the cohort month) using a linear, quadratic, or cubic functional form on either side of } \\
\text { the threshold. Column } 5 \text { presents a local average treatment effect using robust local-linear RD. Columns } 1 \text { - } \\
4 \text { additionally include fixed effects for cohort month and bill cycle. Each cell is the treatment effect from } \\
\text { one regression, with the treatment effects shown from } 72 \text { regressions in total. R-squared values range from } \\
0.037-0.368 \text {. Standard errors are shown in parentheses. } * * * \text {, and } * * * \text { indicate statistical significance at the } \\
10 \%, 5 \% \text {, and } 1 \% \text { levels, respectively. }\end{array}$} \\
\hline
\end{tabular}


Table 2A. Treatment Effect in Future Months Across Specifications

\begin{tabular}{|c|c|c|c|c|c|}
\hline $\mathrm{DV}=$ Peak Consumption & Diff-in-Diff & $\begin{array}{c}(2) \\
\text { RD: } \\
\text { Linear } \\
\end{array}$ & RD: Quadratic & $\begin{array}{c}\text { (4) } \\
\text { RD: } \\
\text { Cubic }\end{array}$ & $\begin{array}{c}(5) \\
\text { RD: Local } \\
\text { Linear } \\
\end{array}$ \\
\hline Treatment $\mathrm{t}+1$ & $\begin{array}{c}107.8 * * * \\
(4.231)\end{array}$ & $\begin{array}{c}23.80 * * * \\
(7.591)\end{array}$ & $\begin{array}{c}38.71 * * * \\
(10.61)\end{array}$ & $\begin{array}{l}23.88^{*} \\
(13.35)\end{array}$ & $\begin{array}{c}0.208 \\
(15.82)\end{array}$ \\
\hline Treatment $\mathrm{t}+2$ & $\begin{array}{c}53.72 * * * \\
(4.241)\end{array}$ & $\begin{array}{c}22.43 * * * \\
(7.559)\end{array}$ & $\begin{array}{c}28.44 * * * \\
(10.47)\end{array}$ & $\begin{array}{c}9.821 \\
(12.95)\end{array}$ & $\begin{array}{l}-32.88^{*} \\
(17.66)\end{array}$ \\
\hline Treatment $\mathrm{t}+3$ & $\begin{array}{c}23.95 * * * \\
(3.759)\end{array}$ & $\begin{array}{c}12.97^{*} \\
(6.786)\end{array}$ & $\begin{array}{c}22.63 * * \\
(9.556)\end{array}$ & $\begin{array}{c}6.698 \\
(11.55)\end{array}$ & $\begin{array}{l}-8.329 \\
(15.38)\end{array}$ \\
\hline Treatment $\mathrm{t}+4$ & $\begin{array}{c}7.134 * * \\
(3.520)\end{array}$ & $\begin{array}{c}0.201 \\
(6.325)\end{array}$ & $\begin{array}{c}3.128 \\
(8.740)\end{array}$ & $\begin{array}{c}-1.344 \\
(10.39)\end{array}$ & $\begin{array}{l}-1.234 \\
(11.17)\end{array}$ \\
\hline Treatment $\mathrm{t}+5$ & $\begin{array}{c}-7.538^{* *} \\
(3.786)\end{array}$ & $\begin{array}{c}-4.693 \\
(7.190)\end{array}$ & $\begin{array}{l}-10.99 \\
(11.05)\end{array}$ & $\begin{array}{c}-13.24 \\
(13.59)\end{array}$ & $\begin{array}{c}-21.24 \\
(13.69)\end{array}$ \\
\hline Treatment $\mathrm{t}+6$ & $\begin{array}{c}-22.20 * * * \\
(4.263)\end{array}$ & $\begin{array}{c}-16.85^{* *} \\
(8.034)\end{array}$ & $\begin{array}{c}-31.74 * * * \\
(11.93)\end{array}$ & $\begin{array}{c}-30.43 * * \\
(14.49)\end{array}$ & $\begin{array}{c}-40.14 * * \\
(17.35)\end{array}$ \\
\hline Treatment $\mathrm{t}+7$ & $\begin{array}{c}-23.13 * * * \\
(4.387)\end{array}$ & $\begin{array}{c}-19.04 * * \\
(8.112)\end{array}$ & $\begin{array}{c}-36.33 * * * \\
(11.61)\end{array}$ & $\begin{array}{c}-37.65^{* * *} \\
(13.79)\end{array}$ & $\begin{array}{c}-29.91 * * \\
(15.12)\end{array}$ \\
\hline Treatment $\mathrm{t}+8$ & $\begin{array}{c}-14.41 * * * \\
(3.775)\end{array}$ & $\begin{array}{r}-11.95^{*} \\
(6.794)\end{array}$ & $\begin{array}{c}-23.85^{* *} \\
(9.452)\end{array}$ & $\begin{array}{c}-24.00^{* *} \\
(11.32)\end{array}$ & $\begin{array}{l}-14.99 \\
(12.15)\end{array}$ \\
\hline Treatment $\mathrm{t}+9$ & $\begin{array}{l}-3.978 \\
(3.295)\end{array}$ & $\begin{array}{l}-8.966 \\
(6.071)\end{array}$ & $\begin{array}{l}-7.120 \\
(8.632)\end{array}$ & $\begin{array}{l}-5.889 \\
(10.56)\end{array}$ & $\begin{array}{c}1.480 \\
(10.81)\end{array}$ \\
\hline Treatment $\mathrm{t}+10$ & $\begin{array}{c}18.70 * * * \\
(4.075)\end{array}$ & $\begin{array}{c}4.438 \\
(7.161)\end{array}$ & $\begin{array}{c}6.127 \\
(10.17)\end{array}$ & $\begin{array}{c}2.125 \\
(12.49)\end{array}$ & $\begin{array}{c}5.898 \\
(16.27)\end{array}$ \\
\hline Treatment $\mathrm{t}+11$ & $\begin{array}{c}45.89 * * * \\
(5.129)\end{array}$ & $\begin{array}{c}24.47 * * * \\
(9.098)\end{array}$ & $\begin{array}{c}27.36^{* *} \\
(12.79)\end{array}$ & $\begin{array}{c}18.09 \\
(15.68)\end{array}$ & $\begin{array}{c}1.251 \\
(20.05)\end{array}$ \\
\hline Treatment $\mathrm{t}+12$ & $\begin{array}{c}67.92 * * * \\
(5.591)\end{array}$ & $\begin{array}{c}39.29 * * * \\
(9.908)\end{array}$ & $\begin{array}{c}43.98 * * * \\
(13.67)\end{array}$ & $\begin{array}{l}29.55^{*} \\
(16.73)\end{array}$ & $\begin{array}{c}1.534 \\
(22.97)\end{array}$ \\
\hline \multicolumn{6}{|c|}{$\begin{array}{l}\text { Notes: Table presents estimated treatment effect on peak consumption with each row estimating the effect } \\
\text { of treatment on peak consumption in future months. Column } 1 \text { presents results from a differences in } \\
\text { differences model. Columns } 2-4 \text { present the local average treatment effect by controlling for the running } \\
\text { variable (consumption during the cohort month) using a linear, quadratic, or cubic functional form on } \\
\text { either side of the threshold. Column } 5 \text { presents a local average treatment effect using robust local-linear } \\
\text { RD. Columns } 1-4 \text { additionally include fixed effects for cohort month and bill cycle. Each cell is the } \\
\text { treatment effect from one regression, with the treatment effects shown from } 72 \text { regressions in total. R- } \\
\text { squared values range from } 0.085-0.382 \text {. Standard errors are shown in parentheses. *, **, and *** indicate } \\
\text { statistical significance at the } 10 \%, 5 \% \text {, and } 1 \% \text { levels, respectively. }\end{array}$} \\
\hline
\end{tabular}


Table 3A. Treatment Effect in Future Months Across Specifications

\begin{tabular}{|c|c|c|c|c|c|}
\hline $\begin{array}{r}\text { DV = Total Consumption } \\
\text { Model: }\end{array}$ & $\begin{array}{c}(1) \\
\text { Diff-in-Diff }\end{array}$ & $\begin{array}{c}(2) \\
\text { RD: } \\
\text { Linear }\end{array}$ & $\begin{array}{c}\text { (3) } \\
\text { RD: Quadratic } \\
\end{array}$ & $\begin{array}{c}(4) \\
\text { RD: } \\
\text { Cubic }\end{array}$ & $\begin{array}{c}(5) \\
\text { RD: Local } \\
\text { Linear } \\
\end{array}$ \\
\hline Treatment $\mathrm{t}+1$ & $\begin{array}{c}432.5 * * * \\
(14.68)\end{array}$ & $\begin{array}{c}109.6 * * * \\
(25.52)\end{array}$ & $\begin{array}{c}146.0 * * * \\
(35.04)\end{array}$ & $\begin{array}{c}95.14^{* *} \\
(43.47)\end{array}$ & $\begin{array}{l}-25.66 \\
(51.86)\end{array}$ \\
\hline Treatment $\mathrm{t}+2$ & $\begin{array}{c}239.1 * * * \\
(16.18)\end{array}$ & $\begin{array}{c}110.7 * * * \\
(28.27)\end{array}$ & $\begin{array}{c}104.9 * * * \\
(38.10)\end{array}$ & $\begin{array}{c}49.51 \\
(46.99)\end{array}$ & $\begin{array}{l}-103.3 \\
(64.41)\end{array}$ \\
\hline Treatment $\mathrm{t}+3$ & $\begin{array}{c}118.9^{* * *} \\
(14.01)\end{array}$ & $\begin{array}{c}70.71 * * * \\
(24.99)\end{array}$ & $\begin{array}{l}74.60^{* *} \\
(34.93)\end{array}$ & $\begin{array}{c}24.54 \\
(42.46)\end{array}$ & $\begin{array}{l}-32.61 \\
(56.56)\end{array}$ \\
\hline Treatment $\mathrm{t}+4$ & $\begin{array}{c}46.25 * * * \\
(12.92)\end{array}$ & $\begin{array}{c}30.99 \\
(23.30)\end{array}$ & $\begin{array}{c}26.24 \\
(33.26)\end{array}$ & $\begin{array}{c}11.83 \\
(40.25)\end{array}$ & $\begin{array}{c}21.42 \\
(41.68)\end{array}$ \\
\hline Treatment $\mathrm{t}+5$ & $\begin{array}{l}-17.01 \\
(12.87)\end{array}$ & $\begin{array}{l}-6.018 \\
(24.24)\end{array}$ & $\begin{array}{l}-38.14 \\
(38.13)\end{array}$ & $\begin{array}{l}-32.19 \\
(47.59)\end{array}$ & $\begin{array}{l}-39.58 \\
(46.81)\end{array}$ \\
\hline Treatment $\mathrm{t}+6$ & $\begin{array}{c}-55.95 * * * \\
(14.02)\end{array}$ & $\begin{array}{l}-41.18 \\
(26.36)\end{array}$ & $\begin{array}{c}-95.75 * * \\
(39.72)\end{array}$ & $\begin{array}{l}-87.52^{*} \\
(49.14)\end{array}$ & $\begin{array}{c}-120.0^{* *} \\
(48.40)\end{array}$ \\
\hline Treatment $\mathrm{t}+7$ & $\begin{array}{c}-56.70 * * * \\
(14.09)\end{array}$ & $\begin{array}{l}-37.67 \\
(26.08)\end{array}$ & $\begin{array}{c}-83.55^{* *} \\
(38.26)\end{array}$ & $\begin{array}{l}-79.63^{*} \\
(46.97)\end{array}$ & $\begin{array}{l}-61.44 \\
(45.44)\end{array}$ \\
\hline Treatment $\mathrm{t}+8$ & $\begin{array}{c}-41.75 * * * \\
(12.52)\end{array}$ & $\begin{array}{l}-38.43 * \\
(23.01)\end{array}$ & $\begin{array}{c}-76.46^{* *} \\
(33.85)\end{array}$ & $\begin{array}{l}-63.53 \\
(41.98)\end{array}$ & $\begin{array}{l}-45.52 \\
(39.76)\end{array}$ \\
\hline Treatment $\mathrm{t}+9$ & $\begin{array}{l}-8.462 \\
(11.65)\end{array}$ & $\begin{array}{c}-48.62^{* *} \\
(21.11)\end{array}$ & $\begin{array}{l}-55.69^{*} \\
(31.02)\end{array}$ & $\begin{array}{l}-43.48 \\
(37.96)\end{array}$ & $\begin{array}{l}-9.113 \\
(41.50)\end{array}$ \\
\hline Treatment $\mathrm{t}+10$ & $\begin{array}{c}80.90 * * * \\
(14.31)\end{array}$ & $\begin{array}{c}31.91 \\
(24.65)\end{array}$ & $\begin{array}{c}23.94 \\
(35.04)\end{array}$ & $\begin{array}{c}21.34 \\
(43.26)\end{array}$ & $\begin{array}{c}40.80 \\
(54.91)\end{array}$ \\
\hline Treatment $\mathrm{t}+11$ & $\begin{array}{c}177.2 * * * \\
(17.12)\end{array}$ & $\begin{array}{c}88.52 * * * \\
(30.25)\end{array}$ & $\begin{array}{l}82.86^{*} \\
(42.42)\end{array}$ & $\begin{array}{c}62.31 \\
(51.56)\end{array}$ & $\begin{array}{l}-14.29 \\
(55.80)\end{array}$ \\
\hline Treatment $\mathrm{t}+12$ & $\begin{array}{c}270.6^{* * * *} \\
(19.85)\end{array}$ & $\begin{array}{c}142.4 * * * \\
(34.68)\end{array}$ & $\begin{array}{c}135.9 * * * \\
(47.84)\end{array}$ & $\begin{array}{l}100.3^{*} \\
(57.79)\end{array}$ & $\begin{array}{l}-0.923 \\
(66.81)\end{array}$ \\
\hline $\begin{array}{l}\text { Notes: Table presents estimat } \\
\text { of treatment on total consum } \\
\text { differences model. Columns } \\
\text { variable (consumption during } \\
\text { either side of the threshold. } \\
\text { RD. Columns } 1-4 \text { additionall } \\
\text { treatment effect from one reg } \\
\text { squared values range from } 0 . \\
\text { statistical significance at the }\end{array}$ & $\begin{array}{l}\text { d treatment ef } \\
\text { tion in future } \mathrm{r} \\
-4 \text { present the } \\
\text { the cohort mo } \\
\text { lumn } 5 \text { preser } \\
\text { include fixed } \\
\text { ession, with th } \\
77-0.463 \text {. Stan }\end{array}$ & $\begin{array}{l}\text { using a lin } \\
\text { a local aver } \\
\text { ects for coh } \\
\text { eatment eff } \\
\text { rd errors are }\end{array}$ & $\begin{array}{l}\text { umption with e } \\
1 \text { presents resul } \\
\text { atment effect by } \\
r \text {, quadratic, or } \\
\text { e treatment effe } \\
t \text { month and bill } \\
\text { ts shown from } \\
\text { hown in parenth }\end{array}$ & $\begin{array}{l}\text { ntrolling } \\
\text { ic functi } \\
\text { sing rob } \\
\text { cle. Each } \\
\text { egressio } \\
\text { s. *, **, }\end{array}$ & $\begin{array}{l}g \text { the effect } \\
\text { ces in } \\
\text { le running } \\
\text { orm on } \\
\text { cal-linear } \\
\text { is the } \\
\text { otal. R- } \\
* * \text { indicate }\end{array}$ \\
\hline
\end{tabular}


Table 4A. Treatment Effect in Future Months Across Specifications

\begin{tabular}{|c|c|c|c|c|c|c|}
\hline $\mathrm{DV}=$ Bill Amount & Model: & Diff-in-Diff & $\begin{array}{c}(2) \\
\text { RD: } \\
\text { Linear } \\
\end{array}$ & RD: Quadratic & $\begin{array}{c}(4) \\
\text { RD: } \\
\text { Cubic }\end{array}$ & $\begin{array}{c}(5) \\
\text { RD: Local } \\
\text { Linear }\end{array}$ \\
\hline \multicolumn{2}{|l|}{ Treatment $\mathrm{t}+1$} & $\begin{array}{c}82.49 * * * \\
(2.775)\end{array}$ & $\begin{array}{c}20.81 * * * \\
(4.821)\end{array}$ & $\begin{array}{c}27.49 * * * \\
(6.624)\end{array}$ & $\begin{array}{l}17.60^{* *} \\
(8.224)\end{array}$ & $\begin{array}{l}-1.693 \\
(9.522)\end{array}$ \\
\hline \multicolumn{2}{|l|}{ Treatment $\mathrm{t}+2$} & $\begin{array}{c}33.26 * * * \\
(2.950)\end{array}$ & $\begin{array}{l}10.32 * * \\
(5.220)\end{array}$ & $\begin{array}{c}10.52 \\
(7.070)\end{array}$ & $\begin{array}{l}-0.823 \\
(8.701)\end{array}$ & $\begin{array}{c}-28.73 * * \\
(11.93)\end{array}$ \\
\hline \multicolumn{2}{|l|}{ Treatment $\mathrm{t}+3$} & $\begin{array}{c}11.83 * * * \\
(2.519)\end{array}$ & $\begin{array}{c}3.261 \\
(4.526)\end{array}$ & $\begin{array}{c}4.987 \\
(6.370)\end{array}$ & $\begin{array}{l}-4.258 \\
(7.756)\end{array}$ & $\begin{array}{l}-13.87 \\
(10.30)\end{array}$ \\
\hline \multicolumn{2}{|l|}{ Treatment $\mathrm{t}+4$} & $\begin{array}{c}0.788 \\
(2.440)\end{array}$ & $\begin{array}{l}-1.750 \\
(4.418)\end{array}$ & $\begin{array}{l}-2.727 \\
(6.334)\end{array}$ & $\begin{array}{c}-4.962 \\
(7.719)\end{array}$ & $\begin{array}{l}-0.599 \\
(8.059)\end{array}$ \\
\hline \multicolumn{2}{|l|}{ Treatment $\mathrm{t}+5$} & $\begin{array}{c}-9.973 * * * \\
(2.586)\end{array}$ & $\begin{array}{c}-7.328 \\
(4.930)\end{array}$ & $\begin{array}{l}-13.96^{*} \\
(7.777)\end{array}$ & $\begin{array}{l}-13.17 \\
(9.711)\end{array}$ & $\begin{array}{l}-10.39 \\
(9.379)\end{array}$ \\
\hline \multicolumn{2}{|l|}{ Treatment $\mathrm{t}+6$} & $\begin{array}{c}-17.27 * * * \\
(2.794)\end{array}$ & $\begin{array}{c}-13.61 * * * \\
(5.272)\end{array}$ & $\begin{array}{c}-25.07 * * * \\
(7.988)\end{array}$ & $\begin{array}{c}-22.49 * * \\
(9.889)\end{array}$ & $\begin{array}{c}-28.25^{* * *} \\
(9.486)\end{array}$ \\
\hline \multicolumn{2}{|l|}{ Treatment $\mathrm{t}+7$} & $\begin{array}{c}-17.01 * * * \\
(2.792)\end{array}$ & $\begin{array}{c}-12.81^{* *} \\
(5.175)\end{array}$ & $\begin{array}{c}-22.34 * * * \\
(7.623)\end{array}$ & $\begin{array}{c}-21.78^{* *} \\
(9.334)\end{array}$ & $\begin{array}{l}-17.18^{*} \\
(9.033)\end{array}$ \\
\hline \multicolumn{2}{|l|}{ Treatment $\mathrm{t}+8$} & $\begin{array}{c}-14.59 * * * \\
(2.475)\end{array}$ & $\begin{array}{c}-13.50^{* * *} \\
(4.535)\end{array}$ & $\begin{array}{c}-21.28 * * * \\
(6.640)\end{array}$ & $\begin{array}{c}-19.50^{* *} \\
(8.175)\end{array}$ & $\begin{array}{l}-15.18^{*} \\
(8.014)\end{array}$ \\
\hline \multicolumn{2}{|l|}{ Treatment $\mathrm{t}+9$} & $\begin{array}{c}-8.943 * * * \\
(2.251)\end{array}$ & $\begin{array}{c}-16.27 * * * \\
(4.106)\end{array}$ & $\begin{array}{c}-17.14 * * * \\
(6.034)\end{array}$ & $\begin{array}{c}-15.37 * * \\
(7.361)\end{array}$ & $\begin{array}{l}-9.678 \\
(7.453)\end{array}$ \\
\hline \multicolumn{2}{|l|}{ Treatment $\mathrm{t}+10$} & $\begin{array}{c}8.204 * * * \\
(2.776)\end{array}$ & $\begin{array}{c}-2.011 \\
(4.786)\end{array}$ & $\begin{array}{l}-3.314 \\
(6.820)\end{array}$ & $\begin{array}{l}-4.571 \\
(8.414)\end{array}$ & $\begin{array}{l}-0.619 \\
(10.82)\end{array}$ \\
\hline \multicolumn{2}{|l|}{ Treatment $\mathrm{t}+11$} & $\begin{array}{c}28.58 * * * \\
(3.347)\end{array}$ & $\begin{array}{l}11.34 * \\
(5.897)\end{array}$ & $\begin{array}{c}9.845 \\
(8.280)\end{array}$ & $\begin{array}{c}5.027 \\
(10.07)\end{array}$ & $\begin{array}{l}-9.758 \\
(11.29)\end{array}$ \\
\hline \multicolumn{2}{|l|}{ Treatment $\mathrm{t}+12$} & $\begin{array}{c}42.34 * * * \\
(3.725)\end{array}$ & $\begin{array}{c}18.85 * * * \\
(6.515)\end{array}$ & $\begin{array}{l}17.58^{*} \\
(9.005)\end{array}$ & $\begin{array}{c}9.562 \\
(10.88)\end{array}$ & $\begin{array}{l}-9.395 \\
(12.97)\end{array}$ \\
\hline \multicolumn{7}{|c|}{$\begin{array}{l}\text { Notes: Table presents estimated treatment effect on bill amount with each row estimating the effect of } \\
\text { treatment on bill amount in future months. Column } 1 \text { presents results from a differences in differences } \\
\text { model. Columns } 2-4 \text { present the local average treatment effect by controlling for the running variable } \\
\text { (consumption during the cohort month) using a linear, quadratic, or cubic functional form on either side of } \\
\text { the threshold. Column } 5 \text { presents a local average treatment effect using robust local-linear RD. Columns 1- } \\
4 \text { additionally include fixed effects for cohort month and bill cycle. Each cell is the treatment effect from } \\
\text { one regression, with the treatment effects shown from } 72 \text { regressions in total. R-squared values range from } \\
0.080-0.428 \text {. Standard errors are shown in parentheses. }{ }^{* * *} \text {, and } * * * \text { indicate statistical significance at the } \\
10 \%, 5 \% \text {, and } 1 \% \text { levels, respectively. }\end{array}$} \\
\hline
\end{tabular}


Table 5A. Treatment Effect on Outcome Measures in Future Months

\begin{tabular}{|c|c|c|c|c|c|}
\hline & & (1) & (2) & (3) & (4) \\
\hline & DV: & Peak Proportion & $\begin{array}{c}\text { Peak } \\
\text { Consumption }\end{array}$ & $\begin{array}{c}\text { Total } \\
\text { Consumption } \\
\end{array}$ & Bill Amount \\
\hline Treatment $\mathrm{t}+1$ & & $\begin{array}{l}0.00544 \\
(0.0162)\end{array}$ & $\begin{array}{l}-45.11 \\
(61.30)\end{array}$ & $\begin{array}{l}-213.5 \\
(197.1)\end{array}$ & $\begin{array}{r}-40.30 \\
(37.37)\end{array}$ \\
\hline Treatment $\mathrm{t}+2$ & & $\begin{array}{c}0.0120 \\
(0.0207)\end{array}$ & $\begin{array}{l}-97.81 \\
(68.81)\end{array}$ & $\begin{array}{l}-446.6^{*} \\
(265.0)\end{array}$ & $\begin{array}{l}-89.05^{*} \\
(49.55)\end{array}$ \\
\hline Treatment $\mathrm{t}+3$ & & $\begin{array}{l}-0.0348 \\
(0.0268)\end{array}$ & $\begin{array}{l}-157.1 \\
(108.3)\end{array}$ & $\begin{array}{l}-316.2 \\
(446.2)\end{array}$ & $\begin{array}{l}-76.88 \\
(82.55)\end{array}$ \\
\hline Treatment $\mathrm{t}+4$ & & $\begin{array}{l}-0.0283 \\
(0.0316)\end{array}$ & $\begin{array}{c}30.69 \\
(69.33)\end{array}$ & $\begin{array}{l}330.4 \\
(311.4)\end{array}$ & $\begin{array}{l}44.60 \\
(57.12)\end{array}$ \\
\hline Treatment $\mathrm{t}+5$ & & $\begin{array}{l}-0.0186 \\
(0.0412)\end{array}$ & $\begin{array}{l}99.00 \\
(61.76)\end{array}$ & $\begin{array}{l}464.9^{*} \\
(244.4)\end{array}$ & $\begin{array}{c}72.22 \\
(44.38)\end{array}$ \\
\hline Treatment $\mathrm{t}+6$ & & $\begin{array}{l}-0.0638 \\
(0.0430)\end{array}$ & $\begin{array}{c}58.14 \\
(70.62)\end{array}$ & $\begin{array}{c}374.5 \\
(253.7)\end{array}$ & $\begin{array}{c}58.11 \\
(48.28)\end{array}$ \\
\hline Treatment $\mathrm{t}+7$ & & $\begin{array}{c}-0.0452 \\
(0.0396)\end{array}$ & $\begin{array}{l}95.26 \\
(112.1)\end{array}$ & $\begin{array}{c}400.8 \\
(332.2)\end{array}$ & $\begin{array}{c}67.79 \\
(66.37)\end{array}$ \\
\hline Treatment $\mathrm{t}+8$ & & $\begin{array}{c}-0.0302 \\
(0.0382)\end{array}$ & $\begin{array}{c}81.51 \\
(97.65)\end{array}$ & $\begin{array}{c}390.0 \\
(302.0)\end{array}$ & $\begin{array}{l}67.67 \\
(61.45)\end{array}$ \\
\hline Treatment $\mathrm{t}+9$ & & $\begin{array}{l}-0.0161 \\
(0.0401)\end{array}$ & $\begin{array}{c}40.21 \\
(89.19)\end{array}$ & $\begin{array}{c}188.3 \\
(276.0)\end{array}$ & $\begin{array}{l}25.56 \\
(57.08)\end{array}$ \\
\hline Treatment $\mathrm{t}+10$ & & $\begin{array}{l}-0.0194 \\
(0.0527)\end{array}$ & $\begin{array}{c}11.60 \\
(69.45)\end{array}$ & $\begin{array}{l}91.67 \\
(235.2)\end{array}$ & $\begin{array}{c}6.475 \\
(47.03)\end{array}$ \\
\hline Treatment $\mathrm{t}+11$ & & $\begin{array}{c}0.0203 \\
(0.0411)\end{array}$ & $\begin{array}{c}1.303 \\
(79.77)\end{array}$ & $\begin{array}{r}-84.44 \\
(303.1)\end{array}$ & $\begin{array}{r}-30.90 \\
(59.02)\end{array}$ \\
\hline Treatment $\mathrm{t}+12$ & & $\begin{array}{l}0.00251 \\
(0.0354)\end{array}$ & $\begin{array}{l}-10.91 \\
(150.8)\end{array}$ & $\begin{array}{l}-56.05 \\
(599.1)\end{array}$ & $\begin{array}{l}-26.86 \\
(118.4)\end{array}$ \\
\hline
\end{tabular}

Notes: Table presents local average treatment effects on four outcome measures. Each cell is the treatment effect from one regression, controlling for total consumption during the cohort month (December 2013 only) using a cubic polynomial on either side of the threshold. Standard errors are shown in parentheses. ${ }^{*}, * *$, and $* * *$ indicate statistical significance at the $10 \%, 5 \%$, and $1 \%$ levels, respectively. 


\title{
Appendix B: Rate Change Alert and Notification of Rate Change Letters
}

\author{
UNITED ILLUMINATING
}

PROCEDURE NAME:
EXCEPTIONS TO MANDATORY TIME OF DAY (TOD)

PROCEDURE NUMBER:

CF-004

\section{EXHIBIT C-Rate Change Alert Letter: R to RT (English version)}

UI Account No.: $\{$ AccNo\}

Dear $\{$ SoldTo\},

As part of Connecticut's regulatory policies to control peak energy use and lower cost, the United Illuminating Company (UI) is working with the Public Utilities Regulatory Authority (PURA) to help customers manage rising electric costs and provide tools that will help control energy use and cost.

Our records show that you are currently on our standard residential rate, Rate $\mathrm{R}$, and that your monthly electric use exceeded 1,750 kilowatt-hours $(\mathrm{kWh})$ in at least one billing period during the past 12 months.

If your consumption should exceed $2,000 \mathrm{kWh}$ during any future billing cycle, you will be placed on Ul's time-ofday rate, known as Rate RT. Rate RT gives you the opportunity to control your energy bill, and helps reduce peak demand on the regional electric grid by shifting some of your consumption to off-peak hours.

When compared to your present rate, Rate RT charges less for electricity used during off-peak hours, 8 p.m. until noon Monday through Friday, plus all hours Saturday and Sunday. Electricity used during on-peak hours, noon to 8 p.m. weekdays, costs more than your current rate. The off-peak period consists of many more hours than the on-peak period.

You can take advantage of the lower off-peak rate by using large appliances/equipment such as dishwashers, washers, clothes dryers, dehumidifiers, and, air conditioners, during off-peak hours. You can also control your peak use by using energy efficient equipment such as CFL and LED lighting, energy star appliances, set-back thermostats and pool pump timers.

If you do not want to switch to Rate RT, you should monitor your electricity use to make sure you do not consume over 2,000 kWh during any billing cycle. Once you have been switched to Rate RT, you cannot be switched back - even if you reduce your consumption. Depending on their particular usage pattern, UI has found that many customers pay about the same under Rate R and Rate RT; however, Ul's time-of-day rate offers you the opportunity to lower your bill. If you believe you would benefit from Rate RT, you may switch by calling $\mathrm{UI}$ at $800-722-5584$

To learn more about the energy efficiency and conservation programs UI offers to help you reduce your energy consumption and cost, visit UI's website, uinet.com, or call UI at 800-722-5584 (800-7-CALL UI). A full explanation of Rate RT can also be found on Ul's web site, www.uinet.com, located under the Rate/Tariffs option.

In addition, to learn how you may be able to further lower your electric bill by choosing an alternate electric supplier, please visit Connecticut's Energy Information Website, EnergizeCT.com. From the home page, click "Choose Your Electric Supplier." Your generation rate appears on your electric bill under the "Generation Services Charge" line item. You may also call 877-WISE USE (877-947-3873) or call Ul at the number shown above.

Sincerely,

The United Illuminating Company

Customer Care Center

Origin Date: 08/04/2011

Revision Date: 09/15/2016

Page 13

Owner Name \& Title: Jill Thomas, Manager, Business Management 


\section{PROCEDURE NAME:}

EXCEPTIONS TO MANDATORY TIME OF DAY (TOD)

\section{EXHIBIT D-Mandatory Switch Letter: R to RT (English version)}

UI Account No.: \{AccNo\}

Dear $\{$ SoldTo\},

$\mathrm{UI}$ is required to switch any customer whose electric usage exceeds 2,000 kilowatt-hours $(\mathrm{kWh})$ in a single month, to its time-of-day rate, Rate RT, to comply with state regulatory policy designed to reduce peak energy use and help customers control their costs.

Our records show your account exceeded the 2,000 kWh threshold during at least one billing period in the last 12 months. Accordingly, we are required to switch you from our standard residential rate, Rate R, to the time-ofday rate, Rate RT.

Your rate will be permanently changed to Rate RT within your next billing cycle. Please note that this is required by the Public Utilities Regulatory Authority.

Under Rate RT, you can control your electric bill and reduce costs by shifting more of your consumption to offpeak periods. Rate RT charges less for electricity used during off-peak hours, 8 p.m. until noon Monday through Friday, plus all hours Saturday and Sunday. Electricity used during on-peak hours, noon to 8 p.m. weekdays, costs more than what you are presently paying.

You can take advantage of the lower off-peak rate by using large appliances/equipment such as dishwashers, washers, clothes dryers, dehumidifiers, and, air conditioners, during off-peak hours.

To learn about the energy efficiency and conservation programs $\mathrm{UI}$ offers to help you reduce your energy consumption and cost, visit Ul's website, uinet.com, or call UI at 800-722-5584 (800-7-CALL UI) to speak with a Customer Care associate. A full explanation of Rate RT can also be found on uinet.com, located under the Rate/Tariffs option.

In addition, to learn how you can further lower your electric bill by choosing an alternate electric supplier, please visit Connecticut's Energy Information Website, EnergizeCT.com. From the home page, click "Choose Your Electric Supplier", then click on "Compare your electric supplier and save." Your rate appears on your electric bill under the "Generation Services Charge" line item. You may also call 877-WISE USE (877-947-3873) or call UI at the number shown above.

Sincerely,

The United Illuminating Company

Customer Care Center 


\section{Appendix C: Empirical Challenges of Difference-in-Differences}

One may argue that a good robustness check would use a difference-indifferences (DID) empirical framework. With such a rich dataset, the DID framework could be interpreted at resulting in a causal effect because we could control for so much variation using a large set of household and time fixed effects. However, there is an interesting empirical challenge using DID with this dataset. I describe the data in full below, along with the method and results. I do not interpret these results causally, but instead see the results as upper and lower bounds on the true causal treatment effect estimated using a regression discontinuity design.

\section{C.1 Spike in Consumption Prior to Rate Change}

It is informative to narrow down our sample to only customers who are mandated into TOU pricing due to exceeding the $2,000 \mathrm{kWh}$ threshold in a single billing cycle. In Figure $1 \mathrm{C}$, we aggregate consumption over each monthly bill and present the number of households that exceed the threshold during each billing cycle. In this figure, billing cycle 0 represents the first bill that a household receives under TOU pricing. In other words, the household is being charged TOU rates for the entire month and sees their first bill with the new charges at the end of the month. There are a couple notable points in this plot. First, most households are switched to TOU pricing within four months of initially exceeding the threshold. This could indicate several months when the household is using a large amount of electricity but does not have information about how continuing this level of electricity use will affect their bills. Seeing a change in rates, corresponding to larger bills, may be a financial shock to households and induce a significant reduction in electricity. In another scenario, these few months of high electricity consumption may 
occur over the winter holidays or cold winter months, when electricity use is high due to heaters running, family or friends visiting, or children being home from school. Rate changes would not occur until the milder (and less eventful) early spring, in agreement with the spikes in rate changes occurring in February through April each year. By the time households see a change in rates, the changes in their electricity bills may be offset due to decreased electricity consumption, possibly attenuating the impact felt by the rate change and associated changes in electricity consumption.

The second notable point about Figure $1 \mathrm{C}$ is that for about five percent of households who are mandated into TOU pricing, they again exceed the 2,000 $\mathrm{kWh}$ threshold per bill about a year after their initial exceedance. An even smaller proportion exceed two years afterwards. We can infer two things from this pattern. For the households who continue to exceed the threshold around the same time each year, this level of electricity consumption appears to represent a structural change in usage patterns. For example, a household may add an additional family member to the household or grow their energy-intensive capital stock, which would increase electricity consumption across all months of the year and push the household over the threshold for those months that are most energy intensive (i.e. due to heating in winter). Or a household may build an addition, which requires more electricity to heat in the winter and would cause a recurring exceedance of the threshold each year.

Figure 1C. Rate of Exceedance in Event Time 


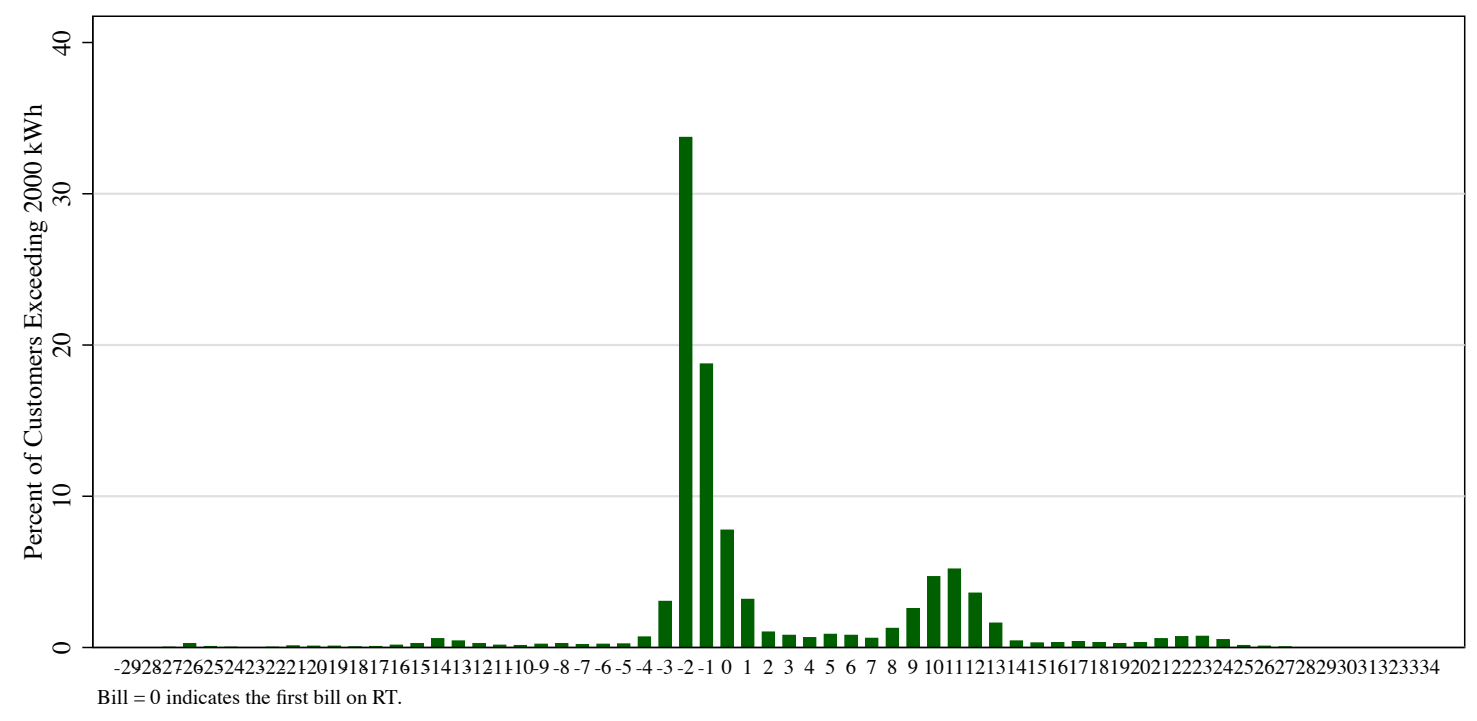

On the other hand, a large proportion of households who exceed the threshold prior to their rate change do not exceed the threshold after the rate change. We can interpret this in two ways. If this level of electricity use is not random, then we would have to infer that the household is on a trajectory towards higher consumption. Following the switch to TOU pricing, the customer adjusts energy-related behaviors at home or invests in energy efficient capital stock, thereby reducing consumption in the months following the rate change. In this instance, we would be able to compare mean consumption before and after the rate change to understand the effects of TOU pricing. However, the initial exceedance of some household may represent a random draw from the high-use tail of their energy consumption distribution. In this case, their consumption during the month of exceedance is abnormal relative to their typical consumption habits. Consumption would then likely decrease in the following months matching typical usage patterns. Simply comparing mean consumption before to after the rate change would then be misleading, as the abnormal exceedance would inflate mean consumption prior to the 
rate change. In this case the difference in means could not be interpreted as the causal effect of TOU pricing.

Figure 2C. Mean Load in Event Time

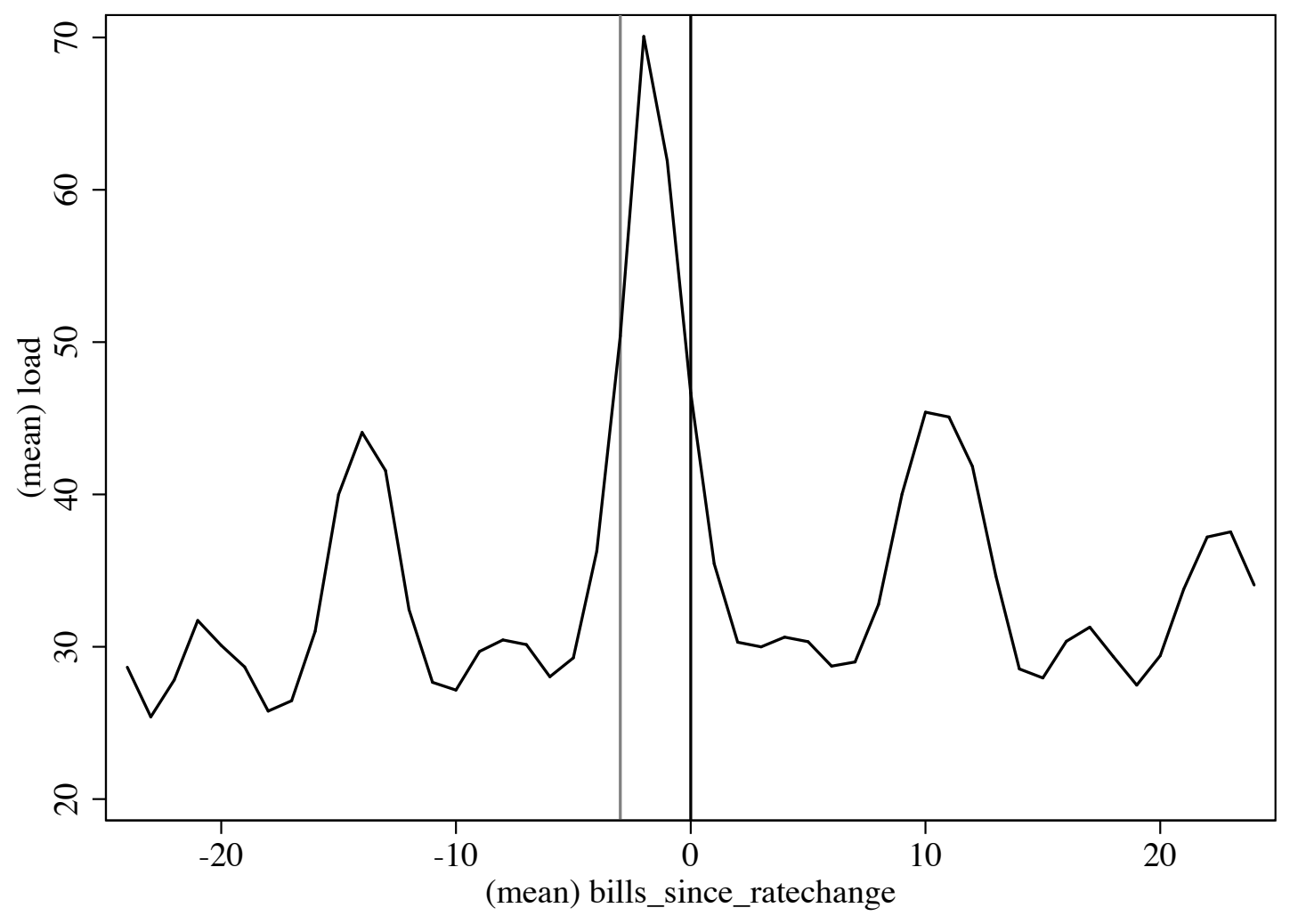

Figure 2C further illustrates this point. The plot shows mean daily load leading up to and following the rate change from flat rate to TOU pricing (which occurs at bill zero). The spike in consumption just prior to the rate change is clear, and seemingly abnormal relative to typical rates of consumption at other times. This is potentially suggestive that this high level of consumption is more along the lines of a fluke, in which case we should take care in designing our empirical approach and interpreting our results. 


\section{C.2 Panel Data Framework}

We exploit the richness and high resolution of our data by using panel data methods to control for time-invariant customer characteristics and daily average electricity consumption across all customers. We estimate the model

$$
y_{i t}=\beta D_{\text {ToUit }}+\alpha_{i}+\tau_{t}+\varepsilon_{i}
$$

where $y_{i t}$ is electric load for customer $i$ at time $t$. We aggregate 15-minute interval data to hourly usage. ${ }^{9} D_{\text {Touit }}$ is an indicator equal to 1 if customer $i$ is being billed under TOU pricing at time $t$ and 0 otherwise. We include household fixed effects, $\alpha_{i}$, to control for each household's typical energy usage. In our preferred model, we interact customer fixed effects with hour-of-the-day dummy variables, to flexibly control for each customer's usage at each hour of the day. We also include a time fixed effect, which controls for events that affect consumption across all households (e.g. weather, holidays). In our preferred model, this time fixed effect controls for average usage across all households in every hour of our sample period. We cluster errors at the household level to allow for correlation in usage for each household. In this model, $\beta$ is our coefficient of interest and is interpreted as the difference in mean hourly load under TOU pricing from under flat rate pricing, ceteris paribus. A significant, negative $\beta$ would indicate reduced electricity consumption under TOU pricing, while an insignificant $\beta$ would indicate that electricity consumption under TOU pricing is statistically indistinguishable from consumption under flat rate pricing.

\footnotetext{
${ }^{9}$ The primary driver of doing so was limitations with computer memory in running such a large data set, cutting an original dataset of around 200 million customer-interval observations to nearly 50 million customer-hour observations. We are not concerned with any loss of information because our dataset is so rich.
} 
In the above model, other households who have not yet switched to TOU pricing serve as the counterfactual to those who have switched in identifying the coefficient of interest. These households are plausibly a reasonable counterfactual because they are all high-use households and all eventually are switched into TOU pricing. However, towards the end of our sample period, the number of households in the counterfactual declines as more and more are switched into TOU pricing. Therefore, we also run the above model with data aggregated at the daily level including a control group of 3,000 high-use households who remain on flat rate pricing throughout the sample period. The inclusion of these households informs the time fixed effect only, since there is no variation in the indicator for TOU pricing and hence household fixed effects absorb that information.

We also estimate the change in consumption during peak hours following the change to TOU pricing from flat rate pricing. We calculate the proportion of total daily load that is consumed during peak hours of noon $-8 \mathrm{pm}$ Monday through Friday. We estimate the following model

$$
p_{i t}=\beta D_{\text {ToUit }}+\alpha_{i}+\tau_{t}+\varepsilon_{i}
$$

where $p_{i t}$ is the proportion of load consumed during peak hours and the remaining variables are defined as above. In this model, we omit weekend days, which are considered off-peak.

Finally, we address the empirical challenge of interpreting the seemingly abnormal spike in consumption just prior to being switched onto TOU pricing. Our concern is that this spike represents unintentional or short-term increased consumption, inconsistent with typically load patterns. Therefore, including data from this period in our model would inflate the treatment effect as households would revert to mean 
consumption after the spike regardless of being treated. We attempt to control for this in two ways. First, we omit the first month a household exceeds the threshold. Second, we omit from the first month a household exceeds the threshold through the first month they are on TOU pricing (i.e. before the household gets their first bill under the new pricing schedule). Our thinking is that households have yet to receive feedback about their abnormal consumption until they receive their first bill with the new rates. We should consider the range of treatment effects to represent upper and lower bounds of how consumption changes following the switch to TOU pricing.

\section{C.3 Results}

Table $1 \mathrm{C}$ builds up to our preferred model using Equation 1 . Column 1 is essentially a ttest of the difference in mean electricity consumption on flat rate pricing to TOU pricing. Column 2 additionally controls for customer-specific levels of consumption, Column 3 interacts the customer fixed effect with hour of the day, and Column 4 adds an hour-ofsample fixed effect. Columns $1-4$ only include households that change rates during the sample period. Column 5 repeats Column 4 but using data aggregated at a daily level. Column 6 extends Column 5 by also including a set of high-use households that remain on flat rate pricing throughout the sample period. In our preferred model (Column 4), we see a significant difference in mean hourly electricity load of $0.300 \mathrm{kWh}$, roughly 20 percent of hourly load. ${ }^{10}$ Inclusion of the control group in Column 6 (using daily aggregated data) leaves the results largely unchanged.

\footnotetext{
${ }^{10}$ Mean hourly load is $1.50 \mathrm{kWh}$ and mean daily load for households who change rates is 36.1 kWh.
} 
Table 1C. Main Results of Panel Data Method

\begin{tabular}{|c|c|c|c|c|c|c|}
\hline DV & $\begin{array}{c}\text { (1) } \\
\text { Hourly Load }\end{array}$ & $\begin{array}{c}\text { (2) } \\
\text { Hourly Load }\end{array}$ & $\begin{array}{c}\text { (3) } \\
\text { Hourly Load }\end{array}$ & $\begin{array}{c}\text { (4) } \\
\text { Hourly Load }\end{array}$ & $\begin{array}{c}\text { (5) } \\
\text { Daily Load }\end{array}$ & $\begin{array}{l}\text { (6) } \\
\text { Daily Load }\end{array}$ \\
\hline $\mathrm{D}_{\mathrm{TOU}}$ & $\begin{array}{l}-0.112 * * * \\
(0.0128)\end{array}$ & $\begin{array}{l}-0.150 * * * \\
(0.00876)\end{array}$ & $\begin{array}{l}-0.151 * * * \\
(0.00876)\end{array}$ & $\begin{array}{c}-0.300 * * * \\
(0.0115)\end{array}$ & $\begin{array}{c}-7.295 * * * \\
(0.277)\end{array}$ & $\begin{array}{c}-7.936^{* * * *} \\
(0.228)\end{array}$ \\
\hline Customer FE & $\mathrm{N}$ & $\mathrm{Y}$ & $\mathrm{N}$ & $\mathrm{N}$ & $\mathrm{Y}$ & $\mathrm{Y}$ \\
\hline Customer-Hour of Day FE & $\mathrm{N}$ & $\mathrm{N}$ & $\mathrm{Y}$ & $\mathrm{Y}$ & $\mathrm{N}$ & $\mathrm{N}$ \\
\hline Hour of Sample FE & $\mathrm{N}$ & $\mathrm{N}$ & $\mathrm{N}$ & $\mathrm{Y}$ & $\mathrm{N}$ & $\mathrm{N}$ \\
\hline Day of Sample FE & $\mathrm{N}$ & $\mathrm{N}$ & $\mathrm{N}$ & $\mathrm{N}$ & $\mathrm{Y}$ & Y \\
\hline Observations & $46,031,006$ & $46,031,006$ & $46,030,958$ & $46,030,958$ & $1,904,122$ & $4,143,150$ \\
\hline R-squared & 0.00177 & 0.129 & 0.213 & 0.319 & 0.413 & 0.398 \\
\hline Adjusted R-squared & 0.002 & 0.129 & 0.212 & 0.318 & 0.412 & 0.397 \\
\hline \multicolumn{7}{|c|}{$\begin{array}{l}\text { Notes: Each column estimates the effect of TOU pricing on electricity load. The dependent variable is hourly electricity load for } \\
\mathrm{N}=2,156 \text { households (Columns } 1-4 \text { ) or daily load for } \mathrm{N}=2,156 \text { households (Column } 5 \text { ) or } \mathrm{N}=5,212 \text { households The coefficient of } \\
\text { interest is on the indicator variable } \mathrm{D}_{\text {TOU }} \text { equal to } 1 \text { if the customer is under TOU pricing and } 0 \text { otherwise. Column } 1 \text { represents } \\
\text { simple differences in average hourly loads when facing flat rate and TOU pricing. Subsequent models build on Column } 1 \text { by } \\
\text { including various fixed effects (FE) to account for time-invariant customer characteristics and unobservable time trends. } \\
\text { Column } 6 \text { additionally includes a control group of high-use households who remain on flat rate pricing throughout the sample } \\
\text { period. Robust standard errors are shown in parentheses and are clustered at the customer level. } * * * \mathrm{p}<0.01, * * \mathrm{p}<0.05, * \mathrm{p}<0.1\end{array}$} \\
\hline
\end{tabular}

We use the Frisch-Waugh-Lovell method to evaluate individual coefficients for each household using hourly data, and plot the distribution of these coefficients in Figure 3C. The mean of these coefficients agrees with the coefficient estimate in Column 4, but there is a surprising amount of variation. For some households, electricity consumption following their rate change increases, but the majority of households sees a decrease in electricity consumption. Some households even see much lower consumption. One empirical concern we have is that the magnitude of reduction is driven by an accidental or abnormal, short-term increase in consumption on flat rate pricing. If this is the case, our estimate would be biased upwards and our interpretation of the effect would be misleading. 
Figure 3C. Distribution of Treatment Effects

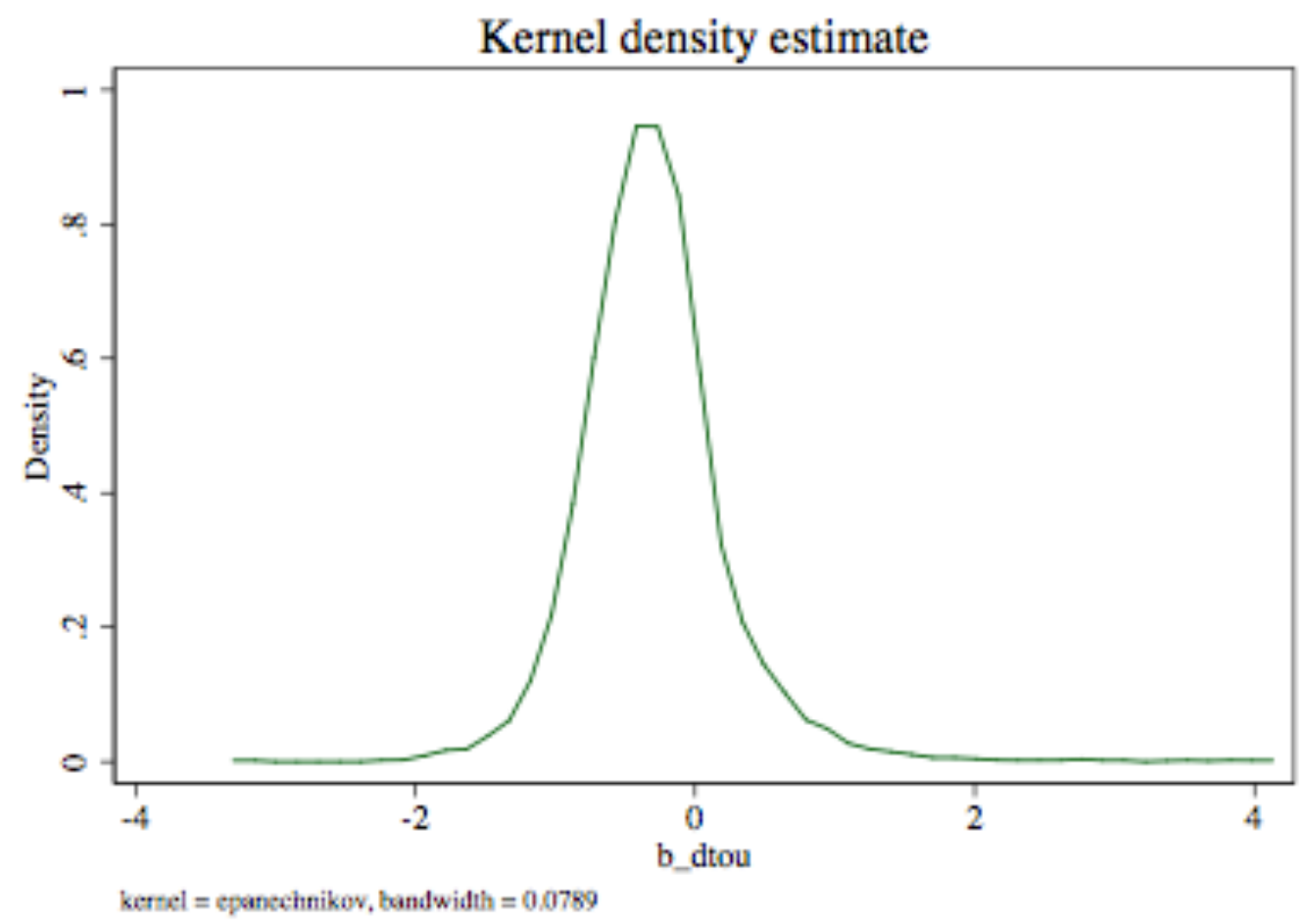

To account for this, we systematically exclude data from the month that the household first exceeds the 2,000 $\mathrm{kWh}$ threshold. Table $2 \mathrm{C}$ presents these results. Column 1 repeats the results from Column 6 of Table 2 for reference. Column 2 excludes the bill during which the household first exceeds the threshold. Column 3 excludes from the first month of exceedance up to the time the household receives a bill on TOU pricing. Intuitively, as we exclude these months, the magnitude of change in electricity consumption decreases. Our most conservative interpretation is Column 3, where there is no statistically distinguishable difference in consumption under either pricing schedule. While there is no way to understand the underlying causes of the spike in consumption that puts households into TOU pricing from our dataset alone, we can at minimum view 
these results as upper (Column 1) and lower (Column 3) bounds for a treatment effect (roughly no effect to 20 percent daily load reduction). Column 4 presents the results estimating Equation 2. We find a small but statistically significant decrease in the proportion of electricity consumed during peak hours.

Table 2C. Excluding the pre-rate change spike in electricity, peak proportion

(1)

DV = Daily Load
(2) $-2.586^{* * *}$ $(0.327)$
(3) 0.123

$(0.350)$
(4) Peak Proportion

$\mathrm{D}_{\mathrm{TOU}}$ $-7.280 * * *$ (0.327)
Customer FE

Day of Sample FE

Observations

R-squared

Adjusted R-squared

\section{$\mathrm{Y}$}

1,431

$1,431,905$

0.385

0.384

$\mathrm{Y} \quad \mathrm{Y}$

$0.384 \quad 0.383$

Notes: Each column estimates the effect of TOU pricing on electricity load. variable is daily electricity load for $\mathrm{N}=1,592$ households. The coefficient of interest is on the indicator variable $\mathrm{D}_{\text {TOU }}$ equal to 1 if the customer is under TOU pricing and 0 otherwise. All columns include customer and day of sample fixed effects. Column 1 uses all data. Column 2 excludes the first month that a household exceeds the threshold. Column 3 excludes from the first month of exceeding the threshold through the first bill on TOU pricing. Column 4 estimates the difference in mean proportion of electricity consumed during peak hours for weekdays only, including all data. Robust standard errors are shown in parentheses and are clustered at the customer level. $* * * \mathrm{p}<0.01, * * \mathrm{p}<0.05, * \mathrm{p}<0.1$ 


\begin{abstract}
Manuscript - 2
Being prepared for submission to the Journal of the Association of Environmental and Resource Economists

Learn to conserve?

The effects of in-school energy education on at-home electricity consumption
\end{abstract}

$$
\text { Carrie Gill and Corey Lang }
$$

Environmental and Natural Resource Economics, University of Rhode Island 


\begin{abstract}
Environmental education for school students, including lessons on recycling, water conservation, and energy reduction, is a popular measure aimed at increasing environmental knowledge, promoting environmental attitudes, and increasing proenvironmental behaviors. Despite the prevalence of such education, there is little empirical evidence to support the efficacy of these programs on tangible outcomes outside of school. This paper contributes a robust empirical analysis of a series of energy lessons in the United States. Using a differences-in-differences approach, we find evidence for short-term reductions on the order of eight percent in electricity use the day of a lesson regarding reducing phantom electric loads, with evidence of deferment in electricity use rather than reduction. We find no effect of lessons on energy pathways or wind energy on the days of the lessons. Findings show that energy education is potentially a valuable tool for encouraging energy efficiency and conservation, though the timing of lessons and curriculum content are critical to optimize treatment effects.
\end{abstract}

Keywords: Energy Education; Electricity; Energy Conservation; Interfamily learning 


\section{Introduction}

Among the suite of strategies to promote sustainable environmental behaviors, environmental education for school children is a popular non-price measure to nudge proenvironmental behavior. Environmental education for school students, including lessons on recycling, water conservation, and energy reduction, aims to increase environmental knowledge, promote environmental attitudes, and increase pro-environmental behaviors. Despite the prevalence of such education, there is little empirical evidence to support the efficacy of these programs on tangible outcomes outside of school.

The link between in-school education and knowledge, attitude, and behavior at the household level is indirect. Education programs target students, including elementaryaged children who have little explicit agency in household management decisions. However, evaluations of environmental education programs show that, while modest, there is potential for intergenerational influence between child and family (see Duvall and Zint (2007) for a review). For example, children treated with environmental education in school encourage their families to engage in pro-environmental behaviors including energy-saving behaviors (Hiramatsu et al., 2014), recycling (Evans and Gill, 1996), and decreasing household waste (Grodzinska-Jurczak et al., 2003). While the literature on energy behavior, and conservation specifically, is extensive (see Abrahamse et al. (2005) for a review), there have been few evaluations of in-school energy education as a nonprice mechanism to nudge residential energy efficiency.

This research seeks to understand the effects of an in-school energy education program on household electricity consumption. We conduct a case study examining the 
effects of such lessons using household daily electricity load panel data for households of all students who received a lesson within one school, as well as for a set of randomly chosen control households from which we construct an appropriate counterfactual. We employ a differences-in-differences framework to estimate changes in electricity use on the days of energy lessons. Our results are consistent with intuition about how curriculum content might affect energy use at home. We find reductions in electricity consumption on the order of eight percent on the day of an energy lesson about reducing phantom electric loads. However, we find an increase in load two days following the lesson of the same magnitude, suggesting deferment of electricity use rather than true conservation. We fail to find effects of lessons on energy pathways and wind energy. Though we cannot say with certainty why we only see an effect of the lesson on phantom electric loads and not energy pathways or wind energy, our intuition points to lesson content. The lesson on phantom loads has direct action items for reducing electricity use at home, while the other lessons offer a more indirect link from content to conservation. We additionally explore heterogeneity in treatment effect for the lesson on phantom loads along dimensions of baseline consumption and house characteristics using assessor data. While small sample size limits our statistical precision, our results suggest that higherconsuming households may reduce more on the day of the lesson, and that reductions may be smaller for newer houses with higher assessed values and enhanced for larger houses.

Through this analysis, we make two primary contributions to the literature. First, we provide critical empirical evidence of how energy education for school students affects electricity use at home, adding a much-needed data point in the sparse literature 
on energy education. Most studies of energy education rely on self-reports, with mixed findings on energy-related behavior change (DiMatteo et al. 2014, Zografakis et al. 2008). Of the two empirical analysis of energy education on consumption, one fails to find any effect while the other finds small reductions in aggregate geographic locations near schools (Osbaldiston and Schmitz 2011, Agarwal et al 2017). However, neither program is directly comparable to the energy lessons in this analysis because of the components and timing of the education treatment.

Second, our findings add to the body of literature on intergenerational learning by showing that in-school energy lessons have an affect on energy-related behaviors at home, especially when lesson content includes direct action items for energy reduction. Our findings have important implications for environmental education policy, suggesting that energy education may be an effective way to encourage energy conservation. However, we find that this effect is temporary and results in deferment rather than reduction. Future research is needed to understand how to optimize timing of energy lessons and curriculum content to achieve deeper and persistent energy reductions at home.

\section{Literature Review}

According to the most recent Residential Energy Consumption Survey, US households consumed over 10 quadrillion Btu of energy in 2009, resulting in over 1,100 million metric tons of carbon dioxide emissions (EIA 2017). Three-quarters of this energy was used for space heating, appliances, electronics, and lighting (EIA 2013). However, with concerns over climate change mitigation, pollution from electricity 
generation, and consumer welfare, both policy makers and environmentalists have been working to encourage energy efficiency and conservation. Broadly speaking, interventions aimed to reduce energy use can be categorized as either a price incentive or non-price mechanism.

Price incentives are the typical recommendation of classical economists, and include strategies to adjust the cost of energy that is passed onto the consumer. In the electricity market, most consumers face either a flat rate or inclining block rate pricing schedule, where rates are independent of total demand for electricity (FERC 2012). However, since electricity cannot be stored and must be generated in real time to meet demand, times of peak demand cause additional electricity generation facilities to come on board, which generate electricity that is often purchased at a higher wholesale cost (Borenstein 2013, EIA 2014). Growing peak demand exacerbates the challenge of producing adequate supplies of electricity to meet varying demand throughout the year (NERC 2013). In regions where peak demand is met through the use of fossil fuel-based generation, reducing peak demand and variability can decrease emissions of greenhouse gases and pollutants (Holland and Mansur 2004). Because these costs are hidden to consumers, consumers have no incentive to reduce their electricity consumption (Borenstein 2002, 2005; Joskow and Wolfram 2012). Newsham and Bowker 2010 and Faruqui and Sergici 2009 provide reviews of various pricing schemes.

One alternative price incentive is dynamic real-time pricing, which translates the actual cost of electricity generation at any given time to the consumer. However, realtime pricing comes with regulatory and political concerns, including difficulty for the consumer to understand and adjust to time-varying prices (see Alexander 2010 for a 
review). Time-of-use pricing is a coarse form of real-time pricing. Under a time-of-use pricing scheme, consumers pay a higher rate during pre-determined hours of peak demand and a lower rate during off-peak hours (Cappers et al 2016, Hydro One 2008, Idaho Power Company 2006, Charles River Associates 2005, Strapp et al. 2007, Hammerstrom et al 2007, Navigant 2008, Hartway 1999, Gill and Lang in prep). In a similar structure, critical peak pricing charges consumers a premium for electricity use only during hours of peak demand on specific high-demand days (Wolak 2006, Charles River Associates 2005, Violette et al 2007). These pricing schemes can be seen as sticks rather than carrots, punishing consumers for high use rather than rewarding them for reduced use. On the other hand, peak time rebates actually pay consumers for not using electricity during critical peak periods (Strapp et al 2007, Wolak 2006, Navigant 2008, Herter et al 2007). Finally, increasing block rate pricing charges consumers increasing marginal prices per kilowatt-hour depending on total consumption (Reiss and White 2005). Price incentives are generally shown to decrease energy consumption, though with varying effectiveness (Newsham and Bowker 2010). For example, Ito (2014) shows that consumers respond to average prices rather than marginal prices when facing an increasing block rate price structure, affecting desired effects of nonlinear pricing on electricity consumption and consumer welfare. The effectiveness of price incentives increases when coupled with non-price strategies (Newsham and Bowker 2010).

Non-price strategies include mandatory energy efficient standards for buildings and appliances (Costa and Kahn 2011, Jacobsen and Kotchen 2013), demand response programs including direct load control (Summit Blue 2004, KEMA 2006), commitment devices and goal setting (Becker 1978, Harding and Hsiaw 2014), social comparisons 
(Allcott 2011), feedback (Jessoe and Rapson 2014, Carrico and Riemer 2011), and education (Agarwal et al 2017). For example, direct load control programs allow the utility provider to automatically curtail sources of electricity use, like air conditioners, in response to total demand during critical peak periods. One reason why direct load control programs are effective is because they obviate the need for behavior change by the consumer. While programs such as this have been shown to be effective, consumer behavior during off peak hours can attenuate predicted energy conservation benefits (Newsham and Bowker 2010, Wolak 2011, Lang and Okwelum 2015). There has been a growing movement for using concepts from psychology and behavioral economics to encourage energy efficiency (Allcott 2014, Gillingham and Palmer 2014, Allcott and Mullainathan 2010). One well-known example is the peer comparison on the OPower home energy reports. Allcott (2011) finds this comparison leads to a persistent two percent reduction in electricity use.

Energy feedback and in-home energy displays can be considered as one type of education geared toward educating energy-related decision-makers about energy use and cost in real-time. These methods have been shown to be effective, especially when coupled with price incentives like critical peak pricing (Jessoe and Rapson 2014, Newsham and Bowker 2010). However, these measures rely on some base knowledge of how to reduce energy use in the home, and motivation to do so. Towards the first point, suggestions for electricity reduction and energy efficiency improvements popular on energy bills (notably also on OPower home energy reports) provide some additional education about how to reduce energy use at home. In-school energy education for students can also provide critical information about actions to reduce energy 
consumption, as well as some key motivation in the form of persistent nudging from eager children.

Utilities expend significant effort and resources on energy education, funded in part by consumers and mandated by state and federal legislation. The goal of energy education programs is to reduce energy consumption in order to even out daily and seasonal energy demand, save consumers money on utility bills, and curb greenhouse gases emissions. These programs promote behaviors that reduce energy consumption in the short-term (i.e., unplugging appliances when not in use) and in the long-term by increasing propensity to acquire energy efficient capital stock (i.e., purchasing Energy Star certified appliances) (Allcott and Rogers, 2014). However, the tangible effect of energy education in schools on energy consumption at home is not well understood.

While the literature on energy behavior and conservation is extensive (see Abrahamse et al. (2005) for a review), there have been few evaluations of in-school energy education. Although the NEED Project (www.need.org) conducts knowledge assessments of their energy education curricula, they do not address the behavioral impacts of energy education. Two studies that rely on before and after surveys find contradicting effects of energy education for in elementary and junior high school. DiMatteo et al. (2014) finds increases in energy knowledge but not self-reported changes in behavior, while Zografakis et al. (2008) do find an increase in self-reported energysaving behaviors and a decrease in 'energy-squandering' behaviors.

The majority of literature on environmental education in general, and energy education in particular, are problematic for several reasons. First, they rely on selfreported behavior change, which is likely to be overstated (Geller, 1981). Second, they 
used methods that fail to construct a counterfactual, compare treatment to control, or used a randomized framework, thereby potentially biasing the estimated treatment effect. Third, they do not quantify a treatment effect in terms of actual energy consumption, falling short of what is needed to properly evaluate the impacts that energy education will have on electricity use and its consequences. While some studies find evidence of increased self-reported pro-environmental behavior and intergenerational learning following energy education, there are no robust research studies that empirically estimate the effects of in-school education on observable, quantifiable outcomes at the household level. This research seeks to estimate the effects of in-school energy education on student household energy consumption.

A recent empirical study of an energy education program in Singapore provides some evidence for the effects of energy lessons on household electricity consumption. Argawal et al. (2017) use a quasi-experimental approach to estimate changes in total monthly electricity consumption aggregated for households within $2 \mathrm{~km}$ from a school that participated in an energy savings campaign. The campaign included frequent energy lessons and an energy savings challenge with a $10 \%$ home electricity reduction goal and prizes for households that reduce the most. As such, the campaign is not directly comparable to the energy education program in our research. However, the findings suggest decreases in electricity consumption for households near treated schools relative to households farther from treated schools on the order of $1-2 \%$. The authors of the study claim this is evidence of both effective nudging and spillover effects to neighbors without school children. However, there are several limitations of this study, including potential 
selection bias, possible contamination between the treatment and control groups, and confoundedness of the energy education with competition and challenge aspects.

Osbaldiston and Schmitz (2011) attempted to conduct an empirical analysis of two one-hour interventions in ninth grade science classes in a Midwestern US city. Researchers collected household electricity consumption data of participating students and gathered additional data through a pre- and post-survey administered to students and mailed to parents four weeks after the intervention. However, the authors find no significant difference in household electricity consumption across years before and after the energy program and estimates are not included in the published article.

A related vein of literature seeks to understand the impact of water conservation education. Of these, only one study empirically examines change in water usage at the household level. Geller et al (1983) find that educational pamphlets elicit no discernable effect on household water usage and posit that only one household member fully receives educational treatment by actively engaging with the pamphlet when it is delivered.

\section{Background on eesmarts energy lessons}

The United Illuminating Company (UI) is a public electrical utility that serves the Greater New Haven area in Connecticut. Mandated by legislation in 1998, UI and four other Connecticut utilities administer the Energy Efficiency Board (EEB), now part of the brand Energize Connecticut ${ }^{\text {SM }}$. The EEB represents public and private interests by assisting utilities in developing and implementing energy efficiency programs (CEEF, 2014). Funding for energy efficiency programs is provided through the Connecticut Energy Efficiency Fund (CEEF), government initiatives, and grants. The CEEF uses the 
Combined Public Benefits Charge, a surcharge on consumer utility bills. Funding for EEB energy efficiency programs in Connecticut totaled $\$ 142 \mathrm{M}$ in $2013,41 \%$ of which was spent on the residential sector (CEEF, 2014).

Among other services, Energize Connecticut programming includes community and childhood education. eesmarts is one of Energize Connecticut's energy education programs and has delivered curricula to K-12 students since 2001. In 2013, eesmarts conducted professional development regarding renewable energy and energy efficiency to 466 educators through the Capitol Region Education Council (CREC) (CEEF, 2014). eesmarts lessons cover energy basics, including energy systems, conventional energy generation, and renewable energy sources, and highlight energy conservation behaviors at home. In 2013, Energize Connecticut programs, administered by the Utilities, cost $\$ 1 \mathrm{M}$ for K-12 education, with $\$ 1 \mathrm{M}$ budgeted for 2014. Despite legislation, costs to consumers, and effort on the part of UI, returns to in-school energy education programs are poorly understood.

In the 2015-2016 academic year, educators delivered eesmarts programming to over 500 students in the Greater New Haven area. We study the effects of three eesmarts lessons delivered to all fourth and fifth graders at one school. The first lesson taught students about 'phantom' electric loads - the electricity used by appliances even when they are turned off. This lesson introduced students to basic concepts of electricity, including types of energy, types of fuel and electricity sources, and compared electricity use of common household appliances. Students participated in two exercises that are particularly relevant to reducing electricity at home. First, they recorded which appliances or equipment they used the previous day (e.g. iPad, TV, lights) and estimated 
how much energy they used in total. Second, students used a wattmeter to measure and record how much electricity various appliances use, both when the appliances are on and off. ${ }^{11}$ Students then came up with recommendations for how they could reduce their electricity use at home. Because of the direct ties linkages between this lesson and electricity conservation, we focus on the effects of this lesson in our main analysis. The second lesson described energy pathways. During this lesson, students built circuits to understand how electricity flows and manifests itself, including as light, heat, and sound. The third lesson discussed wind energy systems and included an activity to understand the impacts of different turbine blade shapes. The same educator taught all lessons, and all students were encouraged to discuss the lessons with their families at home.

\section{Methods}

We employ a differences-in-differences empirical framework to identify the effects of three energy lessons on household electricity consumption. Intuitively, we may expect a school student to talk about something novel or exciting that happened at school at home after school hours. For engaged families, it is not unreasonable to think that such a conversation would include takeaways from an energy lesson. Such communication would provide one mechanism for interfamily learning about energy conservation. Furthermore, some families may even act on specific conservation behaviors or experiment with energy use throughout the house. Therefore, we hypothesize that electricity use decreases on days of energy lessons. However, the energy lessons are only a small part of a student's busy schedule. As much of the literature shows, permanent

\footnotetext{
${ }^{11}$ Activity instructions included in the Appendix.
} 
behavior change is extremely difficult to achieve. In the absence of persistent reminders and feedback about energy conservation, there is limited incentive to continue to reduce energy use. Therefore, we are primarily interested in changes to household electricity use on the day of a lesson.

To test this hypothesis, we rely on a differences-in-differences model that compares the treatment group (households with a student who received an energy lesson) to the control group (households who do not contain a student who received an energy lesson) and examines whether there is differential energy use on the day of the lesson. The basic empirical model is as follows:

$$
\begin{aligned}
\text { load }_{i t} & =\beta_{1} \text { LessonDay }_{t}+\beta_{2} \text { Treatment } H_{i} \\
& +\beta_{3} \text { LessonDay }_{t} \times \text { Treatment } H_{i}+\varepsilon_{i t}
\end{aligned}
$$

where LessonDay ${ }_{t}$ is a binary variable equal to one if an energy lesson occurred on day $t$, Treatment $H H_{i}$ is a binary variable equal to one if household $i$ contains a student who received an energy lesson, and LessonDay $x$ Treatment $H H_{i}$ is the interaction of the two. The dependent variable is electricity load for each household $i$ on each day $t$. The coefficient of interest is on the interaction term, $\beta_{3}$, and is interpreted as an average change in kilowatt-hour $(\mathrm{kWh})$ usage for treated households on the day of the lesson relative to control households. A negative, significant coefficient indicates a reduction in electricity consumption. The error term $\varepsilon_{i t}$ is clustered at the household level to allow for correlations in electricity use within each household unit.

The rich nature of our dataset allows us to additionally control for unobservable characteristics that may affect electricity consumption. We extend the model in Equation 
1 to control for unobservable household-level average electricity use with a householdspecific fixed effect, $\alpha_{i}$. Household fixed effects flexibly control for time-invariant factors including family size, house characteristics, preferences for AC use or heating, household appliances, etc. We also control for average electricity use each day of the sample using a time fixed effect, $\theta_{t}$. These fixed effects flexibly account for determinants of electricity use on each day, including weather, time of day, and day of week norms, without imposing an assumption about the functional form of these relationships. With these fixed effects, our model becomes: ${ }^{12}$

$$
\text { load }_{i t}=\beta_{1} \text { LessonDay }_{t} x \text { Treatment } H_{i}+\alpha_{i}+\theta_{t}+\varepsilon_{i t}
$$

We make two more modifications to the basic model. First, we include the summation of coefficients on the three days prior to each lesson, the third term in Equation 2, to test the assumption of parallel trends between the treatment and control groups within the differences-in-differences framework. Doing so bolsters our confidence that we have an appropriate counterfactual for the treatment group. Second, we hypothesize the effect of the lessons attenuates quickly, within a few days. We make the assumption that the effect will attenuate completely within one week following the lesson, and estimate changes in electricity use for each of the seven days following the lessons. Doing so provides insight into how the effect of energy lessons changes over time. Our full specification is:

$$
\text { load }_{i t}=\beta_{1} \text { LessonDay }_{t} \times \text { Treatment } H_{i}
$$

\footnotetext{
${ }^{12}$ Note that the fixed effects take the place of the other terms from Equation 1. In other words, LessonDay $_{i t}$ is accounted for through the day fixed effect and Treatment $H H_{i t}$ is accounted for through the household fixed effect.
} 


$$
\begin{aligned}
& +\sum_{\tau=1}^{7} \beta_{2}^{\tau} \text { NextDay }_{t} \times \text { Treatment H }_{i}^{\tau} \\
& +\sum_{\tau=1}^{3} \beta_{3}^{\tau} \text { PriorDay }_{t} \times \text { Treatment } H_{i}^{\tau} \\
& +\alpha_{i}+\theta_{t}+\varepsilon_{i t}
\end{aligned}
$$

Our coefficient of interest is again on LessonDay $x$ Treatment $H_{i}$, a binary variable equal to one if a lesson occurred on day $t$ for household $i$ and zero otherwise. The second term in Equation 3 tests for continued changes in electricity consumption over the seven days following each energy lesson. NextDay $x$ TreatmentHH $H_{i}^{\tau}$ is a binary variable equal to one if household $i$ received a lesson $\tau$ days before day $t$, and zero otherwise. The coefficient estimate for $\beta_{2}^{\tau}$ indicates a change in electricity load on $\tau$ days following the lesson. Coefficients that are significantly distinguishable from zero would indicate possible persistence of the treatment effect. PriorDay $x$ Treatment $H_{i}^{\tau}$ is a binary variable equal to one if household $i$ received a lesson $\tau$ days after day $t$, and zero otherwise. If our assumption of parallel trends holds, then the coefficient estimates for $\beta_{3}^{\tau}$ would be insignificant, indicating the electricity use prior to treatment is statistically indistinguishable between the treatment and control groups. These coefficients provide evidence for quality of the control group as an appropriate counterfactual for the treatment group.

\subsection{Exploration of Heterogeneity in Treatment Effect}

Our main analysis focuses solely on the effects of the lesson on phantom power due to the direct linkages with electricity conservation. In a classic scenario using differences-in-differences, there is measurement of the dependent variable prior to some 
treatment and then after the treatment. In our empirical setting, we have not just one, but three treatment dates. Running the model given by Equation 3 would results in an estimated treatment effect that is averaged over the three lessons. However, two potential issues arise with doing so. First, the estimated treatment effect will be smaller in magnitude (and potentially lower in statistical significance) if one or two of the lessons do not affect electricity consumption at home. Second, since the lessons are spread throughout the academic year, if the treatment group responds differently to changes in season, then the same control group may not be an appropriate counterfactual. For example, we can imagine a scenario where a treatment group household increases use of heat or air conditioning in response to colder or hotter weather more so than households without children or with lower income families in the control group. With the use of household fixed effect, which essentially subtract mean daily load for each household, differences in extreme electricity use between treatment and control could bias the estimated treatment effect. To account for these complications, we estimate the treatment effect of each lesson instead of all lessons on average. We use a sample period that includes 30 days prior to the lesson, the day of the lesson, and seven days following the lesson.

We investigate whether the lessons have different effects on electricity use at home. It is plausible that the content of the lesson matters, and curriculum that includes action items for reducing electricity at home may result in deeper energy reductions at home. On the other hand, perhaps any lesson on energy prompts discussion of energy use at home and provides a reminder or cue to engage in energy efficient behaviors. In other words, the mechanism linking energy lessons to energy conservation may be that the 
lessons are reminders, rather than instructions. Therefore, understanding how curriculum relates to electricity conservation has critical implications for curriculum development and timing of lessons depending on programmatic goals. One limitation of our empirical setting is that all students received the same lessons on the same days (i.e. Phantom Power was the first lesson for all students and all students received this lesson on October 27, 2015). Therefore, we must interpret results with caution because the order of the lessons is confounded with the content of the lesson.

Finally, we investigate heterogeneity in treatment effect by several characteristics. We first explore differences in treatment effect by level of electricity consumption. While higher-consuming households potentially have more opportunities to reduce electricity use, lower-consuming households may be more motivated to conserve either because they already have energy efficient capital stock, but may not be engaging in energyefficient household habits, or because they are more financially constrained. Then, we explore heterogeneity based on house characteristics. We focus on four characteristics: assessed value, gross area, number of bedrooms, and year built. While assessed value is highly correlated with square footage and neighborhood, it may also be an indication of improvements due to remodeling. Remodeled houses may have more efficient features, such as insulation. Above median assessed value may also be an indicator of wealth of the household. Wealthier households may be more likely to have many energyconsuming appliances and electronics, which family members could turn off or unplug to conserve electricity. Gross area and number of bedrooms are both indicators of house size. It is possible that larger houses have more opportunity for energy reductions. Newer homes may include more electronics that can either be unplugged or turned off, or that 
allow for easy and precise control of energy use, such as for heating or cooling. These features of newer homes may provide more energy savings opportunities. To test for heterogeneity, we interact the variable of interest with a binary variable equal to one for households who are above median ${ }^{13}$ in each characteristic, based on the treatment group:

$$
\begin{aligned}
\text { load }_{i t} & =\beta_{1} \text { LessonDay }_{t} \times \text { Treatment } H_{i} \\
& +\beta_{2} \text { LessonDay }_{t} \times \text { Treatment }_{H} H_{i} \times \text { Characteristic }_{i} \\
& +\alpha_{i}+\theta_{t}+\theta_{t} \times \text { Characteristic }_{i}+\varepsilon_{i t}
\end{aligned}
$$

We additionally interact day fixed effects with the indicator for high consumption to control differentially for high-consuming control households.

\section{Data}

In the 2015-2016 academic year, 586 students received energy lessons in UI's territory. We made a substantial attempt to obtain data for all students, but most schools declined to share the necessary information we needed to match student households with electricity data. We obtained data for 65 fourth and fifth grade students at a Catholic school in the Greater New Haven area that received three energy lessons. An educator delivered programming on phantom power sources on October 27, 2015, energy pathways on January 12, 2016, and wind energy on May 10, 2016. We obtained electricity consumption data from July 1, 2014 - October 5, 2016 for $\mathrm{N}=50$ households ${ }^{14}$

\footnotetext{
${ }^{13}$ Splitting by treatment group median maximizes the sample size in each bin (e.g. there are an equal number of treated households above and below median).

${ }^{14}$ Data for ten households were not obtained due to students living outside the utility's territory, two households contain two students who are siblings, and three households could not be matched due to issues with addresses.
} 
that contain a student. We additionally obtained electricity consumption data for $\mathrm{N}=1,485$ households selected at random by United Illuminating. ${ }^{15}$ Depending on meter type installed at each house, data were provided at 15-minute intervals, peak and off-peak hours, or at the daily level. We aggregated all data to consumption per day for each household, resulting in a dataset of $\mathrm{N}=756,804$ household-day observations.

Figure 1 plots a 7-day smoothed moving average of daily electricity consumption treated and untreated households. Mean daily load for the treatment group is significantly higher than for untreated households (means $=31.1 \mathrm{kWh} /$ day for treated households and $18.6 \mathrm{kWh} /$ day for control households, $t(1535)=-5.37)$. This difference is likely due to several socioeconomic and demographic factors. All households in the treatment group contain at least one child, whereas only $34 \%$ of households in New Haven contain a child under 18 years old (US Census $2000^{16}$ ). According to 2015 American Community Survey estimates for New Haven, family households earn nearly $\$ 17,000$ more in annual income than non-family households. ${ }^{17}$ Furthermore, all households in the treatment group presumably have sufficient disposable income to enroll their child(ren) in a non-public school. $^{18}$

[Figure 1 about here]

\footnotetext{
${ }^{15}$ One possible concern is that the randomly selected control households may contain a student who received an energy lesson at a different school. However, we are not concerned about this possibility because the chances of contamination are roughly $0.16 \%$ (468 treated student households not included in our treatment group divided by a residential customer base of roughly 290,000 households).

${ }^{16} \mathrm{https} / / /$ factfinder.census.gov/faces/tableservices/jsf/pages/productview.xhtml? src $=\mathrm{bkmk}$

${ }^{17}$ Median family household income $=\$ 45,540$. Median non-family household income $=\$ 27,724$. (ACS 2015) https://factfinder.census.gov/faces/tableservices/jsf/pages/productview.xhtml?src=bkmk

${ }^{18}$ To illustrate: tuition for one student is $\$ 4,500$ per year, with ancillary costs including a $\$ 25$ application fee, uniform purchases, and annual fundraising requirements.
} 
One empirical concern is that the untreated group, which is comprised of randomly chosen households, may not be an adequate counterfactual for the treatment group. We construct a counterfactual for the treatment group by choosing control households with a mean daily load for the thirty days before each lesson that is sufficiently close to the mean daily load of each treatment household in that time period. We match each treatment household to the $\mathrm{k}=2$ nearest neighbors, with replacement, within a caliper of $1 \mathrm{kWh}$ mean daily load. In order to capture the most appropriate counterfactual, we construct a control group for each lesson specifically, using the thirty days prior to that lesson to calculate mean daily load. Figure 2 illustrates the agreement between treatment and control groups for each lesson.

[Figure 2 about here]

We additionally obtain assessor data for $\mathrm{N}=41$ single family homes in the treatment group and $\mathrm{N}=55$ homes in the control group for houses transacted since $1995 .{ }^{19}$ We use this data to test for heterogeneity in treatment effect by house characteristics.

\section{Results and Discussion}

We present main results in Table 1. The dependent variable is daily load for each household, with the coefficient of interest on LessonDay $x$ x Treatment $H H_{i}$ interpreted as a $\mathrm{kWh}$ reduction in electricity use on the day of lesson 1 relative to the control group. Column 1 interacts binary variables for days prior to, day of, and after the lesson with a binary variable indicating treatment status. Column 2 instead uses household and day fixed effects. The preferred model is Column 2 and Figure 3 illustrates the results of this

\footnotetext{
${ }^{19}$ Of course a larger sample would be ideal, and this analysis should be viewed as strictly exploratory.
} 
model. The coefficients on the prior day indicators are all insignificant, which show no statistically discernible difference in electricity load the three days leading up to the lesson and provide evidence for the appropriateness of the constructed control group. ${ }^{20}$

[Table 1 about here]

The coefficient of interest is on the interaction LessonDay $x$ Treatment $H H_{i}$, which estimates the reduction in load on the lesson day for the treatment group relative to control. The coefficient estimate is negative and significant at the 10 percent level, indicating a $2.5 \mathrm{kWh}$ reduction in electricity use on the day of the lesson for households that contain a student who received the lesson, an eight percent decrease in electricity load relative to baseline. While the majority of coefficients on the next day indicators are statistically insignificant, the coefficient estimate for two days following the lesson is positive and similar in magnitude to our coefficient of interest. This could be an indication that households defer electricity use the day of the lesson to two days following the lesson. For example, households may defer doing a load of laundry, watching television, or using a computer. Importantly, evidence of deferment indicates a net zero reduction in electricity load due to the energy lesson.

[Figure 3 about here]

Table 2 compares results of the preferred model from Table 1 using various control groups. This table is meant as a robustness check to ensure the consistency of our

\footnotetext{
${ }^{20}$ Table 1A and Figure 1A in the Appendix present results from the same models using a control group comprised of randomly chosen households. Note that the coefficient on the indicator for treatment status, 7.894, in Column 1 is further evidence of the difference between treatment and control groups, and incentive for constructing a more appropriate counterfactual through nearest neighbor matching. In contrast, this coefficient in Column 1 of Table 1 of the main paper (using matching methods) is both smaller in magnitude and statistically insignificant.
} 
main finding that electricity consumption is reduced on day of the energy lesson. Columns 1-4 use a constructed counterfactual with $\mathrm{k}=1$ through 4 neighbors, respectively. Column 5 uses all neighbors within the $1 \mathrm{kWh}$ /day caliper.

[Table 2 about here]

The coefficient of interest is negative and significant Columns 2-5, indicating a reduction in electricity use on the order of six to eight percent on the day of the lesson. The coefficient of interest in Column 1 is similarly negative, though larger in magnitude with larger standard errors. Consistency of the coefficient of interest lends confidence to our main finding of a short-term reduction in electricity consumption on the days of energy lessons. Across all columns, the coefficient estimate on the two days later indicator is positive, though significance is lost in Column 5. Again, this suggests an increase in electricity load two days following the lesson, and provides evidence of the treatment effect being caused by deferral of load rather than reduction in load.

[Table 3 about here]

Next, we explore differences in treatment effect by lesson. Table 3 presents the results of this analysis, where each column represents each lesson. ${ }^{21}$ Column 1 repeats results of the preferred model in Table 1. Column 2 (3) uses the same model but for the sample period of 30 days before the second (third) lesson, the day of, and seven days following. For each column, the control group is constructed by matching each treated unit to two nearest neighbors based on mean daily baseline load for the thirty days prior to the lesson, subject to a caliper of $1 \mathrm{kWh} /$ day. Coefficients on the three prior day

\footnotetext{
${ }^{21}$ Tables $2 \mathrm{~A}$ and $3 \mathrm{~A}$ in the Appendix present results from models with one through four nearest neighbors and all neighbors, subject to the caliper of $1 \mathrm{kWh} / \mathrm{day}$, for each of lessons 2 and 3 respectively.
} 
indicators are statistically insignificant for all columns, indicating good agreement between treatment and control groups. Results fail to show a significance difference in load on the days of lessons 2 and 3. Interestingly, we see a significant increase in load for two to four days following the third lesson, roughly equal to a ten percent increase in daily use for each day relative to baseline. While we cannot rule out this finding being an odd effect of the lesson on wind energy, our intuition suggests this effect may be more likely due to some other event or occurrence common to all houses of fourth and fifth graders in this particular school. Lesson content, timing, and dates are confounded in our empirical setting, so we cannot disentangle whether the absence of treatment effects of the second and third lesson is due to lesson content (specifically a lack of energy saving action items) or due to other factors. However, that we find a treatment effect for the lesson most directly applicable to energy conservation is suggestive that lesson content matters.

Lastly, we explore heterogeneity in treatment effect by several characteristics. Table 4 presents results from this analysis for the lesson on Phantom Power, which was the only lesson to have a statistically significant treatment effect. ${ }^{22}$ Column 1 investigates heterogeneity in treatment effect by baseline electricity consumption. We fail to find a statically distinguishable difference in electricity use the day of the lesson between above- and below-median consuming households, though the signs on the coefficients suggest higher-consuming households may reduce more on the day of the lesson. Columns 2-5 explore differences based on house characteristics. All coefficients on LessonDay $_{t} \times$ TreatmentH $_{i}$ are negative, indicating reductions in electricity

\footnotetext{
${ }^{22}$ Analogous results for the other lessons are included in the Appendix: Tables 4A and 5A.
} 
consumption for households below median in each characteristic. Signs of coefficients on the interactions with the characteristics suggest that these reductions may be smaller for newer households with higher assessed values and enhanced for larger households. While the magnitudes and signs of the coefficients of interest are interesting - and could align with intuition - the standard errors are unfortunately large due to our limited sample size. This is an area ripe for future research.

[Table 4 about here]

\section{Conclusion}

In this study, we conduct an empirical analysis of the effects of in-school energy lessons for fourth and fifth grade students on household electricity consumption. Using a differences-in-differences empirical framework, we compare electricity load on the day of the energy lesson and on seven days after between households with students who received the energy lesson and control households that closely match treated households in mean daily baseline load. We estimate energy reductions on the order of $2.5 \mathrm{kWh}$ on the day of a lesson regarding phantom loads, roughly equivalent to eight percent of mean daily load. However, we see an increase in load of roughly the same magnitude two days following the lesson, suggesting deferment of electricity use rather than conservation.

We fail to find an effect of lessons about energy pathways and wind energy on electricity consumption the days of those lessons. Our empirical setting cannot allow us to causally attribute this difference in treatment effects to the content of the lessons due to confoundedness with timing and ordering of the lessons. For example, we cannot rule out that students become desensitized to the novelty of the energy lessons by the second 
lesson. However, intuition points to the curriculum content as a driver of the effect. The curriculum for the lesson on phantom loads includes direct action items for the students to take home. We also investigate whether there is a difference in treatment effect for high-consuming households or households with certain house characteristics. The magnitudes of the coefficient estimates suggest that the treatment effect may be larger for high consuming households and families in larger homes, but smaller for households in higher valued or more recently constructed homes. However, our small sample of treated households limits our ability to identify heterogeneity in treatment effect with statistical precision.

This study contributes an empirical case study to the literature on energy education. While there are benefits to a case study-style analysis using all students from one school, there are also critical limitations that influence our interpretation of the treatment effect. Most importantly, this case study is of a private, Catholic school, which arguably differs from other schools both in socio-economic demographic characteristics and other unobservable characteristics. For example, one could argue that the households who went through the effort to enroll their children in a private school are also more motivated than households whose children attend public school. More motivated households may also be more receptive to behavior change or more likely to discuss energy lessons with their children after school. Therefore, the effects we find may represent an upper bound on changes in energy use due to in-school lessons.

Future research should address this limitation by including a more diverse set of schools in the analysis. With a larger sample size and experimental design, empirical analysis would also be able to tease out effects lesson content and timing, as well as 
investigate heterogeneity in effect by student grade, household socioeconomic or demographic characteristics, household characteristics, and consumption levels. 


\section{References}

Abrahamse, Wokje, et al. "A review of intervention studies aimed at household energy conservation." Journal of environmental psychology 25.3 (2005): 273-291.

Agarwal, Sumit, et al. "Nudges from school children and electricity conservation: Evidence from the "Project Carbon Zero" campaign in Singapore." Energy Economics 61 (2017): 29-41.

Alexander, Barbara R. "Dynamic pricing? Not so fast! A residential consumer perspective." The Electricity Journal 23.6 (2010): 39-49.

Allcott, Hunt. "Rethinking real-time electricity pricing." Resource and energy economics 33.4 (2011): 820-842.

Allcott, Hunt. "Social norms and energy conservation." Journal of Public Economics 95.9 (2011): 1082-1095.

Allcott, Hunt, and Todd Rogers. "The short-run and long-run effects of behavioral interventions: Experimental evidence from energy conservation." The American Economic Review 104.10 (2014): 3003-3037.

Allcott, Hunt. "Paternalism and energy efficiency: an overview." Annual Review of Economics 8 (2016): 145-176.

Allcott, Hunt, and Sendhil Mullainathan. "Behavior and energy policy." Science 327.5970 (2010): 1204-1205.

Becker, Lawrence J. "Joint effect of feedback and goal setting on performance: A field study of residential energy conservation." Journal of applied psychology 63.4 (1978): 428.

Borenstein, Severin. "The long-run efficiency of real-time electricity pricing." The Energy Journal (2005): 93-116.

Borenstein, Severin. "Time-varying retail electricity prices: Theory and practice." Electricity deregulation: choices and challenges (2005): 317-357.

Borenstein, Severin. "Effective and equitable adoption of opt-in residential dynamic electricity pricing." Review of Industrial Organization 42.2 (2013): 127-160.

Borenstein, Severin, Michael Jaske, and Arthur Rosenfeld. "Dynamic pricing, advanced metering, and demand response in electricity markets." Center for the Study of Energy Markets (2002). 
Cappers, Peter., et al. "Time-of-Use as a Default Rate for Residential Customers: Issues and Insights.” Lawrence Berkeley National Laboratory, LBNL-1005704. (2016). https://emp.lbl.gov/sites/all/files/lbnl-1005704_0.pdf

Carrico, Amanda R., and Manuel Riemer. "Motivating energy conservation in the workplace: An evaluation of the use of group-level feedback and peer education." Journal of environmental psychology 31.1 (2011): 1-13.

(CEEF) Connecticut Energy Efficiency Fund. Energy Efficiency Board 2013 Programs and Operations Report. N.p., 2014. Print.

Charles River Associates (2005) Impact Evaluation of the California Statewide Pricing Pilot.

Costa, Dora L., and Matthew E. Kahn. "Electricity consumption and durable housing: understanding cohort effects." The American Economic Review 101.3 (2011): 8892.

DiMatteo, Julie, et al. "Is Energy Conservation Education Effective? An Evaluation of the PowerSave Schools Program." Applied Environmental Education \& Communication 13.2 (2014): 99-108.

Duvall, Jason, and Michaela Zint. "A review of research on the effectiveness of environmental education in promoting intergenerational learning." The Journal of Environmental Education 38.4 (2007): 14-24.

Hiramatsu, Ai, et al. "Spillover effect on families derived from environmental education for children." Low Carbon Economy 5.2 (2014): 40.

Energy Information Administration. Office of Energy Statistics, US Department of Energy. (March 2013). Today in Energy: Heating and cooling no longer majority of U.S. home energy use. Retrieved from: https://www.eia.gov/todayinenergy/detail.php?id=10271\&src=\%E2\%80\%B9\%20 Consumption $\% 20 \% 20 \% 20 \% 20 \% 20 \% 20$ Residential\%20Energy $\% 20$ Consumption \%20Survey\%20(RECS)-b1. Accessed February 27, 2017.

Energy Information Administration, 2014. Annual Energy Outlook with Projections 2014. Government Printing Office. https:/www.ferc.gov/legal/staff-reports/1220-12-demand-response.pdf

Energy Information Administration. Office of Energy Statistics, US Department of Energy. (2017). February 2017 Monthly Energy Review (DOE/EIA0035(2017/2)). Washington, DC. https://www.eia.gov/totalenergy/data/monthly/pdf/mer.pdf 
Evans, S. M., M. E. Gill, and J. Marchant. "Schoolchildren as educators: the indirect influence of environmental education in schools on parents' attitudes towards the environment." Journal of Biological Education 30.4 (1996): 243-248.

Faruqui, Ahmad, and Sanem Sergici. "Household response to dynamic pricing of electricity: a survey of 15 experiments." Journal of regulatory Economics 38.2 (2010): 193-225.

Federal Energy Regulatory Commission (2012). Assessment of Demand Response and Advanced Metering. https://www.ferc.gov/legal/staff-reports/12-20-12-demandresponse.pdf

Geller, E. Scott. "Evaluating energy conservation programs: Is verbal report enough?." Journal of Consumer research 8.3 (1981): 331-335.

Geller, E. Scott, Jeff B. Erickson, and Brenda A. Buttram. "Attempts to promote residential water conservation with educational, behavioral and engineering strategies." Population and Environment 6.2 (1983): 96-112.

Gill, Carrie, and Corey Lang. "The Effects of Mandatory Time of Use Electricity Pricing on High Consuming Households using a Regression Discontinuity Framework." (working paper)

Gillingham, Kenneth, and Karen Palmer. "Bridging the energy efficiency gap: Policy insights from economic theory and empirical evidence." Review of Environmental Economics and Policy 8.1 (2014): 18-38.

Grodzinska-Jurczak, Malgorzata, et al. "Evaluating the impact of a school waste education programme upon students', parents' and teachers' environmental knowledge, attitudes and behaviour." International Research in Geographical and Environmental Education 12.2 (2003): 106-122.

Hammerstrom, D. J., et al. "Pacific northwest gridwise testbed demonstration projects." Part I. Olympic Peninsula Project 210 (2007).

Harding, Matthew, and Alice Hsiaw. "Goal setting and energy conservation." Journal of Economic Behavior \& Organization 107 (2014): 209-227.

Hartway, Rob, Snuller Price, and Chi-Keung Woo. "Smart meter, customer choice and profitable time-of-use rate option." Energy 24.10 (1999): 895-903.

Herter, Karen. "Residential implementation of critical-peak pricing of electricity." Energy Policy 35.4 (2007): 2121-2130. 
Holland, Stephen P., and Erin T. Mansur. "Is real-time pricing green? The environmental impacts of electricity demand variance." The Review of Economics and Statistics 90.3 (2008): 550-561.

Hydro One (2008) Hydro One Networks' Time of Use Pricing Pilot Project Results. Report number EB-2007-0086. http://www.ontarioenergyboard.ca/documents/cases/EB-20040205/smartpricepilot/TOU_Pilot_Report_HydroOne_20080513.pdf

Ito, Koichiro. "Do consumers respond to marginal or average price? Evidence from nonlinear electricity pricing." The American Economic Review 104.2 (2014): 537563.

Idaho Power Company (2006) Time-of-day and Energy Watch Pilot Programs Final Report.

http://www.puc.idaho.gov/fileroom/cases/elec/IPC/IPCE0502/company/20060329 PILOT\%20PROGRAMS\%20FINAL\%20REPORT.PDF

Jacobsen, Grant D., and Matthew J. Kotchen. "Are building codes effective at saving energy? Evidence from residential billing data in Florida." Review of Economics and Statistics 95.1 (2013): 34-49.

Jessoe, Katrina, and David Rapson. "Knowledge is (less) power: Experimental evidence from residential energy use." The American Economic Review 104.4 (2014): 1417-1438.

Joskow, Paul L., and Catherine D. Wolfram. "Dynamic pricing of electricity." The American Economic Review 102.3 (2012): 381-385.

KEMA, 2006. 2005 Smart Thermostat Program Impact Evaluation. Report for San Diego Gas and Electric Company. http://www.calmac.org/publications/2005_Smart_Thermostat_FinalES.pdf

Lang, Corey, and Edson Okwelum. "The mitigating effect of strategic behavior on the net benefits of a direct load control program." Energy Economics 49 (2015): 141-148.

Matsukawa, Isamu. "Household response to optional peak-load pricing of electricity." Journal of Regulatory Economics 20.3 (2001): 249-267.

Navigant Consulting (2008) Evaluation of Time-of-Use Pricing Pilot, Prepared for Newmarket Hydro Ltd.

Newsham, Guy R., and Brent G. Bowker. "The effect of utility time-varying pricing and load control strategies on residential summer peak electricity use: a review." Energy policy 38.7 (2010): 3289-3296. 
North American Electric Reliability Corporation (NERC), 2013. 2013 Summer Reliability Assessment. http://www.nerc.com/pa/RAPA/ra/Reliability\%20Assessments\%20DL/2013SRA Final.pdf

Osbaldiston, Richard, and Hannah Schmitz. "Evaluation of an Energy Conservation Program for 9th Grade Students." International Journal of Environmental and Science Education 6.2 (2011): 161-172.

Board, Ontario Energy. "Ontario Energy Board smart price pilot final report." Toronto, ON, July (2007). (formerly Strapp)

Summit Blue, 2004. Load Reduction Analysis of the 2004 Air Conditioning Cycling Pilot Program, Final Report. Prepared for Idaho Power.

Reiss, Peter C., and Matthew W. White. "Household electricity demand, revisited." The Review of Economic Studies 72.3 (2005): 853-883.

Violette, D., Erickson, J., Klos, M., 2007. Final Report for the MyPower Pricing Segments Evaluation. Submitted to Public Service Electric and Gas Company by Summit Blue Consulting.

Wolak, Frank A. "Residential customer response to real-time pricing: The anaheim critical peak pricing experiment." Center for the Study of Energy Markets (2007).

Wolak, F.A., 2011. Do residential customers respond to hourly prices? Evidence from a dynamic pricing experiment. Am. Econ. Rev. 83-87.

Zografakis, Nikolaos, Angeliki N. Menegaki, and Konstantinos P. Tsagarakis. "Effective education for energy efficiency." Energy Policy 36.8 (2008): 3226-3232. 


\section{Tables and Figures}

Figure 1. Electricity consumption

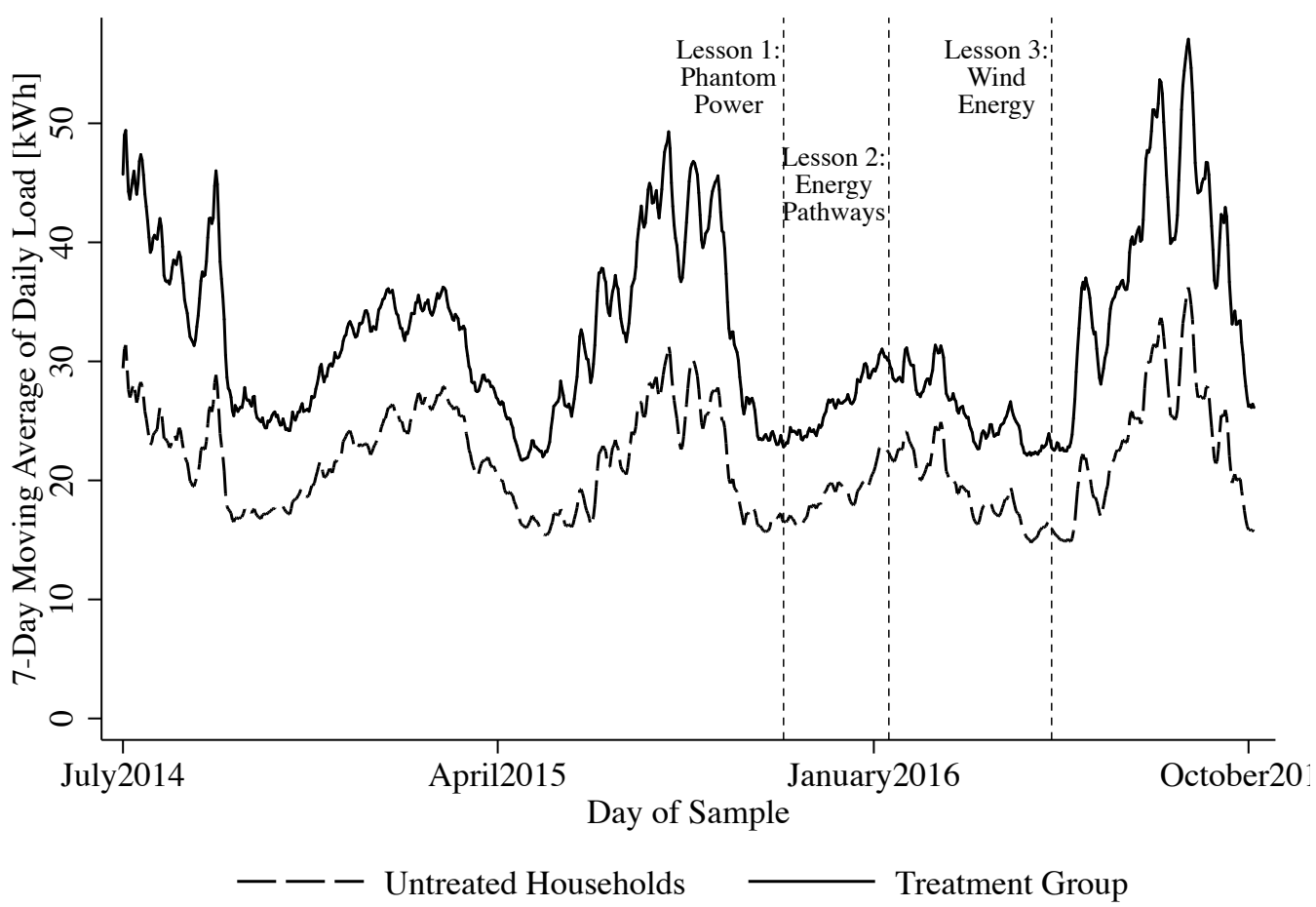

Notes: Figure illustrates smoothed daily load using a 7-day moving average. The treatment group is composed of $\mathrm{N}=50$ households who contain a student who received all three energy lessons (mean daily load $=31.1 \mathrm{kWh} /$ day). Vertical reference lines denote the energy lesson: Phantom Power occurred on 10/27/2015, Energy Pathways occurred on 1/12/2016, and Wind Energy occurred on 5/10/2016. The untreated group is composed of $\mathrm{N}=1485$ randomly chosen households (mean daily load $=18.6 \mathrm{kWh} /$ day). 
Figure 2. Electricity consumption
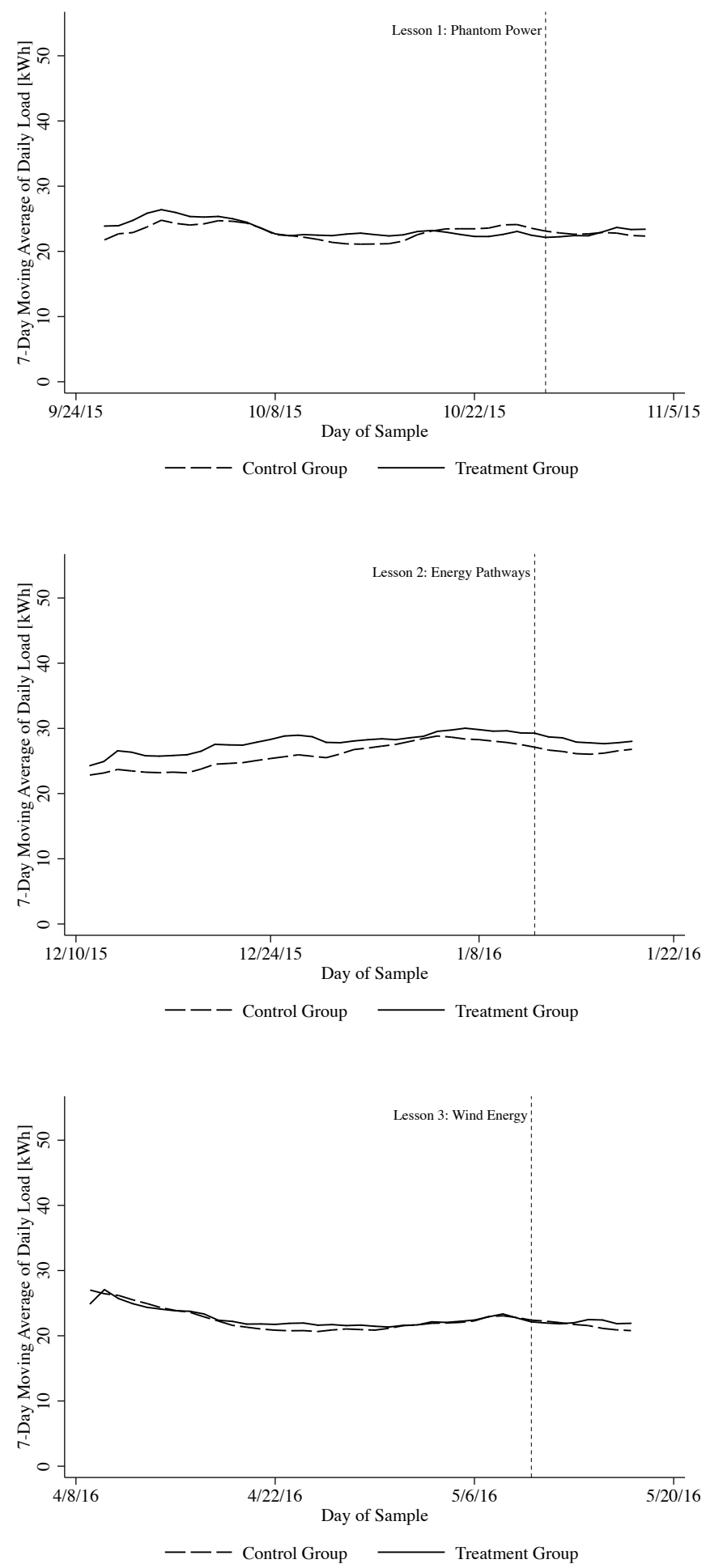
Notes: Figure illustrates mean daily load for the treatment and control groups smoothed using a 7day moving average. The control group ( $\mathrm{N}=85$ households) is constructed by matching on mean daily load for $9 / 26 / 2015-10 / 26 / 2015$, using the two nearest neighbors with replacement and a caliper of $1 \mathrm{kWh} /$ day). Treated households without a match within the caliper are dropped. $\mathrm{N}=48$ households remain in the treatment group. 
Figure 3. Treatment effect over time for lesson 1 on phantom power

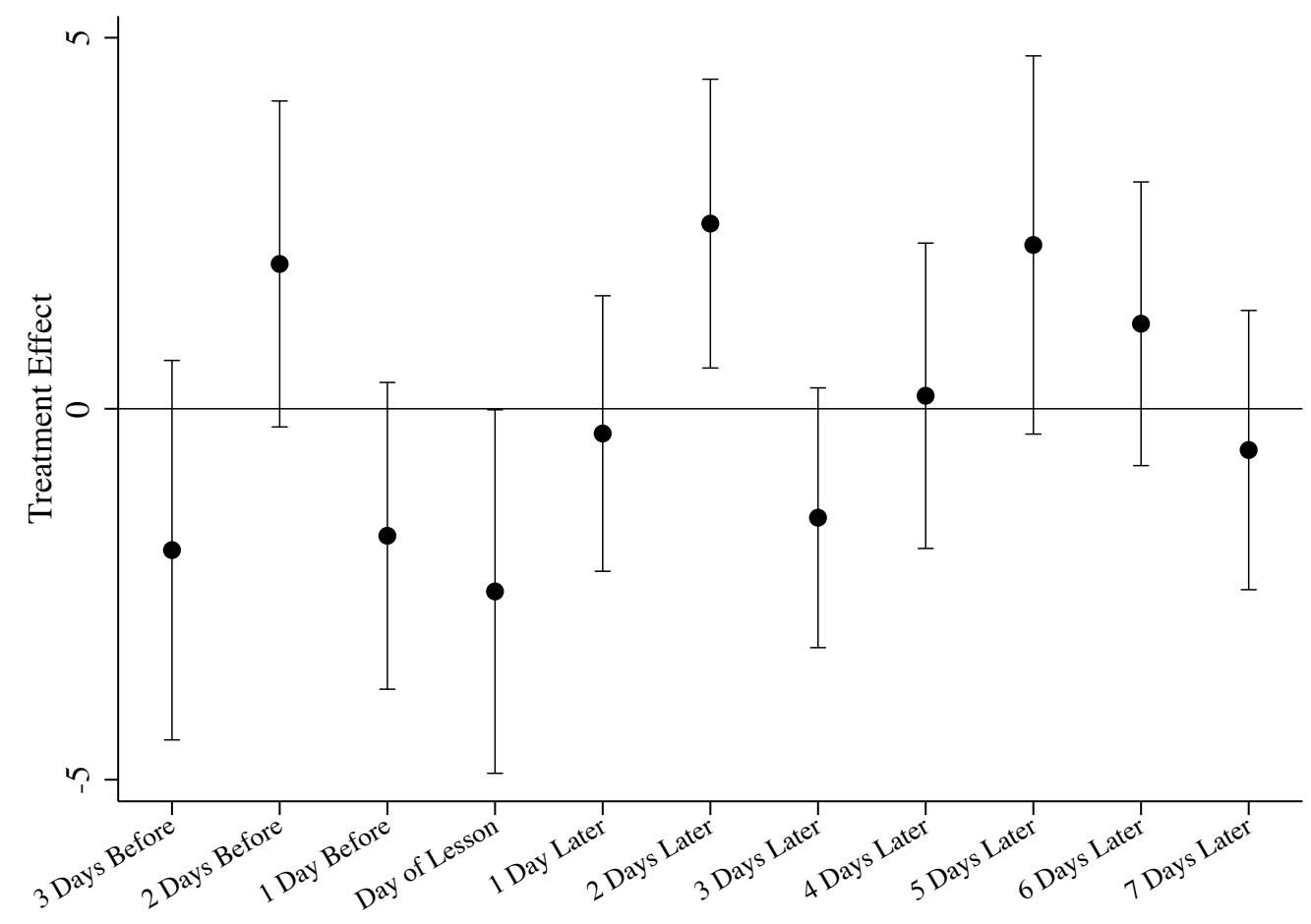

Notes: Figure plots coefficient estimates for three days prior to the date of lesson 1, the day of the lesson, and the seven days following the lesson. This figure illustrates results in Column 2 of Table 1. Error bars indicate the $90 \%$ confidence interval around the point estimate. 
Table 1. Treatment Effect of Lesson 1

\begin{tabular}{|c|c|c|}
\hline $\mathrm{DV}=$ Daily Load [kWh] & (1) & (2) \\
\hline Treatment $\mathrm{HH}$ & $\begin{array}{c}0.486 \\
(2.013)\end{array}$ & \\
\hline Lesson Day & $\begin{array}{c}0.375 \\
(1.295)\end{array}$ & \\
\hline Lesson Day x Treatment HH & $\begin{array}{l}-1.771 \\
(1.609)\end{array}$ & $\begin{array}{l}-2.463^{*} \\
(1.479)\end{array}$ \\
\hline 1 Next Day x Treatment HH & $\begin{array}{c}-0.202 \\
(1.243)\end{array}$ & $\begin{array}{l}-0.334 \\
(1.121)\end{array}$ \\
\hline 2 Next Day x Treatment HH & $\begin{array}{c}1.496 \\
(1.303)\end{array}$ & $\begin{array}{c}2.495^{* *} \\
(1.175)\end{array}$ \\
\hline 3 Next Day x Treatment HH & $\begin{array}{l}-1.165 \\
(1.257)\end{array}$ & $\begin{array}{l}-1.469 \\
(1.057)\end{array}$ \\
\hline 4 Next Day x Treatment HH & $\begin{array}{c}1.151 \\
(1.500)\end{array}$ & $\begin{array}{c}0.175 \\
(1.242)\end{array}$ \\
\hline 5 Next Day x Treatment HH & $\begin{array}{l}3.697 * * \\
(1.694)\end{array}$ & $\begin{array}{c}2.207 \\
(1.538)\end{array}$ \\
\hline 6 Next Day x Treatment HH & $\begin{array}{c}1.524 \\
(1.375)\end{array}$ & $\begin{array}{c}1.145 \\
(1.154)\end{array}$ \\
\hline 7 Next Day x Treatment HH & $\begin{array}{r}-0.904 \\
(1.316)\end{array}$ & $\begin{array}{r}-0.557 \\
(1.136)\end{array}$ \\
\hline 1 Prior Day x Treatment HH & $\begin{array}{r}-1.648 \\
(1.346)\end{array}$ & $\begin{array}{c}-1.713 \\
(1.248)\end{array}$ \\
\hline 2 Prior Day x Treatment $\mathrm{HH}$ & $\begin{array}{c}1.429 \\
(1.409)\end{array}$ & $\begin{array}{c}1.951 \\
(1.326)\end{array}$ \\
\hline 3 Prior Day x Treatment HH & $\begin{array}{l}-2.778^{*} \\
(1.649)\end{array}$ & $\begin{array}{r}-1.906 \\
(1.544)\end{array}$ \\
\hline Household Fixed Effects & $\mathrm{N}$ & Y \\
\hline Day Fixed Effects & $\mathrm{N}$ & $\mathrm{Y}$ \\
\hline Observations & 5,103 & 5,103 \\
\hline R-squared & 0.00551 & 0.689 \\
\hline Adjusted R-squared & 0.001 & 0.678 \\
\hline \multicolumn{3}{|c|}{$\begin{array}{l}\text { Notes: Dependent variable is mean daily load for } \mathrm{N}=48 \text { treatment } \\
\text { households and } \mathrm{N}=85 \text { control households } 9 / 26 / 2015-11 / 3 / 2015 \text {. } \\
\text { Column } 1 \text { uses a differences-in-differences model while Column } 2 \\
\text { adds household and day fixed effects. Errors are clustered at the } \\
\text { household level. *,**, and } * * * \text { indicate significance at the } 10 \% \text {, } \\
5 \% \text {, and } 1 \% \text { levels. }\end{array}$} \\
\hline
\end{tabular}


Table 2. Treatment Effect of Lesson 1

\begin{tabular}{|c|c|c|c|c|c|}
\hline DV = Daily Load [kWh] & $(1)$ & $(2)$ & (3) & $(4)$ & $(5)$ \\
\hline Lesson Day x Treatment HH & $\begin{array}{l}-3.299 \\
(2.022)\end{array}$ & $\begin{array}{l}-2.463^{*} \\
(1.479)\end{array}$ & $\begin{array}{l}-2.306^{*} \\
(1.282)\end{array}$ & $\begin{array}{l}-2.015^{*} \\
(1.176)\end{array}$ & $\begin{array}{c}-2.058 * * \\
(0.967)\end{array}$ \\
\hline 1 Next Day x Treatment HH & $\begin{array}{c}0.275 \\
(1.402)\end{array}$ & $\begin{array}{c}-0.334 \\
(1.121)\end{array}$ & $\begin{array}{c}-0.878 \\
(1.033)\end{array}$ & $\begin{array}{r}-1.009 \\
(0.989)\end{array}$ & $\begin{array}{l}-1.221 \\
(0.839)\end{array}$ \\
\hline 2 Next Day x Treatment HH & $\begin{array}{c}2.721^{* *} \\
(1.292)\end{array}$ & $\begin{array}{c}2.495^{* *} \\
(1.175)\end{array}$ & $\begin{array}{l}2.172^{*} \\
(1.108)\end{array}$ & $\begin{array}{l}2.023^{*} \\
(1.056)\end{array}$ & $\begin{array}{c}1.254 \\
(0.964)\end{array}$ \\
\hline 3 Next Day x Treatment HH & $\begin{array}{r}-0.167 \\
(1.014)\end{array}$ & $\begin{array}{l}-1.469 \\
(1.057)\end{array}$ & $\begin{array}{l}-1.414 \\
(0.968)\end{array}$ & $\begin{array}{l}-1.222 \\
(0.919)\end{array}$ & $\begin{array}{l}-1.487^{*} \\
(0.813)\end{array}$ \\
\hline 4 Next Day x Treatment HH & $\begin{array}{c}0.718 \\
(1.324)\end{array}$ & $\begin{array}{c}0.175 \\
(1.242)\end{array}$ & $\begin{array}{c}0.266 \\
(1.130)\end{array}$ & $\begin{array}{l}-0.359 \\
(1.117)\end{array}$ & $\begin{array}{r}-0.504 \\
(0.965)\end{array}$ \\
\hline 5 Next Day x Treatment HH & $\begin{array}{c}2.313 \\
(1.583)\end{array}$ & $\begin{array}{c}2.207 \\
(1.538)\end{array}$ & $\begin{array}{c}1.843 \\
(1.474)\end{array}$ & $\begin{array}{c}1.384 \\
(1.443)\end{array}$ & $\begin{array}{c}2.201 \\
(1.346)\end{array}$ \\
\hline 6 Next Day x Treatment HH & $\begin{array}{c}1.879 \\
(1.249)\end{array}$ & $\begin{array}{c}1.145 \\
(1.154)\end{array}$ & $\begin{array}{c}0.711 \\
(1.136)\end{array}$ & $\begin{array}{c}0.719 \\
(1.091)\end{array}$ & $\begin{array}{c}0.872 \\
(1.000)\end{array}$ \\
\hline 7 Next Day x Treatment HH & $\begin{array}{c}0.815 \\
(1.161)\end{array}$ & $\begin{array}{c}-0.557 \\
(1.136)\end{array}$ & $\begin{array}{c}-0.405 \\
(1.037)\end{array}$ & $\begin{array}{c}-0.281 \\
(0.979)\end{array}$ & $\begin{array}{c}0.367 \\
(0.856)\end{array}$ \\
\hline 1 Prior Day x Treatment HH & $\begin{array}{c}-0.957 \\
(1.360)\end{array}$ & $\begin{array}{c}-1.713 \\
(1.248)\end{array}$ & $\begin{array}{c}-1.451 \\
(1.106)\end{array}$ & $\begin{array}{c}-0.935 \\
(1.040)\end{array}$ & $\begin{array}{l}-0.517 \\
(0.874)\end{array}$ \\
\hline 2 Prior Day x Treatment HH & $\begin{array}{c}0.852 \\
(1.486)\end{array}$ & $\begin{array}{c}1.951 \\
(1.326)\end{array}$ & $\begin{array}{c}1.332 \\
(1.322)\end{array}$ & $\begin{array}{l}1.018 \\
(1.319)\end{array}$ & $\begin{array}{c}1.772 \\
(1.224)\end{array}$ \\
\hline 3 Prior Day x Treatment HH & $\begin{array}{l}-1.451 \\
(1.900)\end{array}$ & $\begin{array}{l}-1.906 \\
(1.544)\end{array}$ & $\begin{array}{r}-2.077 \\
(1.440)\end{array}$ & $\begin{array}{l}-1.656 \\
(1.377)\end{array}$ & $\begin{array}{r}-1.469 \\
(1.236)\end{array}$ \\
\hline Household Fixed Effects & $\mathrm{Y}$ & Y & Y & Y & $\mathrm{Y}$ \\
\hline Day Fixed Effects & Y & Y & Y & Y & $\mathrm{Y}$ \\
\hline Observations & 3,532 & 5,103 & 6,716 & 7,988 & 29,842 \\
\hline R-squared & 0.696 & 0.689 & 0.698 & 0.700 & 0.708 \\
\hline Adjusted R-squared & 0.683 & 0.678 & 0.688 & 0.690 & 0.699 \\
\hline Caliper & 1 & 1 & 1 & 1 & 1 \\
\hline Neighbors & 1 & 2 & 3 & 4 & all \\
\hline
\end{tabular}


Table 3. Treatment Effect of Lessons 1, 2, and 3

\begin{tabular}{|c|c|c|c|}
\hline DV = Daily Load [kWh] & $(1)$ & $(2)$ & $(3)$ \\
\hline Lesson Day x Treatment HH & $\begin{array}{l}-2.463 * \\
(1.479)\end{array}$ & $\begin{array}{l}-0.0134 \\
(1.326)\end{array}$ & $\begin{array}{r}-0.404 \\
(1.062)\end{array}$ \\
\hline 1 Next Day x Treatment HH & $\begin{array}{r}-0.334 \\
(1.121)\end{array}$ & $\begin{array}{r}-0.456 \\
(1.392)\end{array}$ & $\begin{array}{c}0.102 \\
(0.927)\end{array}$ \\
\hline 2 Next Day x Treatment HH & $\begin{array}{c}2.495 * * \\
(1.175)\end{array}$ & $\begin{array}{c}-0.232 \\
(1.229)\end{array}$ & $\begin{array}{r}-0.538 \\
(1.080)\end{array}$ \\
\hline 3 Next Day x Treatment HH & $\begin{array}{r}-1.469 \\
(1.057)\end{array}$ & $\begin{array}{c}-0.512 \\
(1.191)\end{array}$ & $\begin{array}{c}2.481 * * \\
(1.176)\end{array}$ \\
\hline 4 Next Day x Treatment HH & $\begin{array}{c}0.175 \\
(1.242)\end{array}$ & $\begin{array}{c}1.309 \\
(1.381)\end{array}$ & $\begin{array}{c}3.452 * * * \\
(1.272)\end{array}$ \\
\hline 5 Next Day x Treatment HH & $\begin{array}{c}2.207 \\
(1.538)\end{array}$ & $\begin{array}{c}-0.443 \\
(1.374)\end{array}$ & $\begin{array}{c}2.762 * * \\
(1.110)\end{array}$ \\
\hline 6 Next Day x Treatment HH & $\begin{array}{c}1.145 \\
(1.154)\end{array}$ & $\begin{array}{l}-1.771 \\
(1.584)\end{array}$ & $\begin{array}{r}-0.454 \\
(0.887)\end{array}$ \\
\hline 7 Next Day x Treatment HH & $\begin{array}{c}-0.557 \\
(1.136)\end{array}$ & $\begin{array}{l}-1.543 \\
(1.525)\end{array}$ & $\begin{array}{c}0.364 \\
(0.834)\end{array}$ \\
\hline 1 Prior Day x Treatment HH & $\begin{array}{r}-1.713 \\
(1.248)\end{array}$ & $\begin{array}{c}-0.288 \\
(1.205)\end{array}$ & $\begin{array}{r}-1.456 \\
(1.263)\end{array}$ \\
\hline 2 Prior Day x Treatment HH & $\begin{array}{c}1.951 \\
(1.326)\end{array}$ & $\begin{array}{c}1.677 \\
(1.341)\end{array}$ & $\begin{array}{c}1.509 \\
(1.138)\end{array}$ \\
\hline 3 Prior Day x Treatment HH & $\begin{array}{r}-1.906 \\
(1.544)\end{array}$ & $\begin{array}{c}0.257 \\
(1.280)\end{array}$ & $\begin{array}{r}-0.263 \\
(1.234)\end{array}$ \\
\hline Household Fixed Effects & Y & $\mathrm{Y}$ & Y \\
\hline Day Fixed Effects & $\mathrm{Y}$ & $\mathrm{Y}$ & $\mathrm{Y}$ \\
\hline Observations & 5,103 & 5,403 & 5,219 \\
\hline R-squared & 0.689 & 0.739 & 0.767 \\
\hline Adjusted R-squared & 0.678 & 0.730 & 0.758 \\
\hline \multicolumn{4}{|c|}{$\begin{array}{l}\text { Notes: Dependent variable is mean daily load for thirty days prior to each lesson, the } \\
\text { day of the lesson, and seven days following the lesson. Each column corresponds to a } \\
\text { lesson. Lesson } 1 \text { (column } 1 \text { ) occurred on } 10 / 27 / 2015 \text {. Lesson } 2 \text { (column } 2 \text { ) occurred } \\
\text { on } 1 / 12 / 2016 \text {. Lesson } 3 \text { (column } 3 \text { ) occurred on } 5 / 10 / 2016 \text {. The control group is } \\
\text { constructed by matching on mean daily load for thiry days prior to the lesson using } \\
\text { two nearest neighbors subject to a caliper of } 1 \mathrm{kWh} / \text { day. Errors are clustered at the } \\
\text { household level. *, } * * \text {, and } * * * \text { indicate significance at the } 10 \%, 5 \% \text {, and } 1 \% \text { levels. }\end{array}$} \\
\hline
\end{tabular}


Table 4. Heterogeneity in Treatment Effect of Lesson 1

\begin{tabular}{|c|c|c|c|c|c|}
\hline $\mathrm{DV}=$ Daily Load [kWh] & $\begin{array}{c}(1) \\
\text { Above } \\
\text { Median } \\
\text { Consumption }\end{array}$ & $\begin{array}{c}(2) \\
\text { Above } \\
\text { Median } \\
\text { Value }\end{array}$ & $\begin{array}{c}\text { (3) } \\
\text { Above } \\
\text { Median } \\
\text { Gross Area }\end{array}$ & $\begin{array}{c}(4) \\
\text { Construction } \\
\text { Newer than } \\
1955\end{array}$ & $\begin{array}{l}\text { More than } \\
3 \text { Bedrooms }\end{array}$ \\
\hline Lesson Day x Treatment HH & $\begin{array}{l}-0.760 \\
(1.247)\end{array}$ & $\begin{array}{l}-2.468 \\
(2.108)\end{array}$ & $\begin{array}{r}-0.341 \\
(1.244)\end{array}$ & $\begin{array}{l}-2.763 \\
(2.585)\end{array}$ & $\begin{array}{l}-1.769 \\
(2.044)\end{array}$ \\
\hline $\begin{array}{l}\text { Lesson Day x Treatment HH } \\
\text { x Characteristic }\end{array}$ & $\begin{array}{l}-4.825 \\
(3.325)\end{array}$ & $\begin{array}{c}0.454 \\
(3.701)\end{array}$ & $\begin{array}{l}-4.087 \\
(3.653)\end{array}$ & $\begin{array}{l}1.296 \\
(3.510)\end{array}$ & $\begin{array}{l}-1.634 \\
(4.711)\end{array}$ \\
\hline Household Fixed Effects & $\mathrm{Y}$ & $\bar{Y}$ & $\bar{Y}$ & $\bar{Y}$ & $\bar{Y}$ \\
\hline Day Fixed Effects & $\mathrm{Y}$ & Y & Y & $\mathrm{Y}$ & $\mathrm{Y}$ \\
\hline Day x Characteristic FE & $\mathrm{Y}$ & Y & $\mathrm{Y}$ & $\mathrm{Y}$ & $\mathrm{Y}$ \\
\hline Observations & 5,103 & 3,681 & 3,681 & 3,681 & 3,681 \\
\hline R-squared & 0.694 & 0.657 & 0.656 & 0.656 & 0.656 \\
\hline Adjusted R-squared & 0.681 & 0.640 & 0.639 & 0.639 & 0.639 \\
\hline \multicolumn{6}{|c|}{$\begin{array}{l}\text { Notes: Dependent variable is mean daily load for thirty days prior to the lesson, the day of the lesson, and seven days } \\
\text { following the lesson. Each column explores heterogenetiy in the treatment effect by some characteristic, a binary } \\
\text { variable equal to one if the household is above (treatment group) median for that characteristic. Median consumption }= \\
24.5 \mathrm{kWh} / \text { day averaged over all days prior to the first lesson. Median assessed house value }=\$ 186,690 \text {. Median gross } \\
\text { area }=3,274 \text { square feet. Median year of construction }=1955 \text {. Median number of bedrooms }=3 \text { bedrooms. The control } \\
\text { group is constructed by matching on mean daily load for thiry days prior to the lesson using two nearest neighbors } \\
\text { subject to a caliper of } 1 \mathrm{kWh} / \text { day. Errors are clustered at the household level. } *, * * \text { and } * * * \text { indicate significance at the } \\
10 \%, 5 \% \text {, and } 1 \% \text { levels. }\end{array}$} \\
\hline
\end{tabular}




\section{Appendix}

Phantom Power: Kill-a-Watt Activity Instructions for Students

Name:

\section{KILL-A-WATT ACTIVITY}

Part 1:

OBJECTIVE

By the end of this lesson, students will be able to:

- Determine the number of watts an electrical device uses.

\section{MATERIALS / EQUIPMENT}

- Variety of household electric devices including devices that have a "stand by" power feature and others that have on/off switches. Use electrical devices such as computers, printers, speakers, pencil sharpeners, desk lamps, vacuum cleaners, power chair charger, camera charger, cordless drill charger, fan, coffee maker, digital clock, cell phone charger,

- Power strips

- Extension cords

- Kill-A-Watt meters (* two versions now available: regular and EZ)

- Optional: electric bill

TIME: 30 minutes

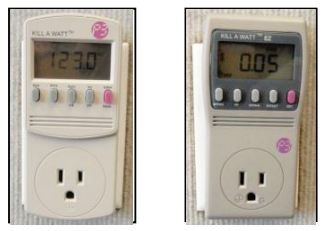

\section{PROCEDURE}

1. Look at the appliances and predict which device you think needs the most power and why.

Watts: The amount of energy a device uses in performing its function; the SI derived unit used to measure power, equal to one joule per second. In electricity, a watt is equal to current (in amperes) multiplied by voltage (in volts).

NOTE: Pay attention to the instructions for using the Kill-A-Watt meter and the safety warning about using electricity.

2. Follow your teacher's directions as to which appliance to begin your testing.

3. Attach the Kill-A-Watt meter as instructed.

4. Turn the appliance on and allow it to run for one minute.

5. Record the number of watts drawn by the appliance.

6. Which device recorded the most number of watts?

7. Which device used the lowest wattage?

8. Why do you think the results were as recorded?

9. Was your prediction correct?

10. Share your findings in the class discussion. 
Table 1A. Treatment Effect of Lesson 1

\begin{tabular}{|c|c|c|}
\hline$\overline{\mathrm{DV}}=$ Daily Load [kWh] & $(1)$ & $(2)$ \\
\hline Treatment HH & $\begin{array}{c}7.894 * * * \\
(1.993)\end{array}$ & \\
\hline Lesson Day & $\begin{array}{c}0.797 * * * \\
(0.275)\end{array}$ & \\
\hline Lesson Day x Treatment HH & $\begin{array}{c}-3.324 * * \\
(1.492)\end{array}$ & $\begin{array}{c}-2.147 * * \\
(0.966)\end{array}$ \\
\hline 1 Next Day x Treatment HH & $\begin{array}{c}-1.513^{*} \\
(0.818)\end{array}$ & $\begin{array}{l}-1.161 \\
(0.817)\end{array}$ \\
\hline 2 Next Day x Treatment HH & $\begin{array}{l}-0.329 \\
(1.016)\end{array}$ & $\begin{array}{c}1.079 \\
(0.957)\end{array}$ \\
\hline 3 Next Day x Treatment HH & $\begin{array}{c}-1.964 * * \\
(0.950)\end{array}$ & $\begin{array}{c}-1.900 * * \\
(0.841)\end{array}$ \\
\hline 4 Next Day x Treatment HH & $\begin{array}{c}-0.572 \\
(1.186)\end{array}$ & $\begin{array}{r}-0.806 \\
(1.037)\end{array}$ \\
\hline 5 Next Day x Treatment HH & $\begin{array}{l}2.525^{*} \\
(1.401)\end{array}$ & $\begin{array}{c}2.078 \\
(1.333)\end{array}$ \\
\hline 6 Next Day x Treatment HH & $\begin{array}{l}-0.0175 \\
(1.301)\end{array}$ & $\begin{array}{c}0.136 \\
(1.159)\end{array}$ \\
\hline 7 Next Day x Treatment HH & $\begin{array}{r}-0.476 \\
(0.965)\end{array}$ & $\begin{array}{l}0.0258 \\
(0.874)\end{array}$ \\
\hline 1 Prior Day x Treatment HH & $\begin{array}{l}-1.061 \\
(0.960)\end{array}$ & $\begin{array}{c}-0.791 \\
(0.909)\end{array}$ \\
\hline 2 Prior Day x Treatment HH & $\begin{array}{c}1.163 \\
(1.258)\end{array}$ & $\begin{array}{c}1.718 \\
(1.241)\end{array}$ \\
\hline 3 Prior Day x Treatment HH & $\begin{array}{l}-2.517^{*} \\
(1.451)\end{array}$ & $\begin{array}{l}-1.974 \\
(1.417)\end{array}$ \\
\hline $\begin{array}{l}\text { Household Fixed Effects } \\
\text { Dav Fixed Effects }\end{array}$ & $\begin{array}{l}\mathrm{N} \\
\mathrm{N}\end{array}$ & $\begin{array}{l}\mathrm{Y} \\
\mathrm{Y}\end{array}$ \\
\hline Observations & 36,819 & 36,819 \\
\hline R-squared & 0.0132 & 0.850 \\
\hline Adjusted R-squared & 0.013 & 0.845 \\
\hline \multicolumn{3}{|c|}{$\begin{array}{l}\text { Notes: Dependent variable is mean daily load for } \mathrm{N}=49 \text { treatment } \\
\text { households and } \mathrm{N}=932 \text { control households } 9 / 26 / 2015-11 / 3 / 2015 \text {. } \\
\text { Column } 1 \text { uses a differences-in-differences model while Column } 2 \\
\text { adds household and day fixed effects. Errors are clustered at the } \\
\text { household level. } *, * * \text {, and } * * * \text { indicate significance at the } 10 \% \text {, } \\
5 \% \text {, and } 1 \% \text { levels. }\end{array}$} \\
\hline
\end{tabular}


Figure 1A. Treatment effect over time

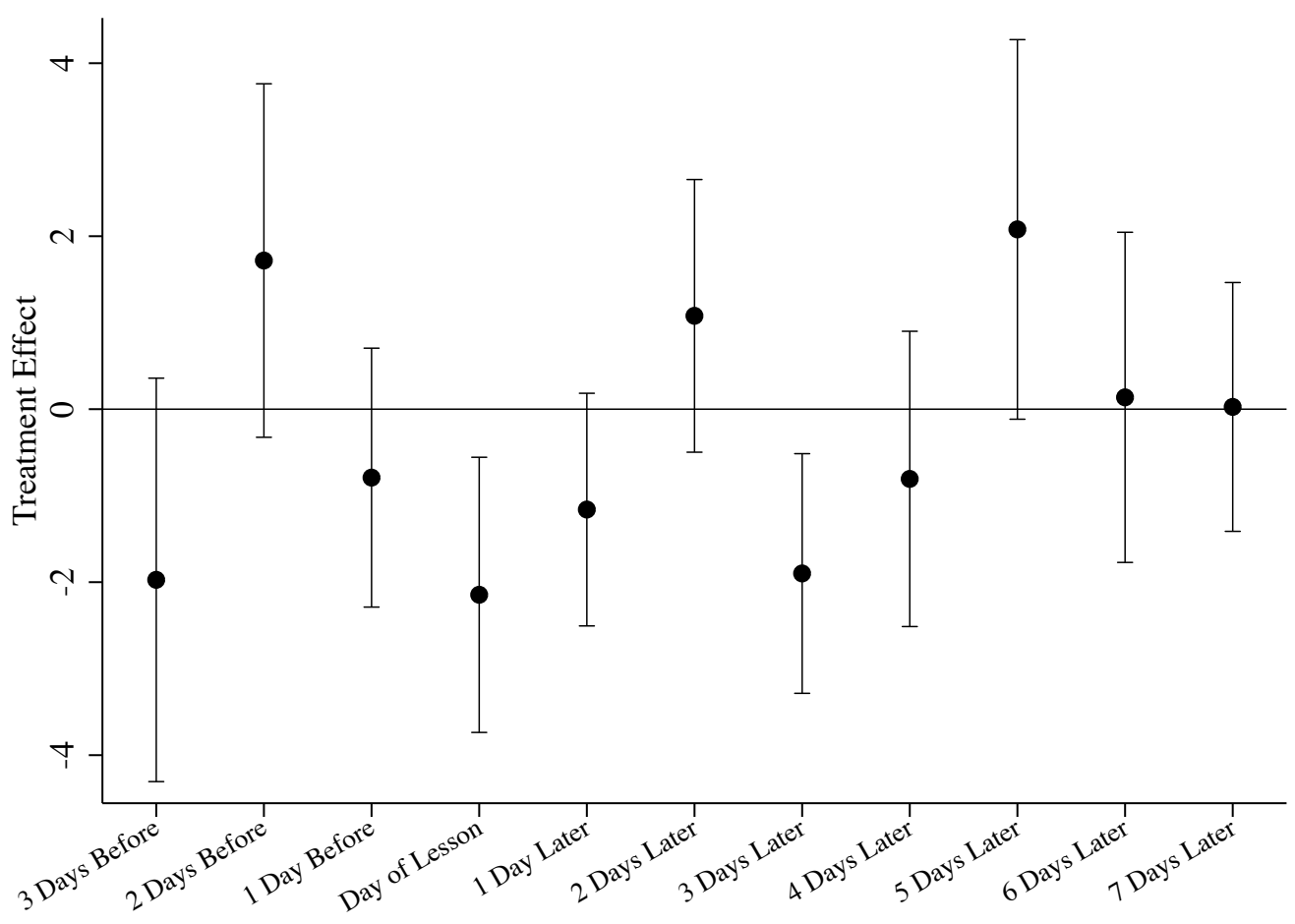

Notes: Figure plots coefficient estimates for three days prior to the date of lesson 1, the day of the lesson, and the seven days following the lesson. This figure illustrates results in Column 2 of Table 1A. Error bars indicate the $90 \%$ confidence interval around the point estimate. 
Table 2A. Treatment Effect of Lesson 2

\begin{tabular}{|c|c|c|c|c|c|}
\hline DV = Daily Load [kWh] & $(1)$ & $(2)$ & $(3)$ & $(4)$ & $(5)$ \\
\hline Lesson Day x Treatment HH & $\begin{array}{l}-0.105 \\
(1.795)\end{array}$ & $\begin{array}{l}-0.0134 \\
(1.326)\end{array}$ & $\begin{array}{c}-0.939 \\
(1.181)\end{array}$ & $\begin{array}{l}-1.441 \\
(1.138)\end{array}$ & $\begin{array}{l}-1.045 \\
(0.948)\end{array}$ \\
\hline 1 Next Day x Treatment HH & $\begin{array}{c}0.117 \\
(1.795)\end{array}$ & $\begin{array}{l}-0.456 \\
(1.392)\end{array}$ & $\begin{array}{c}-0.990 \\
(1.306)\end{array}$ & $\begin{array}{c}-0.964 \\
(1.236)\end{array}$ & $\begin{array}{c}-1.011 \\
(1.083)\end{array}$ \\
\hline 2 Next Day x Treatment HH & $\begin{array}{l}0.0501 \\
(1.641)\end{array}$ & $\begin{array}{c}-0.232 \\
(1.229)\end{array}$ & $\begin{array}{c}-0.433 \\
(1.136)\end{array}$ & $\begin{array}{r}-0.560 \\
(1.079)\end{array}$ & $\begin{array}{r}-0.414 \\
(0.904)\end{array}$ \\
\hline 3 Next Day x Treatment HH & $\begin{array}{c}-0.192 \\
(1.608)\end{array}$ & $\begin{array}{c}-0.512 \\
(1.191)\end{array}$ & $\begin{array}{l}-1.025 \\
(1.095)\end{array}$ & $\begin{array}{l}-1.978^{*} \\
(1.083)\end{array}$ & $\begin{array}{c}-1.786 * * \\
(0.886)\end{array}$ \\
\hline 4 Next Day x Treatment HH & $\begin{array}{c}0.959 \\
(1.954)\end{array}$ & $\begin{array}{c}1.309 \\
(1.381)\end{array}$ & $\begin{array}{c}1.316 \\
(1.208)\end{array}$ & $\begin{array}{c}0.527 \\
(1.208)\end{array}$ & $\begin{array}{c}-0.136 \\
(0.958)\end{array}$ \\
\hline 5 Next Day x Treatment HH & $\begin{array}{r}-0.156 \\
(1.757)\end{array}$ & $\begin{array}{c}-0.443 \\
(1.374)\end{array}$ & $\begin{array}{c}-0.772 \\
(1.269)\end{array}$ & $\begin{array}{c}-1.503 \\
(1.228)\end{array}$ & $\begin{array}{l}-1.576 \\
(1.058)\end{array}$ \\
\hline 6 Next Day x Treatment HH & $\begin{array}{l}-2.216 \\
(1.939)\end{array}$ & $\begin{array}{l}-1.771 \\
(1.584)\end{array}$ & $\begin{array}{l}-2.515^{*} \\
(1.467)\end{array}$ & $\begin{array}{c}-2.746^{* *} \\
(1.378)\end{array}$ & $\begin{array}{l}-1.705 \\
(1.194)\end{array}$ \\
\hline 7 Next Day x Treatment HH & $\begin{array}{l}-1.218 \\
(1.935)\end{array}$ & $\begin{array}{l}-1.543 \\
(1.525)\end{array}$ & $\begin{array}{l}-2.258 \\
(1.396)\end{array}$ & $\begin{array}{l}-2.577 * \\
(1.366)\end{array}$ & $\begin{array}{l}-2.188^{*} \\
(1.217)\end{array}$ \\
\hline 1 Prior Day x Treatment HH & $\begin{array}{c}-0.195 \\
(1.486)\end{array}$ & $\begin{array}{c}-0.288 \\
(1.205)\end{array}$ & $\begin{array}{c}-0.307 \\
(1.097)\end{array}$ & $\begin{array}{c}-0.544 \\
(1.051)\end{array}$ & $\begin{array}{l}-0.610 \\
(0.927)\end{array}$ \\
\hline 2 Prior Day x Treatment HH & $\begin{array}{l}1.588 \\
(1.587)\end{array}$ & $\begin{array}{c}1.677 \\
(1.341)\end{array}$ & $\begin{array}{c}1.680 \\
(1.273)\end{array}$ & $\begin{array}{l}1.050 \\
(1.247)\end{array}$ & $\begin{array}{c}1.415 \\
(1.112)\end{array}$ \\
\hline 3 Prior Day x Treatment HH & $\begin{array}{c}0.201 \\
(1.308)\end{array}$ & $\begin{array}{c}0.257 \\
(1.280)\end{array}$ & $\begin{array}{c}0.357 \\
(1.223)\end{array}$ & $\begin{array}{c}0.228 \\
(1.199)\end{array}$ & $\begin{array}{c}0.223 \\
(1.126)\end{array}$ \\
\hline Household Fixed Effects & Y & Y & Y & $\mathrm{Y}$ & $\mathrm{Y}$ \\
\hline Day Fixed Effects & $\mathrm{Y}$ & $\mathrm{Y}$ & $\mathrm{Y}$ & $\mathrm{Y}$ & $\mathrm{Y}$ \\
\hline Observations & 3,744 & 5,403 & 6,948 & 8,500 & 28,536 \\
\hline R-squared & 0.746 & 0.739 & 0.725 & 0.717 & 0.694 \\
\hline Adjusted R-squared & 0.736 & 0.730 & 0.716 & 0.708 & 0.685 \\
\hline Caliper & 1 & 1 & 1 & 1 & 1 \\
\hline Neighbors & 1 & 2 & 3 & 4 & all \\
\hline
\end{tabular}

Notes: Dependent variable is mean daily load 12/11/2015-1/19/2016. The treatment group contains N=48 households. The control group is constructed by matching on mean daily load for 12/11/15-1/11/2016. Each column uses a different number of nearest neighbors, all subject to a caliper of $1 \mathrm{kWh} /$ day. Errors are clustered at the household level. $* * *$, and $* * *$ indicate significance at the $10 \%, 5 \%$, and $1 \%$ levels. 
Table 3A. Treatment Effect of Lesson 3

\begin{tabular}{|c|c|c|c|c|c|}
\hline DV = Daily Load [kWh] & $(1)$ & $(2)$ & (3) & $(4)$ & $(5)$ \\
\hline Lesson Day x Treatment HH & $\begin{array}{c}0.681 \\
(1.191)\end{array}$ & $\begin{array}{c}-0.404 \\
(1.062)\end{array}$ & $\begin{array}{c}-0.448 \\
(1.004)\end{array}$ & $\begin{array}{c}-0.438 \\
(0.999)\end{array}$ & $\begin{array}{l}-1.149 \\
(0.908)\end{array}$ \\
\hline 1 Next Day x Treatment HH & $\begin{array}{c}0.514 \\
(1.135)\end{array}$ & $\begin{array}{c}0.102 \\
(0.927)\end{array}$ & $\begin{array}{c}0.254 \\
(0.858)\end{array}$ & $\begin{array}{c}0.704 \\
(0.850)\end{array}$ & $\begin{array}{c}0.378 \\
(0.724)\end{array}$ \\
\hline 2 Next Day x Treatment HH & $\begin{array}{l}-0.0970 \\
(1.308)\end{array}$ & $\begin{array}{c}-0.538 \\
(1.080)\end{array}$ & $\begin{array}{r}-0.350 \\
(1.033)\end{array}$ & $\begin{array}{r}-0.107 \\
(1.019)\end{array}$ & $\begin{array}{r}-0.310 \\
(0.871)\end{array}$ \\
\hline 3 Next Day x Treatment HH & $\begin{array}{c}2.882^{* *} \\
(1.247)\end{array}$ & $\begin{array}{c}2.481^{* *} \\
(1.176)\end{array}$ & $\begin{array}{c}2.496^{* *} \\
(1.118)\end{array}$ & $\begin{array}{c}2.535^{* *} \\
(1.139)\end{array}$ & $\begin{array}{c}2.103^{* *} \\
(1.042)\end{array}$ \\
\hline 4 Next Day x Treatment HH & $\begin{array}{c}3.726^{* *} \\
(1.515)\end{array}$ & $\begin{array}{c}3.452 * * * \\
(1.272)\end{array}$ & $\begin{array}{c}3.405^{* * *} \\
(1.151)\end{array}$ & $\begin{array}{c}3.564 * * * \\
(1.124)\end{array}$ & $\begin{array}{c}3.630^{* * * *} \\
(0.924)\end{array}$ \\
\hline 5 Next Day x Treatment HH & $\begin{array}{c}4.089 * * * \\
(1.198)\end{array}$ & $\begin{array}{c}2.762^{* *} \\
(1.110)\end{array}$ & $\begin{array}{c}3.060 * * * \\
(1.039)\end{array}$ & $\begin{array}{c}2.402 * * \\
(1.024)\end{array}$ & $\begin{array}{c}2.065^{* *} \\
(0.881)\end{array}$ \\
\hline 6 Next Day x Treatment HH & $\begin{array}{r}-0.179 \\
(0.841)\end{array}$ & $\begin{array}{c}-0.454 \\
(0.887)\end{array}$ & $\begin{array}{c}-0.188 \\
(0.842)\end{array}$ & $\begin{array}{c}-0.498 \\
(0.832)\end{array}$ & $\begin{array}{c}-0.865 \\
(0.749)\end{array}$ \\
\hline 7 Next Day x Treatment HH & $\begin{array}{c}0.863 \\
(0.968)\end{array}$ & $\begin{array}{c}0.364 \\
(0.834)\end{array}$ & $\begin{array}{c}0.431 \\
(0.776)\end{array}$ & $\begin{array}{c}0.553 \\
(0.758)\end{array}$ & $\begin{array}{c}0.322 \\
(0.652)\end{array}$ \\
\hline 1 Prior Day x Treatment HH & $\begin{array}{c}0.467 \\
(1.005)\end{array}$ & $\begin{array}{l}-1.456 \\
(1.263)\end{array}$ & $\begin{array}{c}-0.821 \\
(1.090)\end{array}$ & $\begin{array}{r}-0.790 \\
(1.019)\end{array}$ & $\begin{array}{c}-0.909 \\
(0.798)\end{array}$ \\
\hline 2 Prior Day x Treatment HH & $\begin{array}{l}2.431^{*} \\
(1.245)\end{array}$ & $\begin{array}{c}1.509 \\
(1.138)\end{array}$ & $\begin{array}{c}1.290 \\
(1.065)\end{array}$ & $\begin{array}{c}1.204 \\
(1.048)\end{array}$ & $\begin{array}{c}1.345 \\
(0.920)\end{array}$ \\
\hline 3 Prior Day x Treatment HH & $\begin{array}{c}0.161 \\
(1.437)\end{array}$ & $\begin{array}{c}-0.263 \\
(1.234)\end{array}$ & $\begin{array}{c}-0.134 \\
(1.161)\end{array}$ & $\begin{array}{c}0.233 \\
(1.138)\end{array}$ & $\begin{array}{c}1.379 \\
(1.035)\end{array}$ \\
\hline Household Fixed Effects & $\mathrm{Y}$ & Y & Y & Y & $\mathrm{Y}$ \\
\hline Day Fixed Effects & Y & Y & $\mathrm{Y}$ & Y & $\mathrm{Y}$ \\
\hline Observations & 3,609 & 5,219 & 6,708 & 7,907 & 32,066 \\
\hline R-squared & 0.789 & 0.767 & 0.760 & 0.745 & 0.739 \\
\hline Adjusted R-squared & 0.781 & 0.758 & 0.752 & 0.737 & 0.732 \\
\hline Caliper & 1 & 1 & 1 & 1 & 1 \\
\hline Neighbors & 1 & 2 & 3 & 4 & all \\
\hline
\end{tabular}


Table 4A. Heterogeneity in Treatment Effect of Lesson 2

\begin{tabular}{|c|c|c|c|c|c|}
\hline $\mathrm{DV}=$ Daily Load [kWh] & $\begin{array}{c}(1) \\
\text { Above } \\
\text { Median } \\
\text { Consumption }\end{array}$ & $\begin{array}{c}(2) \\
\text { Above } \\
\text { Median } \\
\text { Value }\end{array}$ & $\begin{array}{c}(3) \\
\text { Above } \\
\text { Median } \\
\text { Gross Area }\end{array}$ & $\begin{array}{c}(4) \\
\text { Construction } \\
\text { Newer than } \\
1955\end{array}$ & $\begin{array}{l}\text { More than } \\
3 \text { Bedrooms }\end{array}$ \\
\hline Lesson Day x Treatment HH & $\begin{array}{l}-1.543 \\
(1.496)\end{array}$ & $\begin{array}{l}-0.470 \\
(2.772)\end{array}$ & $\begin{array}{l}-6.627 * * * \\
(1.472)\end{array}$ & $\begin{array}{l}-2.111 \\
(2.532)\end{array}$ & $\begin{array}{l}-2.207 \\
(2.045)\end{array}$ \\
\hline $\begin{array}{l}\text { Lesson Day x Treatment HH } \\
\text { x Characteristic }\end{array}$ & $\begin{array}{c}3.821 \\
(2.563)\end{array}$ & $\begin{array}{l}-1.073 \\
(3.618)\end{array}$ & $\begin{array}{l}5.712 * * \\
(2.483)\end{array}$ & $\begin{array}{c}2.555 \\
(3.258)\end{array}$ & $\begin{array}{c}4.780 \\
(3.573)\end{array}$ \\
\hline Household Fixed Effects & $\mathrm{Y}$ & $\bar{Y}$ & $\bar{Y}$ & $\bar{Y}$ & $\bar{Y}$ \\
\hline Day Fixed Effects & $\mathrm{Y}$ & Y & Y & $\mathrm{Y}$ & $\mathrm{Y}$ \\
\hline Day x Characteristic FE & $\mathrm{Y}$ & $\mathrm{Y}$ & $\mathrm{Y}$ & $\mathrm{Y}$ & $\mathrm{Y}$ \\
\hline Observations & 5,403 & 2,030 & 2,030 & 2,030 & 2,030 \\
\hline R-squared & 0.746 & 0.728 & 0.727 & 0.724 & 0.726 \\
\hline Adjusted R-squared & 0.735 & 0.709 & 0.708 & 0.706 & 0.707 \\
\hline \multicolumn{6}{|c|}{$\begin{array}{l}\text { Notes: Dependent variable is mean daily load for thirty days prior to the lesson, the day of the lesson, and seven days } \\
\text { following the lesson. Each column explores heterogenetiy in the treatment effect by some characteristic, a binary } \\
\text { variable equal to one if the household is above (treatment group) median for that characteristic. Median consumption }= \\
24.5 \mathrm{kWh} / \text { day averaged over all days prior to the first lesson. Median assessed house value }=\$ 186,690 \text {. Median gross } \\
\text { area }=3,274 \text { square feet. Median year of construction }=1955 \text {. Median number of bedrooms }=3 \text { bedrooms. The control } \\
\text { group is constructed by matching on mean daily load for thiry days prior to the lesson using two nearest neighbors } \\
\text { subject to a caliper of } 1 \mathrm{kWh} / \text { day. Errors are clustered at the household level. } *, * * \text { and } * * * \text { indicate significance at the } \\
10 \%, 5 \% \text {, and } 1 \% \text { levels. }\end{array}$} \\
\hline
\end{tabular}


Table 5A. Heterogeneity in Treatment Effect of Lesson 3

\begin{tabular}{|c|c|c|c|c|c|}
\hline $\mathrm{DV}=$ Daily Load [kWh] & $\begin{array}{c}(1) \\
\text { Above } \\
\text { Median } \\
\text { Consumption }\end{array}$ & $\begin{array}{c}(2) \\
\text { Above } \\
\text { Median } \\
\text { Value }\end{array}$ & $\begin{array}{c}\text { (3) } \\
\text { Above } \\
\text { Median } \\
\text { Gross Area }\end{array}$ & $\begin{array}{c}(4) \\
\text { Construction } \\
\text { Newer than } \\
1955\end{array}$ & $\begin{array}{l}\text { More than } \\
3 \text { Bedrooms }\end{array}$ \\
\hline Lesson Day x Treatment HH & $\begin{array}{c}0.527 \\
(0.880)\end{array}$ & $\begin{array}{r}-2.033 \\
(3.060)\end{array}$ & $\begin{array}{r}-2.166 \\
(3.046)\end{array}$ & $\begin{array}{l}-5.562 * * \\
(2.710)\end{array}$ & $\begin{array}{l}-2.280 \\
(2.396)\end{array}$ \\
\hline $\begin{array}{l}\text { Lesson Day x Treatment HH } \\
\text { x Characteristic }\end{array}$ & $\begin{array}{l}-3.925 \\
(2.652)\end{array}$ & $\begin{array}{l}-2.181 \\
(3.533)\end{array}$ & $\begin{array}{l}-1.688 \\
(3.625)\end{array}$ & $\begin{array}{c}4.320 \\
(3.060)\end{array}$ & $\begin{array}{l}-2.453 \\
(2.950)\end{array}$ \\
\hline Household Fixed Effects & $\mathrm{Y}$ & $\bar{Y}$ & $\bar{Y}$ & $\bar{Y}$ & $\mathrm{Y}$ \\
\hline Day Fixed Effects & $\mathrm{Y}$ & Y & Y & $\mathrm{Y}$ & $\mathrm{Y}$ \\
\hline Day x Characteristic FE & $\mathrm{Y}$ & $\mathrm{Y}$ & $\mathrm{Y}$ & $\mathrm{Y}$ & $\mathrm{Y}$ \\
\hline Observations & 5,219 & 1,907 & 1,907 & 1,907 & 1,907 \\
\hline R-squared & 0.774 & 0.711 & 0.712 & 0.714 & 0.711 \\
\hline Adjusted R-squared & 0.765 & 0.690 & 0.692 & 0.694 & 0.690 \\
\hline \multicolumn{6}{|c|}{$\begin{array}{l}\text { Notes: Dependent variable is mean daily load for thirty days prior to the lesson, the day of the lesson, and seven days } \\
\text { following the lesson. Each column explores heterogenetiy in the treatment effect by some characteristic, a binary } \\
\text { variable equal to one if the household is above (treatment group) median for that characteristic. Median consumption }= \\
24.5 \mathrm{kWh} / \text { day averaged over all days prior to the first lesson. Median assessed house value }=\$ 186,690 \text {. Median gross } \\
\text { area }=3,274 \text { square feet. Median year of construction }=1955 \text {. Median number of bedrooms }=3 \text { bedrooms. The control } \\
\text { group is constructed by matching on mean daily load for thiry days prior to the lesson using two nearest neighbors } \\
\text { subject to a caliper of } 1 \mathrm{kWh} / \text { day. Errors are clustered at the household level. } *, * * \text { and } * * * \text { indicate significance at the } \\
10 \%, 5 \% \text {, and } 1 \% \text { levels. }\end{array}$} \\
\hline
\end{tabular}


Manuscript $-\mathbf{3}$
Being prepared for submission to the Journal of Public Policy and Marketing

Matching costs to context:

Status quo bias, temporal framing, and household energy decisions

Carrie Gill, Stephen Atlas, and David Hardisty

Environmental and Natural Resource Economics, University of Rhode Island 


\begin{abstract}
One challenge of promoting energy-efficient behavior change is status quo bias: limiting energy use often requires sacrificing convenience and comfort now and in the future. Using experimental data with hypothetical scenarios, we explore what temporal frame (e.g. daily, monthly, or yearly) minimizes status quo bias and encourages energy-efficient intentions. Results suggest individuals are most willing to adopt energy-efficient behaviors when the cost savings are framed on a monthly basis, relative to daily and yearly frames. We investigate whether cognitive fluency - the perceived ease of processing information - could be an underlying mechanism. We find suggestive evidence that individuals are indeed most fluent with energy costs framed on a monthly basis, possibly because most individuals receive monthly energy bills. When individuals are faced with energy costs in relatively disfluent frames (daily and yearly), we find that energy efficiency intentions are greatest when given a context for total energy spending in a matching frame.
\end{abstract}

Keywords: Status Quo Bias, Temporal Framing, Energy Conservation, Energy Efficiency, Behavior Change 


\section{Introduction}

The US residential sector had a total consumption of 20,558 trillion Btu of energy in 2015, amounting to billions of dollars spent on household energy bills in addition to negative environmental and health externalities from conventional energy generation (EIA, 2017). Uptake of energy efficient technologies has been quite slow, in spite of the large savings available (the "energy paradox", Jaffe \& Stavins, 1994). One low-cost way to nudge more energy-efficient decisions is to make the costs and savings of energy choices more salient. Indeed, information about costs is becoming more prevalent (e.g. cost comparisons of CFL versus incandescent light bulbs on product packaging, and savings of energy-efficient alternatives for household decisions on utility electric bills) and consumer responses to energy labels have been studied for nearly four decades (e.g. McNeill \& Wilke, 1979). Yet there is substantial variation in how these costs and savings are presented (e.g. per day, per month, per year) and we lack a comprehensive framework to understand how individuals respond to this information.

With large potential for savings on energy bills and information about the costs of energy-inefficiency, why aren't individuals making more energy-efficient choices? For individuals who typically engage in energy-inefficient household habits and purchases, status quo bias could be a contributing factor towards energy consumption and persistent inefficiency (Samuelson \& Zeckhauser, 1988). For example, individuals were more likely to keep a contractor's arbitrary light bulb choice, despite zero switching cost and the potential for future monetary savings (Dinner et al., 2011). In addition, limiting energy use often requires sacrificing comfort or convenience, which may make behavior change difficult (Kahneman, Knetsch, \& Thaler, 1990). Emphasizing the costs of energy- 
inefficient choices and the benefits of energy efficiency may help overcome reluctance to energy-efficient behavior change (Novemsky \& Kahneman, 2005).

Our research explores which temporal frame (per day, per month, per year) for presenting the costs of energy decisions is optimal for promoting energy-efficient choices. We conduct four studies drawing from two online populations. Findings from hypothetical scenarios indicate that presenting monthly costs of energy-inefficient behaviors decreases the influence of status quo energy behaviors on energy efficiency intentions (Study 1). We hypothesize this is because individuals are most easily able to think about monthly costs relative to daily and yearly costs (Studies 2 and 3). We find that supplementing information about costs of energy inefficiency with explicit information about typical energy spending in a matching frame increases intentions to engage in energy efficiency relative to providing the same information in mismatching frames (Study 4). This research contributes to two bodies of literature. First, we show that ease of processing may present a boundary of status quo bias. Second, we contribute to the literature on choice architecture, specifically regarding household energy decisions. Recent literature has compared the effects of long-term temporal framing on energy efficient choices, and has generally found that longer timeframes that are within the lifecycle of the product are most effective. However, our findings show that the ease of processing information in a given temporal frame also plays a role in consumer choice.

We start with a literature review in Section 2. We describe choice architecture broadly and non-price strategies to encourage energy efficiency and conservation specifically. We turn to concepts from behavioral economics and marketing to give context to our research question. In light of these underpinnings, we formulate our 
hypotheses regarding how cost frames can affect status quo bias, cognitive fluency as a possible mechanism, and how we can operationalize costs and contexts to encourage energy efficiency in Section 3. Section 4 presents the results of the four studies in which we test our hypotheses. We first provide an overview of all studies and a description of the general experimental design. Within this section, we then present each study with specific details on methods, data, results, and discussion. We conclude with a general discussion of all four studies and implications for energy policy in Section 5.

\section{Literature Review}

The motivation for reducing energy use is clear: energy conservation can save households money on their electricity bills, reduce greenhouse gas emissions and mitigate climate change, and reduce pollution. Given the extent of energy consumption in the residential sector, encouraging household energy-efficient behavior change represents a significant strategy to conserve energy and mitigate externalities of electricity generation (Dietz et al., 2009). Economists, policy makers, and others have developed strategies to encourage energy efficiency ranging in degree of autonomy for the decision maker. For example, at one end of the spectrum are policies like residential direct load control where utility providers control the level of electricity consumption of household appliances, such as by set backs on air conditioning temperatures during hours of peak demand - and regulations that mandate certain levels of energy efficiency, such as fuel efficiency standards for cars, energy efficiency standards for appliances, or prohibition of energy-inefficient products like incandescent light bulbs. While such policies may be effective in reducing energy use, they take away autonomy from the individual. At the 
other end of the spectrum are nudges and non-price strategies that preserve individual freedom of choice while still encouraging energy efficient choices.

Any decision context is an opportunity to nudge individuals toward choices that are socially desirable, such as energy efficiency. Choice architecture is the framework for how to display choices to decision makers, including what content to present and how to present it (Johnson et al., 2012; Thaler et al., 2014). There is an emerging body of literature that provides evidence of the effects of choice architecture on decisions (see Johnson et al., 2012 for a review of choice architecture tools). While neoclassical microeconomic theory predicts individual choice is independent of how the choice is described, there is a vast body of literature documenting violations of descriptive invariance. Conditions of these violations inform choice architecture. For example, one prevalent tool of choice architecture is defaults. Johnson and Goldstein (2003) showed that individuals were more likely to be organ donors when defaulted into the program and allowed to opt out rather than having to actively opt into the program. Each individual is faced with the same alternatives - to be enrolled as an organ donor or to not be enrolled as an organ donor - but the way the decision is set up affects the end choice.

Policy makers have turned to concepts from choice architecture as a low-cost and politically feasible way to encourage pro-environmental behaviors without restricting the consumer's choice set. Within the larger context of measures to reduce energy consumption, choice architecture is a non-price strategy that fits alongside recommended behavioral interventions (Allcott \& Mullainathan, 2010), including peer comparisons (Allcott, 2011; Allcott \& Rogers, 2014), commitment devices and goal setting (Becker, 
1978; Harding \& Hsiaw, 2014), feedback (Jessoe \& Rapson, 2014; Carrico \& Riemer, 2011), and education (Agarwal et al., 2017; Gill \& Lang, 2017), among others.

Enacted in 1975, the Energy Policy and Conservation Act requires that new appliances be labeled with energy consumption information and new vehicles be labeled with information about fuel consumption. This information necessarily enters into the choice architecture of energy-consuming product purchase decisions and energy-related behavior decisions. Therefore, the way information about energy consumption and costs is presented affects individual choice. Over the years, these labels have been subject to criticism and redesign to improve ease of use and information communication. For example, Larrick and Soll (2008) highlight the difficulty in interpreting the miles per gallon figure in terms of fuel-efficient vehicle choices. The recently revised fuel economy labels (2013) additionally report gallons per hundred miles, two measures of fuel cost, and information about greenhouse gas emissions. These additional measures not only make information about comparative fuel use easier to access, but the number of measures add weight to the fuel attribute in consumer choice, provide a signpost to consider environmental preferences ${ }^{23}$, and provide a reference point against which to weigh attribute levels (Ungemach et al., 2014; Weber et al., 1988; Costa \& Kahn, 2013; Larrick et al., 2015). These labels provide otherwise missing information about energy consumption and cost to consumers, and remove one barrier to consumers considering this attribute in their decision-making process (Newell \& Siikimaki, 2014). By definition, information like energy labels is inherently subject to choice architecture, and decisions about what information to present and how to present it affect the consumer's choices. In

23 Though consumers may react differentially to the connection between pro-environmental preferences and fuel economy based on political ideology (Gromet et al., 2013). 
this paper, we seek to understand the role of temporal framing - over what time period energy-related costs and benefits are aggregated - in energy-related household choices.

Prior research has explored effects of temporal framing of energy costs in product evaluation, but there are some gaps in the literature that prevent comprehensive understanding of these effects (Kaenzig \& Wustenhagen, 2010). Most of this literature has focused on long-term temporal frames (per year or longer) and suggest that consumers put more weight on attributes whose levels are framed on longer terms (Larrick et al., 2015; Burson et al., 2009; Pandelaere et al., 2011; Kaenzig \& Wustenhagen, 2010). Hutton and Wilkie (1980) found increased purchase intentions for energy-efficient refrigerators when lifecycle cost information was provided more so than when annual cost information was provided. Similarly, Hardisty et al. (2014) find that providing 10-year energy costs generally encourages more energy-efficient choices than providing 1-year or 5-year costs. While long-term temporal frames make intuitive sense for durable goods, like vehicles and houses, unreasonably long frames may prompt the consumer to feel manipulated, be too abstract to fully comprehend, or be unreasonable timeframes to consider for behavior change or short-term decisions. For example, it may not make sense to the consumer to think of the cost savings of washing a load of laundry with cold water rather than hot water on a yearly or ten-yearly basis.

One notable study looks at shorter-term temporal frames. McNeill and Wilke (1979) found no differences in a set of measures regarding refrigerator evaluation when typical energy costs were framed in monthly versus yearly terms. In a study on preferences for fuel efficiency, Camilieri and Larrick (2014) find that providing information about fuel costs per 100 miles encouraged more fuel-efficient vehicle choices 
than when fuel costs were framed per 15,000 miles, and less efficient choices than a per 100,000 mile framing. In sum, the literature suggests that presenting energy costs on larger scales may be most effective at encouraging energy-efficient choices, but the findings are inconclusive for how individuals respond to smaller scales and suggest there may exist a nonlinearity in response.

\section{Conceptual Underpinnings and Hypotheses}

How we frame costs and savings influences how individuals perceive their choices. Since we are considering gains and losses with respect to individuals' budgets and changes in comfort and convenience, it is reasonable to look to prospect theory for inference on how to present the costs and savings of behavior change. Central to prospect theory is the concept of loss aversion: individuals dislike losses more than they like equivalent gains (Kahneman \& Tversky, 1979). Under the framework of prospect theory (Kahneman \& Tversky, 1979) and principles of hedonic editing (Thaler, 1985), individuals maximize utility by aggregating costs (pay \$y per year) and segregate savings (save \$x per day). This allows individuals to capitalize on the asymmetric shape of prospect theory's value function. However, other research suggests individuals have limited ability to cope with multiple losses at the same time (Linville \& Fischer, 1991). Individuals prefer to break up negative events to different days, which seemingly points toward segregating costs instead.

Evidence from a third vein of literature suggests individuals tend to neglect small recurring costs, the Pennies-a-Day (PAD) effect (Gourville, 1998; 2003). Under PAD, individuals may be more likely to spend \$x per day to get the comfort and convenience 
associated with energy-inefficient choices. For example, individuals were more likely to donate $\$ 1$ per day to a charitable organization than $\$ 350$ per year, despite equal payment schemes between the two frames (i.e. automatic deductions from a monthly paycheck), and that individuals compared the daily donation to other small, recurring expenses like coffee and taxi fares (Gourville, 1998). However, there is no research on whether this phenomenon extends to small, recurring monetary gains, such as savings and associated benefits from engaging in an energy-efficient household behavior, or whether individuals stick with energy-inefficient behaviors when the costs are framed narrowly. If PAD extends to small gains, individuals may just round down small recurring savings from engaging in energy efficiency. There is evidence, though, that periodic pricing prompts individuals to consider repeat experiences of the purchase in question. As applied to recurring decisions about energy-related behaviors, narrowly framed savings may make the inconveniences or discomforts associated with a switch to energy efficiency more salient (Atlas \& Bartels, 2017). In other words, messaging about saving \$x per day by taking energy-efficient colder showers may call to mind the daily discomfort of each colder shower and steer individuals away from efficient choices.

Novemsky and Kahneman (2005) posit several boundaries of loss aversion. They find that loss aversion is attached to the benefits of the good rather than the attributes. In other words, an individual is willing to give up one good to get another that provides the same benefits without loss aversion. They also find that individuals do not exhibit loss aversion for goods intended to be exchanged (e.g. cash). Our research investigates whether choices about temporal framing can minimize loss aversion for energy inefficiency. We operationalize this through a scenario that sets up a status quo level of 
energy consumption and present individuals with relative costs of energy-inefficient and energy-efficient choice alternatives. Theory is conflicted about how consumers may react to narrow cost frames when it comes to behavior decisions. Theory generally supports broader frames as most encouraging product uptake, but gives little guidance on how broader frames affect behavior change decisions. As we describe later, we posit that frames that make cost information most easy to process will best encourage energyefficient choices. Specifically, we test the hypothesis:

H1: Status quo behavior influences intention to engage in energy efficiency differentially across cost frames - specifically, status quo bias is minimized when consumers are most easily able to process cost information.

We find that individuals exhibit status quo bias in their choices when costs are framed as daily and yearly, but not when costs are framed as monthly. We look to ease of cognitive processing and fluency with monthly framing of costs to understand the cognitive processes underlying this interesting result. Cognitive fluency - the subjective experience of ease of processing information - may further influence how individuals perceive information about costs and savings when making energy decisions. Fluency has been shown to affect several areas of judgment, with messages that are easier to process being linked to judgments of truth, preference, confidence, and familiarity (Alter \& Oppenheimer, 2009). For example, Song and Schwarz (2008) found that individuals had stronger intentions to exercise and cook when the instructions were visually easy to read. In relation to fuel-efficient vehicle choices, Camilieri and Larrick (2014) find preliminary evidence that scale familiarity may be driving their finding of more fuel-efficient vehicle choices when fuel costs were presented per 100 miles rather than per 15,000 miles. 
Individuals have an intuitive sense for which units and scales are most familiar, and place more decision weight on attributes with familiar scales (Lembregts \& Pandelaere, 2013). Furthermore, individuals find it difficult to translate between units and are prone to incorrect comparisons when performing calculations to determine impacts of fuel and energy consumption (e.g. Heinzle, 2012; Larrick \& Soll, 2008). Moreover, weighing tradeoffs between energy alternatives and their attributes can feel difficult, and this disfluency may encourage individuals to stick with status quo behaviors (Novemsky et al., 2007). This body of literature suggests that we may be able to overcome decision avoidance and encourage energy-efficient behavior choices by increasing fluency when presenting costs of inefficiency.

We hypothesize that individuals are most familiar with monthly energy bills, and are therefore able to process cost savings information most easily when the framing matches their implicit context. By providing an easy-to-process context for the magnitude of the costs or savings, individuals may be more easily able to understand the benefits of alternatives in the choice set and more likely to overcome status quo bias. We test the hypothesis:

$\mathrm{H} 2$ : Individuals are most fluent with monthly framing of energy costs.

We elicit measures of fluency with the temporal frame and confirm that individuals are more fluent with the monthly presentation of costs relative to daily and yearly frames. Furthermore, individuals' stated preferences for monthly cost frames provide additional evidence that individuals think of energy expenditures in monthly terms. 
If fluency between the cost frame and an implicit context for that frame can influence individuals' decisions, then we hypothesize that providing an explicit context for energy spending in a matching frame can make relatively disfluent frames easier to process. We define context as the typical frame of energy costs (i.e. a monthly energy bill). In other words, the monthly energy bill for total household energy use is the context for the marginal costs of energy-related behavior choices. In addition to information about costs of energy-inefficient behavior alternatives, we explicitly provide a context for typical spending on household energy. We manipulate whether these two pieces of information match in temporal frame and compare energy-efficient intentions for participants who were given context and costs in a matching frame to those given costs and context in different frames (i.e. inefficiency costs $\$ x$ per day and typical energy spending $\$ y$ per year). We specifically test the hypothesis

H3: Individuals have a higher intention to engage in energy efficiency when costs are framed in the same way as total spending context.

As predicted, we find that individuals indicated higher intentions for energy-efficiency when given cost and context in matching frames, and particularly if these frames were broad (i.e. per year).

\section{Studies}

\subsection{Overview}

We test our hypotheses through four experimentally designed studies. The primary advantage of conducting experiments is that we can isolate the specific effects of nuances in how decisions are presented. In such a controlled setting, random assignment 
of treatment conditions also allows us to interpret differences in response as causal. We rely on hypothetical scenarios and self-reported behavior intentions, which could lead to biased estimates of treatment effects in a non-experimental setting. However, we expect such biases (e.g. inflated intentions of pro-environmental behavior) to occur with equally likelihood across all treatment conditions due to random assignment. Therefore, our online studies provide a solid foundation for hypothesis testing. Due to the hypothetical nature of the scenarios, we interpret treatment effects as changes in intention to make energy efficient choices rather than actual changes in energy efficiency. In this section, we first outline the general experimental design and elements common across all studies. Then, we describe each study along with specific details of the method and design, results, and discussion of results as pertains to our hypotheses.

\subsection{General Experimental Design}

We conduct four online surveys from 2015-2016 drawing participants from two online populations: Amazon Mechanical Turk and Qualtrics. Each study was completed in less than 20 minutes and all respondents were compensated for their time.

The primary component similar across all studies was a scenario based around a household energy decision between energy-inefficient and energy-efficient alternatives. The decision varied between some studies, but typically included a behavioral choice rather than a purchase. For example, we asked individuals about with what water temperature they would wash their laundry. The behavior is to choose a water temperature and the alternatives ranged from hot water, which is energy-inefficient because hot water requires energy to heat, to cold water, which is energy-efficient 
because cold water achieves the same outcome while using less energy comparatively. ${ }^{24}$ Individuals read the scenario and are given information about the costs of choosing the energy-inefficient alternative. The main treatment is random assignment of how the cost information is framed - per day, per month, or per year.

\subsection{Study 1: Boundaries of Status Quo Bias}

In our first study, we investigate which temporal framing of costs encourages the most energy-efficient choices. We presented individuals with scenarios about household energy-related behavior decisions. We asked individuals what they would choose given a randomly assigned status quo behavior and information about the energy costs or savings of switching behaviors. According to literature on status quo bias, we expect to find that individuals' intentions are a function of their randomly assigned status quo, across all cost frame conditions. If individual behavior intention is consistent with the literature on cost framing, we would expect costs aggregated over longer temporal frames would encourage the most energy-efficient choices, while individuals may neglect costs or savings that are framed narrowly. A deviation from expected findings may suggest that existing theory about longer-term cost frames does not extend to narrower frames. Furthermore, any affect of cost frame on status quo bias would provide evidence for a potential boundary of status quo bias, with implications for how to best describe costs of household energy behaviors to motivate behavior change.

\section{Method}

\footnotetext{
${ }^{24}$ Some may argue that the same outcome is not achieved using hot and cold water because they have a prior belief that hot water gets laundry cleaner than cold water. However, many of today's detergents are specifically formulated for use in cold water, rendering the same outcome. Furthermore, even if individuals have a strong preference for washing laundry with hot water, these preferences would show up as noise due to the experimental design of the study.
} 
Participants. We recruited 353 on-line participants to complete a study on household decisions through Amazon Mechanical Turk. ${ }^{25}$ Participants received an average of $\$ 1.50$ for completing the study. Average time to complete was 11.3 minutes $(s d=6.8$ minutes $)$.

Procedure. Participants were presented with two scenarios about household energy-related decisions in a between-subjects survey design. ${ }^{26}$ First, they were faced with a decision between using hot or cold water to wash laundry. Then, they had to choose between using or not using a second household refrigerator. Through random assignment, participants were told to consider a status quo of either an energy-efficient behavior alternative (e.g. always using cold water to wash laundry; not using a second refrigerator) or the energy-inefficient alternative (e.g. using warm or hot water to wash laundry; using a second refrigerator). Participants with an energy-efficient (inefficient) status quo were presented with the cost (savings) of engaging in the energy-inefficient (efficient) behavior alternative behavior. Costs and savings were randomly presented as daily, monthly, or yearly for each participant.

All participants first saw a description of the scenario and then answered a question to confirm their scenario status quo. For example, participants assigned the inefficient status quo and yearly frame condition saw: "Suppose you often use warm water, but you are considering whether to use only cold water for your laundry. If you always use cold water, you will save $\$ 63.00$ per year on energy costs. What do you think

${ }^{25}$ Two individuals failed a survey-level attention check. Exclusion of these individuals from analysis does not substantially alter results.

${ }^{26}$ The study included three additional scenarios, but results from these scenarios were discarded due to concerns about overwhelming the participants and quality of data. Only the first two scenarios were used in this analysis. Full text of scenarios is included in the Appendix, as are similar results for analysis using all scenarios. 
you would do?" Participants used a 0-10 slider scale (shown in Appendix A) to indicate their likelihood of engaging in the energy-inefficient or energy-efficient behavior alternative. Our dependent measure is each individual's response to this question averaged over the two scenarios. Individuals also answered a short series of questions related to the scenarios, environmental concern, construal level, cognitive reflection, and loss aversion. ${ }^{27}$

\section{Results}

Figure 1 shows intention to engage in energy efficient behavior, averaged over the two scenarios for each status quo and frame condition. In the daily and yearly frames, participants were influenced by their status quo, but not in the monthly condition. We used analysis of variance to analyze differences in behavior intention between the status quo groups, the temporal frame conditions, and the interaction between the two. There were main effects of status quo, $F(1,347)=15.93, p=.0001$, temporal frame, $F(2,347)$ $=4.67, p=.0099$, and the interaction, $F(2,347)=4.33, p=0.0139$.

[Figure 1 about here]

In the daily condition, participants preferred efficient behaviors more strongly when that was their assigned status quo, $t(113)=3.9376, p=.0001, d=0.735$. Likewise, participants in the yearly condition also showed statistically significant differences in their behavior intentions, in line with their assigned status quos, $t(117)=2.7845, p=$ $0.0063, d=0.511$. However, participants assigned to the monthly frame showed no

27 Measures of construal level, cognitive reflection and numeracy, loss aversion, and environmental concern are included in the Appendix, as are additional methodology details about scale construction. 
difference in behavior intention as a function of status quo, $t(117)=0.0781, p=.9378, d$ $=0.014$, and they tended toward energy-efficient choices relative to participants assigned the inefficient status quo in the daily and yearly conditions. For individuals assigned a status quo energy-efficient behavior, there was no effect of temporal frame, $F(2,347)=$ $1.46, \mathrm{p}=.233, \eta^{2}=.02$. However, there was an effect of temporal frame for individuals assigned an energy-inefficient status quo, $F(2,347)=7.69, \mathrm{p}<0.001$. We replicate main findings even when controlling for loss aversion, environmental concern, cognitive reflection, stated actual frequency of engaging in the energy efficient behavior, and typical energy bill spending.

We investigated a number of individual differences, including loss aversion, environmental concern, construal level, cognitive reflection and numeracy, stated actual frequency of engaging in the energy efficient behavior, and typical energy bill spending. We find neither a main effect of loss aversion $(p=0.180)$ nor an interaction between loss aversion and status quo $(p=0.404)$. Environmental concern is significant in predicting behavior intention $(p<0.001)$ but does not interact with the treatment $(p=0.791)$ or affect main findings. Construal level does not produce a main effect $(p=0.661)$ or an interaction $(p=0.863)$. Cognitive reflection, given by the number of correct responses to five tasks (e.g. the bat and ball problem), is not significantly correlated with behavior intention ( $p=0.276)$ and does not interact with treatment $(p=0.536)$. Stated actual status quo frequency of engaging in energy-efficient behaviors measured on a 5-point Likert scale and averaged over the two scenarios has neither a main effect $(p=0.320)$ nor interaction $(p=0.535)$. Finally, we find neither a main effect of typical energy spending $(p=0.474)$ nor an interaction with treatment $(p=0.356)$. 
We also find that individuals tend to neglect small recurring savings. A main effect of temporal frame, $F(1,347)=1.426, \mathrm{p}<0.001$, indicates that individuals in the daily condition selected a behavior intention that was less energy efficient than individuals who saw monthly or yearly frames, given an energy-inefficient status quo. This suggests that the Pennies-a-Day effect (Gourville, 1998) extends to the small recurring savings that accrue from adopting energy-efficient household habits and switching to more efficient behavior alternatives. In other words, we found that individuals given an energy-inefficient status quo were more likely to forgo savings from switching to energy-efficient behavior alternatives when the gains from doing so were framed as daily, relative to monthly or yearly.

\section{Discussion}

Data support our hypothesis that individuals are influenced by status quo behaviors (H1). Interestingly, we found significant effects of status quo when monetary consequences were framed as yearly or daily, but not monthly. We also found evidence that the Pennies-a-Day effect - neglect for small recurring costs - extends to neglect for small recurring savings. This study showed how costs and savings of energy decisions are framed makes a difference in how likely individuals are to engage in energy efficiency.

One possible explanation for a decreased sensitivity to status quo bias is ease of cognitive processing of monthly costs and savings. Many individuals typically receive a monthly energy bill, and by framing the costs and savings of energy decisions as monthly, individuals may be more readily able to evaluate monetary consequences in relation to their typical household energy expenses. This ease of processing may then make the value of the costs or savings more salient relative to typical energy expenses, 
and allow individuals to be more calculating in their energy decisions. We test this hypothesis in Studies 2-4.

\subsection{Study 2: Fluency with monthly framing}

In our second study, we test whether individuals are more easily able to process monthly costs relative to other temporal frames. We present individuals with one of five scenarios, with the same experimental conditions as Study 1. Specifically, we randomly assign individuals to either an energy efficient or inefficient status quo and present the costs of changing behavior in either a daily, monthly, or yearly frame. We then ask individuals five questions to measure fluency with the temporal frames. We find that individuals are more fluent with monthly costs and savings than with daily or yearly/seasonal costs and savings.

\section{Method}

Participants. We recruited 1,199 online participants to complete a short survey on household decisions through Amazon Mechanical Turk. The average time to complete the survey was 2.4 minutes $(s d=3.9$ minutes $)$.

Procedure. Each participant was randomly presented with one of five scenarios regarding shower water temperature, bus ridership, light bulb choice, use of a space heater, and use of a window air conditioning unit. ${ }^{28}$ Individuals were randomly assigned to a status quo (energy efficient or inefficient) and temporal frame of costs/savings (per day, per month, per year for scenarios 1-3 or per season for scenarios 4-5) similar to Study 1. Our dependent variable is intention to engage in energy efficiency as measured

\footnotetext{
${ }^{28}$ Text of the scenarios and additional measures are provided in the Appendix.
} 
by individuals' responses to the question "What would you do?" Individuals indicated their intentions using a 0-10 slider scale between definitely engaging in the energy efficient behavior or the inefficient behavior.

Individuals then indicated their fluency using a seven-point Likert scale on four measures: ease of estimating the financial impacts of the decision, ease understanding of the decision, clarity of the decision, and clarity of the financial impacts. Text of the scenarios and fluency measures are provided in the appendix. We aggregated responses to fluency measures using a standardized Cronbach's alpha $(a l p h a=0.811)$. Participants also ranked how involved they were in making the decision on a seven-point Likert scale $\left(M_{\text {involvement }}=5.93, s d=1.18\right)$, and how much they care about saving money and the environment on five-point Likert scales $\left(M_{\text {saving money }}=4.49, s d=0.77 ; M_{\text {environment }}=4.02\right.$, $s d=0.95)$

\section{Results and Discussion}

Using the Cronbach's alpha index of fluency measures across all five scenarios, we find significantly higher fluency scores for individuals who are presented with monthly costs rather than other temporal frames $\left(M_{\text {month }}=0.079, M_{\text {other }}=-0.039, t(1197)=2.42, p=\right.$ 0.016). Analysis of variance confirms a significant effect of frequency on fluency $(F(2$, $1196)=3.11, p=0.045)$. Figure 2 plots mean fluency for each temporal frame condition, with higher values indicating higher fluency. Fluency is significantly positively correlated with intention to engage in energy efficiency (beta $=0.47$, se $=0.119, t(1198)$ $=3.97, p<0.001$ ), though the variance in our dependent measure explained by this effect is small $(r$-squared $=0.012)$. 
[Figure 2 about here]

We can further investigate how fluency changes for different temporal frames. Scenarios 1-3 use the temporal frames per day, per month, and per year, while scenarios 4-5 regarding use of $\mathrm{AC}$ and heat present costs per season instead of per year. First, we restrict our sample to only individuals who saw scenarios 1-3 and re-index the fluency measures $($ alpha $=0.811)$. We continue to see a marginally significant difference in fluency means between individuals who saw monthly costs and those who saw daily or yearly costs $\left(M_{\text {month }}=0.066, M_{\text {other }}=-0.033, t(912)=1.77, p=0.077\right)$. We do the same analysis for individuals who saw scenarios $4-5($ alpha $=0.804)$ and find a marginally significantly higher level of fluency for individuals in the monthly condition $\left(M_{\text {month }}=\right.$ $\left.0.118, M_{\text {other }}=-0.058, t(283)=1.77, p=0.079\right)$.

Study 2 reveals that individuals find it easier to understand decisions about energy use when the costs of choice alternatives are framed as monthly, providing support for H2. Despite using a range of scenarios, two of which include seasonal instead of yearly cost frames, fluency seems to be highest with monthly costs. In Study 3, we further explore what temporal frame individuals tend to use when they think about their energy expenditures and costs of energy-related behaviors.

\subsection{Study 3: Experience with and preference for monthly framing}

In contrast to Study 2, which elicits fluency with a randomly assigned cost frame, Study 3 directly asks individuals for their preferences in frame. Among other components (not included in this paper), individuals were given a scenario where they were asked to recommend which cost frame should be used to easily convey costs of energy inefficient 
behaviors to their neighbors. Then they were asked to indicate their preferred way of thinking about various expenses, including costs of energy-related behaviors and their energy bill. Individuals overwhelmingly prefer monthly cost framing. In combination with Study 2, we build evidence in support of monthly framing of costs being the easiest to process.

\section{Method}

Participants. We recruited 315 online participants to complete a short survey on household decisions from the Qualtrics panel of respondents. The average time to complete the survey was 14.3 minutes ( $s d=12.2$ minutes). All participants were screened to ensure they pay their own energy bills.

Procedure. Individuals were presented with a scenario regarding how to frame costs of energy-related household behaviors. ${ }^{29}$ In this scenario, individuals are told that their neighbors each have energy meters in their homes. Each individual was randomly assigned to one of three treatment conditions, and were told that their neighbors saw total household energy expenditures either per day, per month, or per year on their energy meters. They were then asked to advise a neighbor that wanted to design flyers with a cost frame that would be most easy to understand. Individuals ranked each frame on a 7point Likert scale from "doesn't make any sense at all" to "make complete sense." Then individuals chose only one frame to recommend to the neighbor.

Next, individuals were given a scenario in which they were designing a flyer to convey costs of several various activities. Individuals indicated which frame made the

\footnotetext{
${ }^{29}$ Full text provided in the Appendix.
} 
most sense for each activity, choosing from a selection of seven frames (per day, per week, per month, per year, trip, per load, per fill-up). Activities included both energyrelated activities and non-energy activities. Finally, individuals responded to a set of control questions, not included in this analysis.

\section{Results and Discussion}

When asked to rate cost frames on a 7-point Likert scale, individuals rated all frames as making sense $\left(M_{\text {day }}=4.94 s d=0.117, M_{\text {month }}=4.99 s d=0.115, M_{\text {year }}=4.84 s d\right.$ $=0.118$ ). However, monthly framing was rated significantly more sensible than the yearly frame $(t(314)=1.70, p=0.091$; difference in means not significant between month and day frames $t(314)=0.54, p=0.587)$. Individuals then chose one of the three frames to recommend as the frame that made the most sense to use to communicate costs of energy-related household decisions. Figure 3 illustrates the results of this question. A majority of individuals recommended describing costs in the monthly frame $(\mathrm{N}=130$, 41.3\%). The remaining individuals were approximately split between daily and yearly frames: $\mathrm{N}=88(27.9 \%)$ recommended daily framing while $\mathrm{N}=97(30.8 \%)$ recommended yearly framing. Interestingly, more individuals recommended monthly framing than daily or yearly regardless of the framing used in their neighbors' energy meters. We argue this is further evidence for the ease of processing energy-related costs per month.

[Figure 3 about here]

Then, we elicited preferred cost frames for nine activities. Table 1 summarizes these results. Individuals preferred monthly framing for all activities except for the activities about washing laundry, driving, and grocery shopping. Of particular interest, 
71.4 percent of individuals consider their energy bills on a monthly basis. This exercise provides additional evidence for monthly framing being both easy to process and familiar, and supporting $\mathrm{H} 2$.

[Table 1 about here]

\subsection{Study 4: Providing context for unfamiliar frames}

Studies 1-3 showed that individuals respond differently to temporal frames, and that framing costs of energy efficiency may reduce status quo bias (Study 1). The findings regarding fluency in Study 2 suggest that ease of cognitive processing plays a role in the effectiveness of monthly framing in the absence of an explicit context for energy spending (or other relevant comparison metric). Study 3 provides additional evidence that monthly framing is not only easiest to process but also explicitly preferred. The scenarios in Studies 1 and 2 rely on individuals' implicit contexts for energy decisions, and we posit their monthly energy bills serve as this context. This begs the question of whether we can enhance the fluency of typically less-fluent temporal frames by providing an explicit context (e.g. for energy spending) in the same temporal frame. Study 4 has two aims. First, we explicitly test the hypothesis of cognitive fluency for matching the frame of behavior-specific costs to the frame of typical household energy expenses. In other words, if people are given a daily energy bill, do daily costs work better? Second, we test whether broad (i.e., yearly) framing of both costs and typical expenses encourages more energy-efficient behavior intentions than narrow (i.e., daily) framing.

\section{Method}


Participants. We recruited 132 participants for a fifteen-minute online survey through Qualtrics. Participants (51\% male, $49 \%$ female) had an average age of 48 years and an average household income of $\$ 50,000-59,999$ with at least some college. All participants were screened to ensure they pay their own energy bills.

Procedure. Participants were presented with three scenarios: laundry water temperature, use of a second fridge, and light bulb choice, as in previous studies. Following a description of the scenario, we presented typical household energy spending in a randomly assigned frame (daily or yearly), representing an explicit context for easy evaluation of costs of choosing an energy-inefficient behavior alternative. Participants saw the costs of engaging in the energy-inefficient alternative in a randomly assigned frame (daily or yearly), which either matched the typical spending context or did not. ${ }^{30}$ Our dependent measure was similarly defined as in Studies 1 and 2, and we average over the three scenarios to generate our dependent measure for each individual. Figure 4 shows an example of how typical energy spending and scenario-specific costs were presented. We also solicited fluency using the same four measures as in Study 2.

[Figure 4 about here]

\section{Results and Discussion}

Figure 5 shows that intention to choose energy efficient behaviors are strongest when the cost frame and the typical spending frame are matched. In other words, a daily

\footnotetext{
${ }^{30}$ Some participants were instead assigned to monthly frames of typical spending context and costs of energy-inefficiency. We do not present results from these conditions here due to concerns about unintentionally prompting individuals to instead think about their own monthly spending. We argue that using daily and yearly conditions, which are relatively less familiar than a monthly frame, provides a cleaner experimental context to examine the effects of matching versus nonmatching frames.
} 
cost frame works best when matched with a daily spending bill, and a yearly cost frame works best when matched with a yearly spending bill. In analysis of variance, we do not see a significant main effect of cost frame $(F(1,128)=0.82, p=0.366)$ but there is a marginal main effect of spending frame $(F(1,128)=3.70, p=0.056)$ and a statistically significant interaction effect $(F(1,128)=5.47, p=0.021)$. Pairwise comparisons reveal a significant effect of cost frame when daily typical spending is presented $(t(63)=2.178, p$ $=0.033$, but an insignificant effect of cost frame when yearly typical spending is presented $(t(65)=1.070, p=0.289)$. These results provide partial support for $\mathrm{H} 3$, though we cannot statistically distinguish between behavior intentions with matching or mismatching contexts when individuals see an annual total spending context.

[Figure 5 about here]

We were unable to test for fluency as a mediator due to suspected ceiling effects. Fluency measures were on seven-point Likert scales $\left(M_{\text {fluency measures }}=6.31, s d=0.80\right)$. Thirty-eight percent of individuals chose a seven for all measures, while 92 percent had an average raw fluency score greater than five, resulting in very little variation among respondents. We think the potential cause for reported high fluency was the clarity of the images used to portray costs and typical spending. We also see higher intentions for energy efficiency in Study 4 relative to Study 1. Though the scenarios are not directly comparable, this suggests that providing an explicit context for energy spending may increase fluency, which may in turn elicit more energy-efficient behavior intentions.

\section{General Discussion}

In four studies, we investigate how individuals respond to cost frames within the context of energy-related household decisions. Prior literature has mainly focused on 
longer-term temporal framing of costs, ranging from one year to the life cycle of the product in question (Kaenzig \& Wustenhagen, 2010; Hutton \& Wilkie, 1980; Hardisty et al., 2014; Larrick et al., 2015). We extend this work in two ways. First, we focus on short-term temporal frames to build a more comprehensive understanding of how individuals respond to cost framing in general. Second, our scenarios involve costs related to household behaviors rather than product purchases. We find that intentions to engage in energy efficient behaviors are subject to status quo bias when the costs or savings of behavior change are framed as per day or per year. However, individuals who see costs and savings framed on a monthly basis overcome status quo bias in their behavior intentions. This provides evidence that is potentially inconsistent with current thinking about cost framing, which recommends using longer-term frames to promote product purchase. Furthermore, in the same vein as Novemsky et al. (2005) with boundaries of loss aversion, we show a possible boundary of status quo bias.

We postulate that cognitive fluency plays a role in why monthly cost framing minimizes status quo bias. Prior literature on cognitive fluency links easy-to-process attributes to judgments of truth, preference, and ease (Alter \& Oppenheimer, 2009). Therefore, a cost frame that is more cognitively fluent may affect individual choices. In two studies, we find evidence that monthly framing is easiest to process and the preferred unit to describe costs of several household choices. This finding is consistent across a randomized experiment that elicits fluency through a set of measures, and in stated preference-style measures. We also see that over seventy percent of individuals think about their energy expenses in monthly terms. Prevalence of monthly energy bills may provide an implicit context against which to evaluate or understand the costs of energy- 
inefficient behavior alternatives. Findings from these studies point to cognitive fluency as a possible boundary of status quo bias, and one that we may be able to leverage to further encourage energy efficient choices.

A fourth study ditches implicit monthly framing to explore the benefits of providing an explicit context for relatively disfluent cost frames. If our conceptual framework is an accurate description of the decision making process regarding household energy choices, then we would expect that manipulations of explicit context framing to match cost framing would increase energy-efficient behavior intentions. Consistent with this framework, we find that individuals have the greatest intention to engage in energy efficiency when they see a context for total household energy expenditures in a frame that matches information about the costs of a specific energy-inefficient behavior, relative to receiving an explicit context in a mismatched frame.

Our findings suggest two additional tools that choice architects can consider. First, we show that cognitively fluent framing can reduce status quo bias. If a policy maker's goal were to encourage some behavior that is hindered by attachment to the status quo, then framing the costs of inaction in a frame that is easier to process could lead to more decisions to act. To illustrate with an example outside of energy contexts, consider the choice of whether to purchase relatively healthy fresh produce or comparatively unhealthy prepared foods at the grocery store. Individuals tend to think about their budgets for groceries in weekly terms. Advocates for healthy eating that want to encourage purchases of fresh produce instead of prepared foods could consider framing the additional costs of unhealthy foods relative to fresh produce in terms of costs 
per week. Future research should expand on how fluent framing and descriptions might be able to counteract other biases, like default bias and loss aversion.

The second tool available to choice architects is providing a context against which to evaluate disfluent cost frames. We find that providing an explicit context for frames that are relatively difficult to think about increases behavior intention. The PAD literature recommends using narrow framing because doing so elicits comparisons to trivial recurring purchases. However, we find that framing costs as daily is less easy to process than equivalent monthly costs. Future research should investigate how providing explicit contexts could enhance the PAD effect. To illustrate with an example from one of Gourville's (1998) motivating studies, individuals were asked about intentions to donate to a charity and provided the donation amount in a narrow frame ( $\$ 0.85$ per day) or a broad frame ( $\$ 300$ per year). While individual donation intentions were highest with the narrow cost frame, it is possible that disfluency with daily framing within the context of donations attenuated this effect, and that providing an explicit context for this amount (e.g. average daily spending on other products somehow related to charitable giving, or even perhaps setting up a contrast with daily spending on selfish purchases) could further increase donation intentions.

It is also worth further investigating how fluency with the magnitude of the cost impacts choice. PAD finds that narrowly framed costs call to mind other familiar small costs, like a cup of coffee. But some very small costs (e.g. $\$ 0.11$ per day relative cost of incandescent light bulbs) may not have a clear comparison, and this disfluency with magnitude may also play a role in how individuals respond to PAD framing. To this point, providing an explicit context against which to compare very small, narrowly 
framed costs could increase fluency by increasing ease of recall of comparable trivial recurring purchases.

We face several limitations in our studies. Ideally, we would have liked to run a formal statistical test of cognitive fluency as a mediator. However, we were limited by the high fluency ratings of aspects of the energy decisions. One possible cause of high fluency ratings is the explicit (versus implicit) context given. Future research should investigate changes in behavior intention when there is an implicit versus explicit context for total energy expenditures. We suspect that individuals evaluated costs against an implicit context of monthly spending on energy bills in the absence of an explicit context. Study 4 attempted to manipulate fluency by providing an explicit context of total household energy spending in a relatively unfamiliar frame (per day or per year). However, providing an explicit context regardless of frame may render all aspects of the decision easy to process, and hence contributed to the ceiling effects we found with our fluency measure. Instead, future research could compare across product or behavior categories where individuals use contexts in different frames. For example, researchers could present costs in various frames and compare intentions for energy efficiency (with the context for total spending being on a monthly basis) to intentions to, say, substitute less expensive produce for more expensive prepared foods (with the context for total grocery budgets being on a weekly basis). To be consistent with findings from this research, we would expect to see status quo bias when energy costs are framed other than monthly and food costs are framed other than weekly.

Additionally, future research should compare monthly cost framing to annual and longer-term framing, to provide a more comparable result to literature on longer-term 
frames. Future research could also investigate alternative mechanisms that decrease status quo bias, for example evaluability of the costs or the changes in underlying judgments due to increased fluency. Song and Schwarz (2008) found that individuals were significantly more likely to engage in certain behaviors when the instructions for doing so were cognitively fluent. In terms of energy-related household decisions, cognitively fluent cost framing could cause individuals to think of the behavior changes as easy to do, increase preference for the energy efficient alternative, or allay underlying doubt about actual savings by increasing judgments of ease, preference, or truth. Lastly, future research should include an incentive compatible experiment. Our studies relied on hypothetical scenarios, in which hypothetical bias may affect individuals' responses and inflate intentions for energy efficiency. A field experiment in particular would be beneficial to understand the external validity of our findings, both within an energy conservation context as well as in other decisions.

Our findings have important implications for how to convey information about energy choices, both in framing and in content. Specifically, policy makers and energy conservation advocates should consider framing costs of energy-inefficient choices in the frame that is most fluent for the target audience. While prior literature recommends describing costs over longer time horizons, our research prompts another call to think of costs in terms of shorter horizons if those frames are easiest to process. We suspect these guidelines are particularly appropriate for costs of energy-related behaviors rather than energy-consuming products. In the case of using a frame that could be less fluent, a context against which to weigh those costs should also be provided. 


\section{References}

Agarwal, S., Rengarajan, S., Sing, T. F., \& Yang, Y. (2017). Nudges from school children and electricity conservation: Evidence from the "Project Carbon Zero" campaign in Singapore. Energy Economics, 61, 29-41.

Allcott, H. (2011). Social norms and energy conservation. Journal of Public Economics, 95(9), 1082-1095.

Allcott, H., \& Mullainathan, S. (2010). Behavior and energy policy. Science, 327(5970), 1204-1205.

Allcott, H., \& Rogers, T. (2014). The short-run and long-run effects of behavioral interventions: Experimental evidence from energy conservation. The American Economic Review, 104(10), 3003-3037.

Alter, A. L., \& Oppenheimer, D. M. (2009). Uniting the tribes of fluency to form a metacognitive nation. Personality and social psychology review.

Atlas, S., \& Bartels, D., "Periodic Pricing Revisited: Beyond Pennies-a-Day.” working paper (2016)

Becker, L. J. (1978). Joint effect of feedback and goal setting on performance: A field study of residential energy conservation. Journal of applied psychology, 63(4), 428.

Burson, K. A., Larrick, R. P., \& Lynch Jr, J. G. (2009). Six of one, half dozen of the other: Expanding and contracting numerical dimensions produces preference reversals. Psychological Science, 20(9), 1074-1078.

Camilleri, A. R., \& Larrick, R. P. (2014). Metric and scale design as choice architecture tools. Journal of Public Policy \& Marketing, 33(1), 108-125.

Carrico, A. R., \& Riemer, M. (2011). Motivating energy conservation in the workplace: An evaluation of the use of group-level feedback and peer education. Journal of environmental psychology, 31(1), 1-13.

Costa, D. L., \& Kahn, M. E. (2013). Energy conservation "nudges" and environmentalist ideology: Evidence from a randomized residential electricity field experiment. Journal of the European Economic Association, 11(3), 680-702.

Dietz, T., Gardner, G. T., Gilligan, J., Stern, P. C., \& Vandenbergh, M. P. (2009). Household actions can provide a behavioral wedge to rapidly reduce US carbon emissions. Proceedings of the National Academy of Sciences, 106(44), 1845218456. 
Dinner, I., Johnson, E. J., Goldstein, D. G., \& Liu, K. (2011). Partitioning default effects: why people choose not to choose. Journal of Experimental Psychology: Applied, 17(4), 332.

Energy Information Administration. Office of Energy Statistics, US Department of Energy. (2017). February 2017 Monthly Energy Review (DOE/EIA0035(2017/2)). Washington, DC. https://www.eia.gov/totalenergy/data/monthly/pdf/mer.pdf

Frederick, S. (2005). Cognitive reflection and decision making. The Journal of Economic Perspectives, 19(4), 25-42.

Gill, C. and Lang, C. (2017). Learn to Conserve? The effects of in-school energy education on at-home electricity consumption. working paper.

Gourville, J. T. (1998). Pennies-a-day: The effect of temporal reframing on transaction evaluation. Journal of Consumer Research, 24(4), 395-408.

Gourville, J. T. (2003). The effects of monetary magnitude and level of aggregation on the temporal framing of price. Marketing Letters, 14(2), 125-135.

Gromet, D. M., Kunreuther, H., \& Larrick, R. P. (2013). Political ideology affects energy-efficiency attitudes and choices. Proceedings of the National Academy of Sciences, 110(23), 9314-9319.

Harding, M., \& Hsiaw, A. (2014). Goal setting and energy conservation. Journal of Economic Behavior \& Organization, 107, 209-227.

Hardisty, D. J., Shim, Y., \& Griffin, D. (2014). Encouraging energy efficiency: Product labels activate temporal tradeoffs. Vancouver, British Columbia, Canada: University of British Columbia Sauder School of Business. Contact David Hardisty.

Heinzle, S. L. (2012). Disclosure of energy operating cost information: A silver bullet for overcoming the energy-efficiency gap?. Journal of Consumer Policy, 35(1), 4364.

Hutton, R. B., \& Wilkie, W. L. (1980). Life cycle cost: A new form of consumer information. Journal of Consumer Research, 6(4), 349-360.

Jaffe, A. B., \& Stavins, R. N. (1994). The energy paradox and the diffusion of conservation technology. Resource and Energy Economics, 16(2), 91-122.

Jessoe, K., \& Rapson, D. (2014). Knowledge is (less) power: Experimental evidence from residential energy use. The American Economic Review, 104(4), 1417-1438. 
Johnson, E. J., \& Goldstein, D. (2003). Do defaults save lives?. Science, 302(5649), 1338-1339.

Johnson, E. J., Shu, S. B., Dellaert, B. G., Fox, C., Goldstein, D. G., Häubl, G., ... \& Wansink, B. (2012). Beyond nudges: Tools of a choice architecture. Marketing Letters, 23(2), 487-504.

Kaenzig, J., \& Wüstenhagen, R. (2010). The effect of life cycle cost information on consumer investment decisions regarding eco-innovation. Journal of Industrial Ecology, 14(1), 121-136.

Kahneman, D., Knetsch, J. L., \& Thaler, R. H. (1990). Experimental tests of the endowment effect and the Coase theorem. Journal of political Economy, 98(6), $1325-1348$.

Kahneman, D., \& Tversky, A. (1979). Prospect theory: An analysis of decision under risk. Econometrica: Journal of the econometric society, 263-291.

Larrick, R. P., \& Soll, J. B. (2008). The MPG illusion. SCIENCE-NEW YORK THEN WASHINGTON-, 320(5883), 1593.

Larrick, R. P., Soll, J. B., \& Keeney, R. L. (2015). Designing better energy metrics for consumers. Behavioral Science \& Policy, 1(1), 63-75.

Lembregts, C., \& Pandelaere, M. (2013). Are all units created equal? The effect of default units on product evaluations. Journal of Consumer Research, 39(6), 12751289.

Linville, P. W., \& Fischer, G. W. (1991). Preferences for separating or combining events. Journal of personality and social psychology, 60(1), 5.

Lipkus, I. M., Samsa, G., \& Rimer, B. K. (2001). General performance on a numeracy scale among highly educated samples. Medical decision making, 21(1), 37-44.

McNeill, D. L., \& Wilkie, W. L. (1979). Public policy and consumer information: Impact of the new energy labels. Journal of Consumer Research, 6(1), 1-11.

Newell, R. G., \& Siikamäki, J. (2014). Nudging energy efficiency behavior: The role of information labels. Journal of the Association of Environmental and Resource Economists, 1(4), 555-598.

Newsham, G. R., \& Bowker, B. G. (2010). The effect of utility time-varying pricing and load control strategies on residential summer peak electricity use: a review. Energy policy, 38(7), 3289-3296. 
Novemsky, N., \& Kahneman, D. (2005). The boundaries of loss aversion. Journal of Marketing research, 42(2), 119-128.

Novemsky, N., Dhar, R., Schwarz, N., \& Simonson, I. (2007). Preference fluency in choice. Journal of Marketing Research, 44(3), 347-356.

Pandelaere, M., Briers, B., \& Lembregts, C. (2011). How to make a 29\% increase look bigger: The unit effect in option comparisons. Journal of Consumer Research, 38(2), 308-322.

Samuelson, W., \& Zeckhauser, R. (1988). Status quo bias in decision making. Journal of risk and uncertainty, 1(1), 7-59.

Smith, N. C., Goldstein, D. G., \& Johnson, E. J. (2013). Choice without awareness: Ethical and policy implications of defaults. Journal of Public Policy \& Marketing, 32(2), 159-172.

Song, H., \& Schwarz, N. (2008). If it's hard to read, it's hard to do processing fluency affects effort prediction and motivation. Psychological Science, 19(10), 986-988.

Thaler, R. (1985). Mental accounting and consumer choice. Marketing science, 4(3), 199214.

Thaler, R. H. and Sunstein, C. R. and Balz, J. P., Choice Architecture (December 10, 2014). The Behavioral Foundations of Public Policy, Ch. 25, E. Shafir, ed. (2012). Available at SSRN: https://ssrn.com/abstract $=2536504$ or http://dx.doi.org/10.2139/ssrn.2536504

Ungemach, C., Camilleri, A. R., Johnson, E. J., Larrick, R. P., \& Weber, E. U. (2014). Translated attributes as a choice architecture tool. Durham, NC: Duke University.

Vallacher, R. R., \& Wegner, D. M. (1989). Levels of personal agency: Individual variation in action identification. Journal of Personality and Social psychology, 57(4), 660.

Weber, M., Eisenführ, F., \& Von Winterfeldt, D. (1988). The effects of splitting attributes on weights in multiattribute utility measurement. Management Science, 34(4), 431-445. 


\section{Tables and Figures}

Figure 1. Energy efficient behavior intentions by status quo condition and cost frame

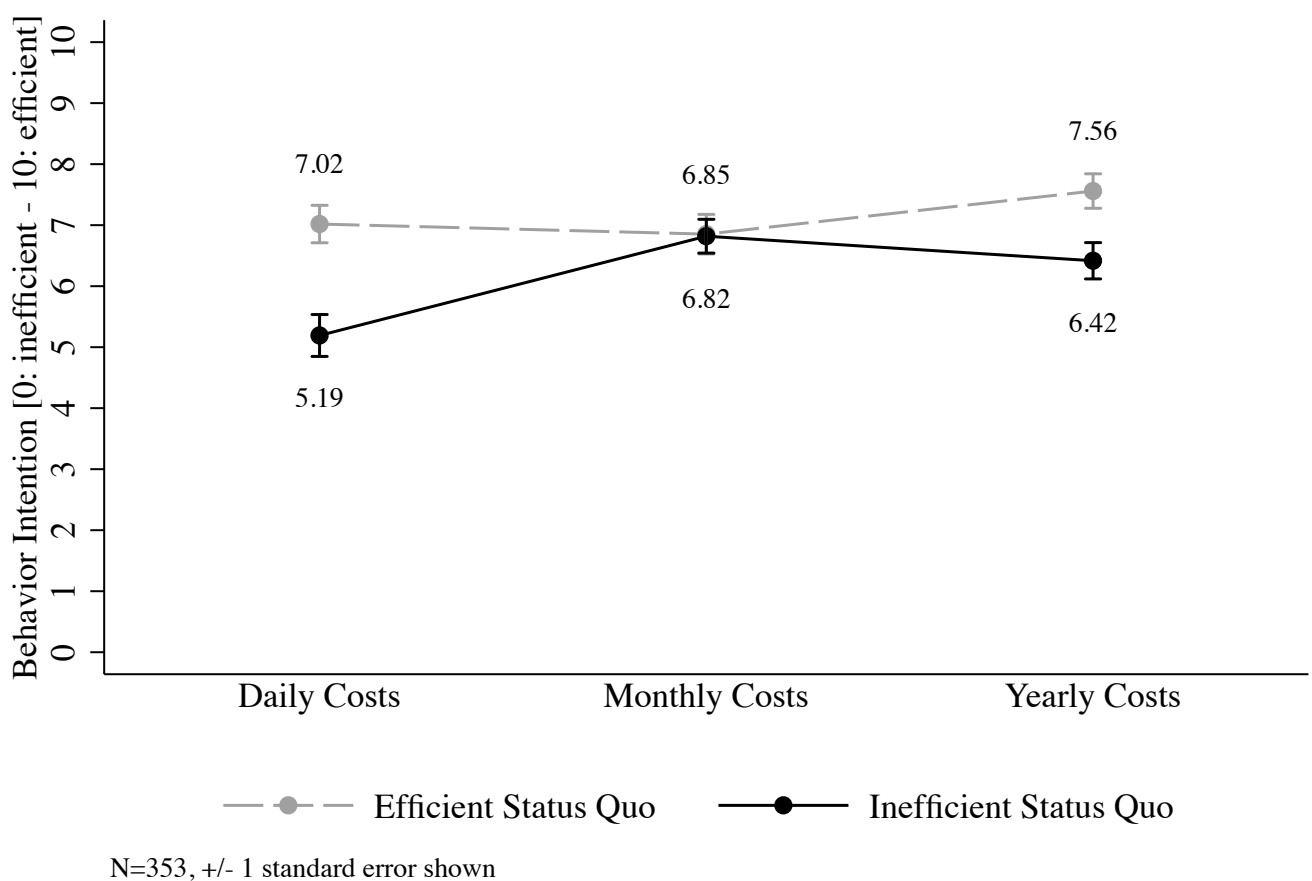

Notes. Figure illustrates intention to engage in energy efficient behavior as a function of status quo and assigned frame of costs or savings, averaged across scenarios in Study 1. 
Figure 2. Fluency by cost frame

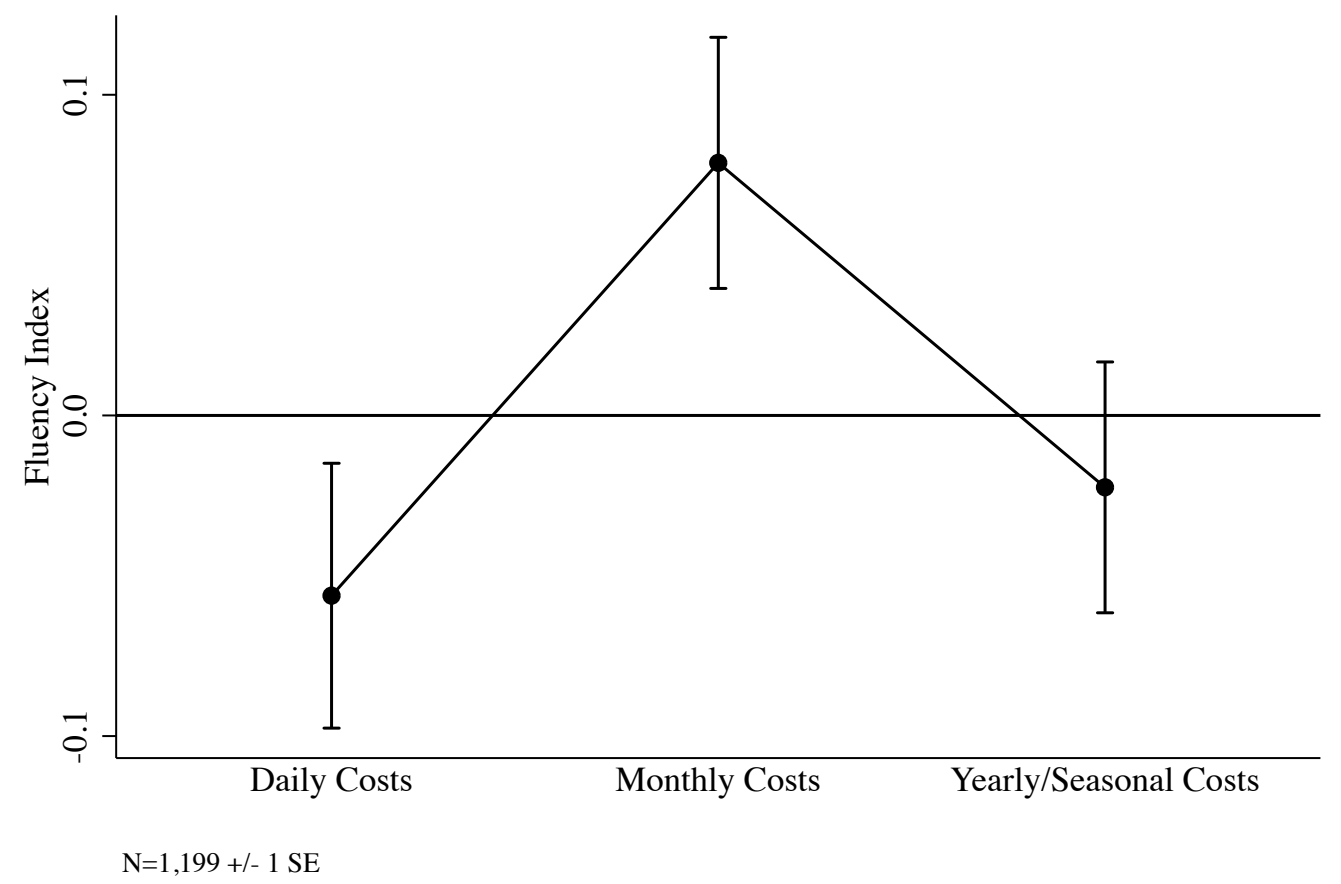

Notes: Figure illustrates Cronbach's alpha of fluency measures by cost frame in Study 2. 
Figure 3. Stated preference for cost frame

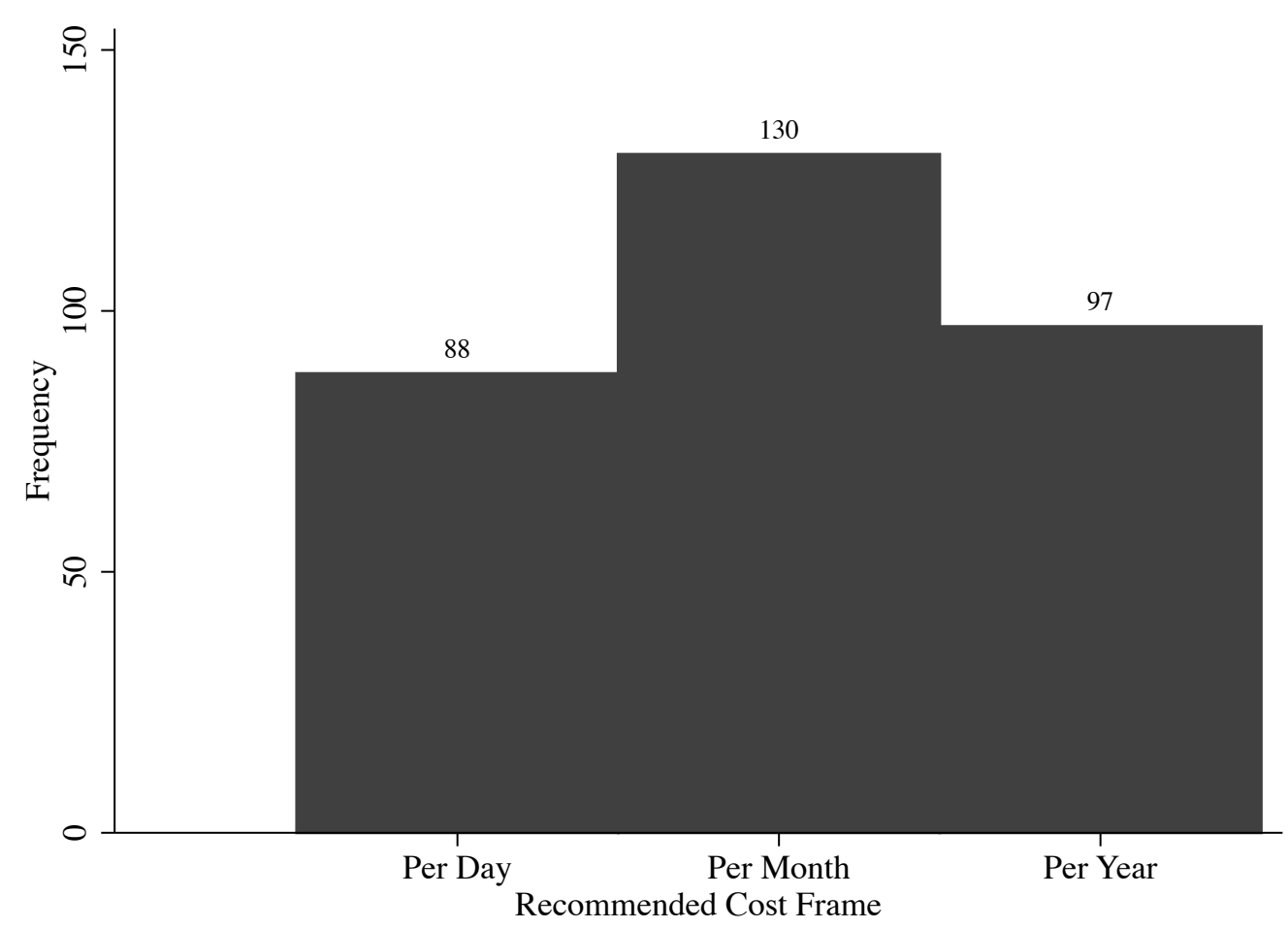

Notes: Figure shows number of individuals who recommended each cost frame. $\mathrm{N}=315$ 
Figure 4. Energy meter context and cost sticker
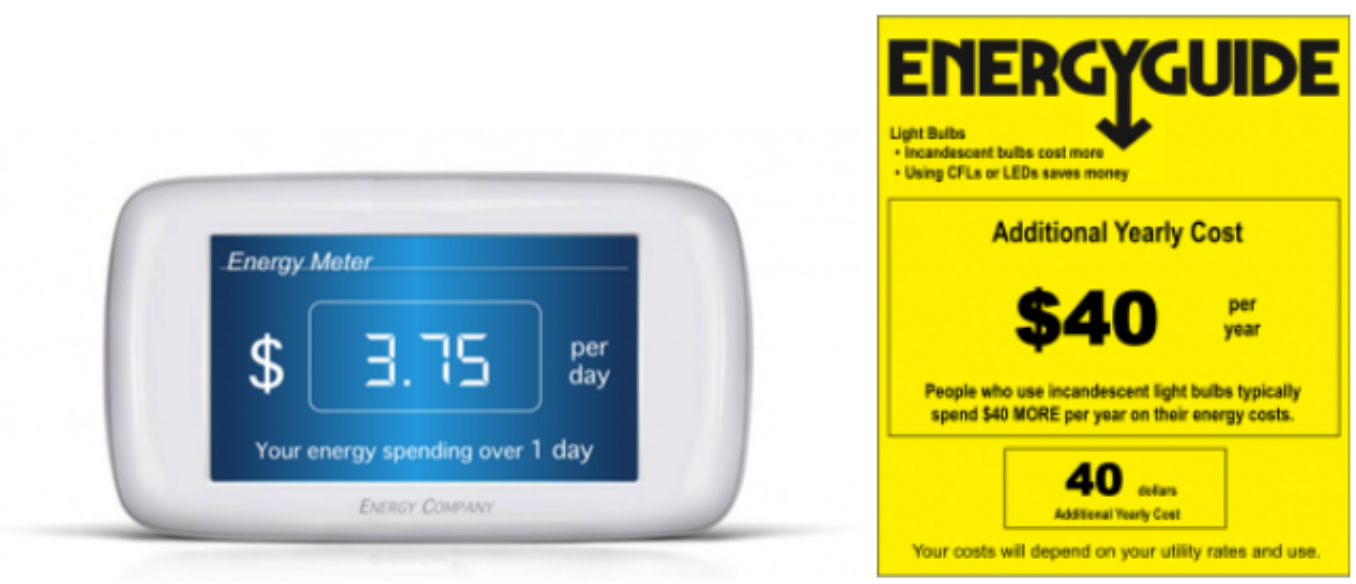

Notes: Participants saw the above images depicting typical energy spending (left) and costs of energy-inefficient choice alternatives (right). Energy meters showed daily and yearly frames ( $\$ 3.75$ per day, $\$ 1,370$ per year). Cost labels showed daily and yearly frames $(\$ 0.11$ per day, $\$ 40$ per year). 
Figure 5. Energy efficient behavior intention cost frame and total expenditure context

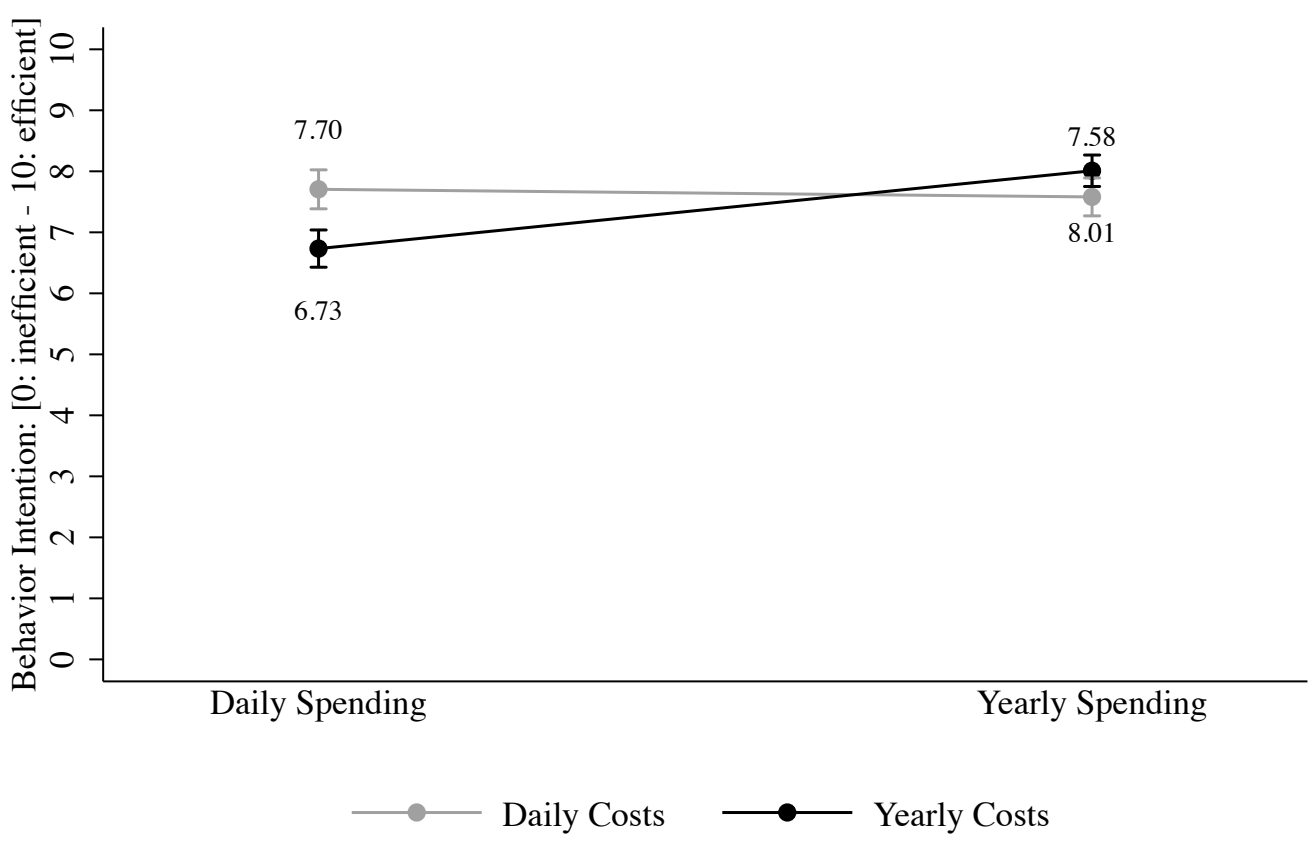

$\mathrm{N}=132,+/-1$ standard error shown

Notes: Figure shows intention to engage in the energy-efficient alternative by cost and context condition in Study 4. Measures of energy efficiency intentions were highest when an explicit context for typical energy spending was provided in a frame that matched the frame of cost of energy-inefficient choices. 
Table 1. Stated preferences for cost frames

\begin{tabular}{|c|c|c|c|c|c|c|c|}
\hline Cost & per day & per week & per month & per year & per trip & per load & per fill up \\
\hline $\begin{array}{l}\text { Washing laundry with hot water } \\
\text { instead of cold }\end{array}$ & 4.8 & 10.2 & 30.2 & 10.8 & 1.9 & 41.3 & 1.0 \\
\hline $\begin{array}{l}\text { Using two refrigerators instead of } \\
\text { one }\end{array}$ & 13.3 & 4.1 & 49.8 & 30.5 & 1.6 & 0.3 & 0.3 \\
\hline $\begin{array}{l}\text { Driving a gas-powered vehicle } \\
\text { instead of an electric vehicle }\end{array}$ & 3.5 & 11.1 & 25.7 & 14.6 & 10.2 & 0.6 & 34.3 \\
\hline $\begin{array}{l}\text { Using a space heater or window air } \\
\text { conditioner }\end{array}$ & 19.4 & 6.0 & 56.2 & 16.5 & 0.6 & 0.6 & 0.6 \\
\hline $\begin{array}{l}\text { Using incandescent instead of CFL } \\
\text { or LED light bulbs }\end{array}$ & 20.6 & 2.9 & 45.1 & 29.2 & 1.6 & 0.3 & 0.3 \\
\hline Going to the grocery store & 3.5 & 31.8 & 26.0 & 4.4 & 33.0 & 0.3 & 1.0 \\
\hline My energy bill & 9.2 & 2.5 & 71.4 & 15.2 & 0.6 & 0.6 & 0.3 \\
\hline My movie budget & 3.2 & 7.3 & 44.8 & 23.5 & 20.0 & 0.6 & 0.6 \\
\hline $\begin{array}{l}\text { Taking public transportation to work } \\
\text { instead of a personal vehicle }\end{array}$ & 11.8 & 14.3 & 27.3 & 11.1 & 31.8 & 1.6 & 2.2 \\
\hline
\end{tabular}

Notes: Cells indicate percentage of $\mathrm{N}=315$ individuals who prefer each frame for the costs in each row. Percentages sum to $100 \%$ in each row. Darker shading indicates higher percentage. 


\title{
Appendices
}

\section{Appendix A: Sample slider measuring energy-efficient behavior intention}

\author{
Suppose you only use cold water, but you are considering whether to often use warm water for your \\ laundry. \\ If you often use warm water, you will pay $\$ 63.00$ more per year for energy costs.
}

What do you think you would do? Please answer on the following scale, where 0 means that you definitely would use only cold water and $\mathbf{1 0}$ means that you definitely would use warm water.

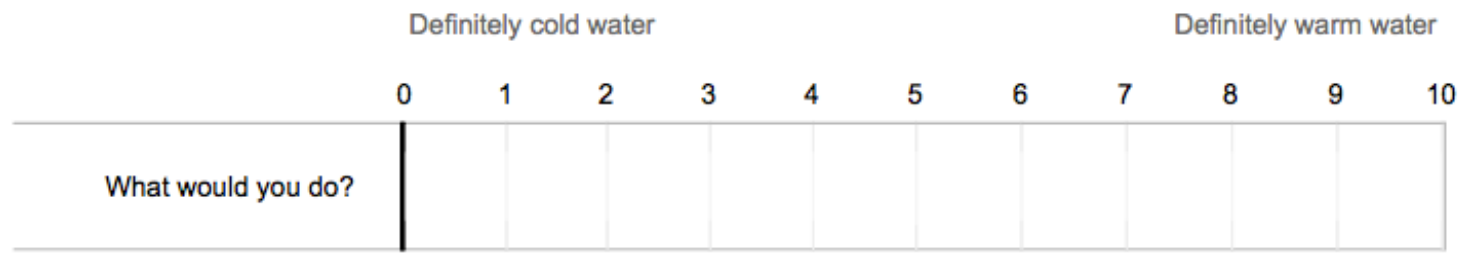

Note: Slider was anchored at 5 . Responses were reverse coded (definitely energy efficient choice $=10$, definitely energy inefficient choice $=0$ ). 


\section{Appendix B: Full text of scenarios used in main analysis of Study 1}

\section{Scenario: Laundry}

\section{Scenario description}

When doing the laundry, you can choose what water temperature your washing machine uses. Some people choose to use warm or hot water because they think warmer water is most effective for cleaning laundry. However, warm and hot water use more energy than cold water.

\section{Status quo manipulation}

For this scenario, suppose you often use [warm/cold] water.

\section{Status quo condition check}

This scenario asks you to assume that you currently use a certain type of water. What temperature is the water in this scenario?
o warm
○ cold

Suppose you often use [warm/cold] water, but you are considering whether to use [cold/warm] water for your laundry. 


\section{Cost frame manipulation}

If you always use cold water, you will save 17 cents per day on energy costs.

If you always use cold water, you will save $\$ 5.25$ per month on energy costs.

If you always use cold water, you will save $\$ 63.00$ per year on energy costs.

If you often use warm water, you will pay 17 cents more per day for energy costs.

If you often use warm water, you will pay $\$ 5.25$ more per month for energy costs.

If you often use warm water, you will pay $\$ 63.00$ more per year for energy costs.

What do you think you would do? Please answer on the following scale, where 0 means that you definitely would use only cold water and 10 means that you definitely would use warm water.

\section{Scenario: Second refrigerator}

\section{Scenario description}

Many homes have a second fridge or freezer. They are typically used for additional food storage or convenience, and are typically located in a garage, basement or another room in the house. Suppose you own a second fridge, and are deciding what to do with it. If it's plugged in, you can use it to keep things cold, but you must pay for its energy costs. If it's not plugged in, it you can store it in the house, give it away or sell it. 


\section{Status quo manipulation}

For this scenario, suppose you own a second fridge and your second fridge is [plugged in/not plugged in].

\section{Status quo condition check}

This scenario asks you to assume something about your fridge. In the scenario, is it currently plugged in?

$\circ$ Yes, it is plugged in

$\circ$ No, it is not plugged in

Suppose you are considering whether to disconnect [connect] a second fridge in your home.

\section{Cost frame manipulation}

If you disconnect the second fridge, you will save 33 cents per day on energy costs.

If you disconnect the second fridge, you will save $\$ 10.00$ per month on energy costs.

If you disconnect the second fridge, you will save $\$ 120.00$ per year on energy costs.

If you connect the second fridge, you will pay 33 cents more per day on energy costs.

If you connect the second fridge, you will pay $\$ 10.00$ more per month on energy costs. 
If you connect the second fridge, you will pay $\$ 120.00$ more per year on energy costs.

What do you think you would do? Please answer on the following scale, where 0 means that you definitely would disconnect the fridge and 10 means that you definitely would connect the fridge. 


\section{Appendix C: Main analysis of Study 1 using all five scenarios}

Figure 1A shows mean behavior intention averaged across all five scenarios. In an ANOVA, there were main effects of status quo $(F(1,347)=6.67, p=.0102)$, temporal frame $(F(2,347)=8.38, p=.0003)$, and the interaction $(F(2,347)=18.34, p=0.0607)$. In the daily condition, participants preferred efficient behaviors more strongly when that was already their status quo, $t(113)=2.465, p=0.015, d=0.460$. Likewise, participants in the yearly condition also showed statistically significant differences in their behavior intentions, in line with their assigned status quos, $t(117)=2.337, p=0.0211, d=0.429$. However, participants assigned to the monthly frame showed no difference in behavior intention as a function of status quo, $t(117)=0.449, p=0.0 .654, d=.0824$.

The results from this analysis are consistent with those presented in the main paper. Additional scenarios include decisions about whether to shower with warmer or cooler water, ride the bus to work or commute using a personal vehicle, and whether to use a space heater or window air conditioning unit (based on each individual's response to a question about which is more applicable to them). 
Figure 1A. Energy efficient behavior intention averaged across five scenarios by status quo condition and cost frame

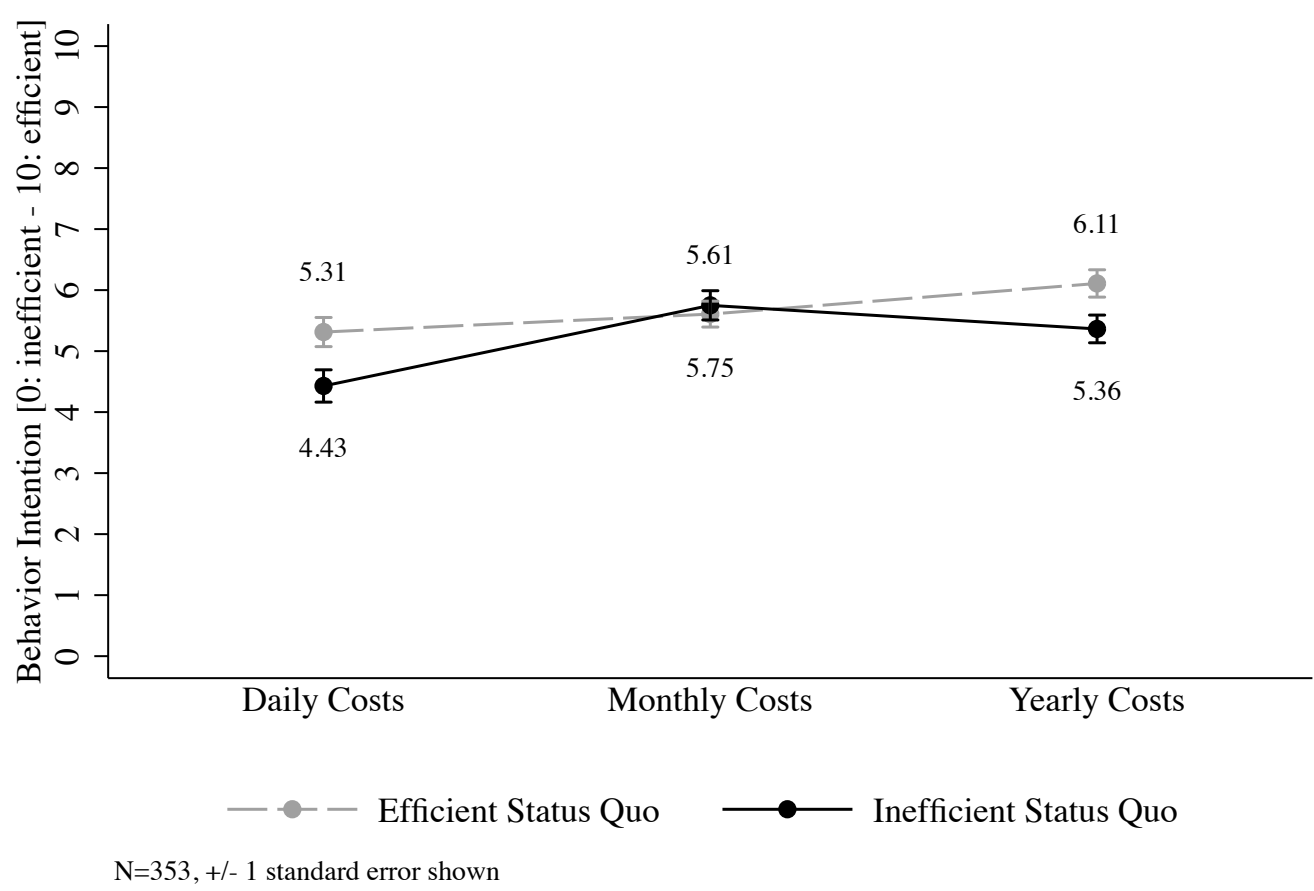




\section{Appendix D: Independent measures and scale construction used in Study 1}

Cognitive reflection and numerical ability items were taken from Atlas and Bartels (2017), based originally on Frederick (2005) and Lipkus, Samsa, and Rimer (2001). Scale was constructed as the proportion of correct responses (mean $=0.40, s d=$ $0.28, \min =0, \max =1)$. Similarly, we measured construal level using the four items in Atlas and Bartels (2017) originally from Vallacher and Wegner's (1989) 24-item Behavioral Identification Form. Scale was constructed as the proportion of abstract descriptions $($ mean $=0.60, s d=0.22, \min =0, \max =1)$. We constructed a scale about environmental concern using four measures. Together, these measures had a Cronbach's $\alpha$ of 0.866 and ranged from -2.4 to $1.6($ mean $=0, s d=0.84)$.

Typical Energy Spending

Approximately how much did you spend on your energy bill last month?
○ $\$ 0$
○ $\$ 1-50$
○ $\$ 51-100$
○ $\$ 101-200$
○ $\$ 201-300$
○ $\$ 301-400$
○ $\$ 401-500$
○ \$501+
- I don't remember 
Actual status quo

Please identify how often you do the following behaviors:

[measured on a 5-point Likert scale from Always - Never]

- Wash my clothes using only cold water

- Use a second refrigerator in my home

- Shower using cooler water

○ Take a bus to work

- Use a personal vehicle to commute to work

- Use a window AC unit in my home

○ Use a space heater in my home

Perceived discomfort or inconvenience

How much discomfort, inconvenience, or effort would you experience following each of the following behaviors?

[measured on a 4-point Likert scale from Severe - Little to none]

- Always washing clothes in cold water (instead of using warm or hot water)

- Removing a second refrigerator from the home

- Always shower using cool or cold water (instead of warm or hot water)

- Using public transportation instead of a personal vehicle

- Removing a window AC unit from one room in my home 
○ Removing a space heater from your home

\section{Environmental concern}

Please select the option that best describes your opinion:

[measured on a 5-point Likert scale from Strongly agree - Strongly disagree]

- I care about the environmental impact of my energy choices

- I frequently think about the environmental impact of my energy choices

- I am an environmentally conscious person

- I value how environmentally conscious I appear to others

\section{Cognitive reflection and numerical ability}

Next we will ask you a few brain teasers. Please answer the following as best you can. [Correct answers in parentheses.)

O A bat and a ball cost $\$ 1.10$ in total. The bat costs $\$ 1.00$ more than the ball. How much does the ball cost? (5 or 0.05$)$

O In a lake, there is a patch of lilypads. Everyday, the patch doubles in size. If it takes 48 days for the patch to cover the lake, how long would it take for the patch to cover half the lake? (47)

- A 21 page album contains 480 photos. Each page displays either 18 large photos or 24 small photos. How many pages display small photos? (17)

- In the ACME PUBLISHING SWEEPSTAKES, the chance of winning a car is 1 
in 1,000. What percent of tickets of ACME PUBLISHING SWEEPSTAKES win a car? $(0.1)$

- Suppose you have a close friend who has a lump in her breast and must have a mammogram. Of 100 women like her, 10 of them actually have a malignant tumor and 90 of them do not. Of the 10 women who actually have a tumor, the mammogram indicates correctly that 9 of them have a tumor and indicates incorrectly that 1 of them does not have a tumor. Of the 90 women who do not have a tumor, the mammogram indicates correctly that 81 of them do not have a tumor and indicates incorrectly that 9 of them do have a tumor. The table below [omitted here] summarizes all of this information. Imagine that your friend tests positive (as if she had a tumor), what is the likelihood that she actually has a tumor? (Please enter a percent.) (50)

\section{Construal level}

[Concrete (versus abstract) items are denoted with a*.]

Any behavior can be described in many ways. For example, one person might describe a behavior as "writing a paper," while another person might describe the same behavior as “pushing keys on the keyboard." Yet another person might describe it as "expressing thoughts." This form focuses on your personal preferences for how a number of different behaviors should be described. Below you will find several behaviors listed. After each behavior will be two different ways in which the behavior might be identified. For example: 


\section{Attending class}
a. sitting in a chair
b. looking at a teacher

Your task is to choose the option, a or b, that best describes the behavior for you. Simply select the option you prefer. Be sure to respond to every item. Please mark only one alternative for each pair. Remember, mark the description that you personally believe is more appropriate for each pair.

1. Making a list

$\bigcirc$ a. Getting organized

o b. Writing things down*

2. Voting
$\circ$ a. Influencing the election
$\circ$ b. Marking a ballot*

3. Taking a test
$\circ$ a. Answering questions*
- b. Showing one's knowledge

4. Eating
○. Getting nutrition
○ b. Chewing and swallowing*

\section{Loss aversion}


Consider a bet based on the toss of a (fair) coin. If the coin turns up heads then you win $\$ 20$, and if the coin turns up tails you lose $\$ 2$. Would you make this bet? For each of the following bets, please indicate if you would make the bet:

[individuals selected "yes" or "no"]

○ HEADS: win $\$ 20$ - TAILS: lose $\$ 2$

○ HEADS: win $\$ 20$ - TAILS: lose $\$ 5$

- HEADS: win $\$ 20$ - TAILS: lose $\$ 10$

- HEADS: win \$20 - TAILS: lose \$15

- HEADS: win \$20 - TAILS: lose \$20

- HEADS: win $\$ 20$ - TAILS: lose \$25 


\section{Appendix E: Full text of scenarios used in main analysis of Study 2}

Individuals saw one of the following scenario descriptions

- Most people shower in temperatures ranging from 115 degrees (very hot) to around 65 degrees (cold). While many people find warmer showers to be more pleasant than cooler showers, warmer showers cost more than cooler showers.

- Suppose you live near a bus route that is convenient for your work commute and you also own a car. You must decide whether to drive or take the bus to work every day. If you take the bud your commute will take 20-30 minutes longer. Driving a personal vehicle to and from work is more convenient than the bus, but you must pay for the additional fuel cost.

- Most lamps and lighting fixtures are compatible with incandescent light bulbs, LEDs and CFL (compact fluorescent) light bulbs. Some people choose to use incandescent light bulbs because they prefer the color and tone of their light. However, incandescent light bulbs use more energy than LED and CFL light bulbs.

- Many homes have an air conditioner (AC) installed in a window to keep a room cool during the hot months. Suppose you own a window AC unit, and are deciding what to do with it. If you don't use it you can store it in the house, give it away, or sell it. If you use it, the air conditioner will help you keep the room cool during the summer, but you must pay the energy costs.

- Many homes have a portable space heater to keep a room warm during the colder months. Suppose you own a portable space heater, and are deciding what to do 
with it. If you don't use it you can leave it unused in the house, give it away, or sell it. You can use it to keep the room warm during the winter, but you must pay the energy costs.

\section{Status quo manipulation and check}

For this scenario, suppose you currently [do the energy efficient/inefficient alternative]. This scenario asks you to assume that you currently [do a certain type of behavior]. What is [the behavior]?

- example: For this scenario, suppose you currently use cooler water to shower. This scenario asks you to assume that you currently use a certain type of water. What temperature is the water in this scenario?

○ warmer

$\circ$ cooler

\section{Cost manipulation}

Suppose you currently [do the energy efficient/inefficient alternative]. You are considering switching to [do the other alternative]. If you [do the alternative] you will [pay/save] \$x per [day/month/year] on energy costs.

- example: Suppose you currently shower using warmer water. You are considering switching to take showers using 15 degrees cooler water. This would be a noticeable, but not painful, difference in water temperature. If you use cooler water, you will save 12 cents per day on energy costs. 
Dependent measure

What do you think you would do? Please answer on the following scale, where 0 means that you definitely would take cooler showers and 10 means that you definitely would take warmer showers. (note: reverse code)

Fluency measures [7-point Likert scale from Very Difficult - Very Easy]

- Estimating how the energy decision would financially impact me was...

- Understanding what the energy decision meant was...

- The description of the financial impact seemed...

- The description of the energy decision seemed...

Involvement [7-point Likert scale from Not at all involved - Very involved]

- How involved were you in the energy decision?

Concern about money [5-point Likert scale from Not at all - A lot]

- How much do you care about saving money?

Concern about environment [5-point Likert scale from Not at all - A lot]

- How much do you care about saving the environment? 


\section{Appendix F: Text used in main analysis of Study 3}

Recommended cost frame

Now, suppose that in your neighborhood, most of your neighbors have energy meters in their houses. The meters have different settings for how to display energy costs. You know that all of your neighbors have left the meter on its default setting, which displays household energy expenses in the same way as the meter below.

[energy meter] Energy spending is $[\$ 3.75$ per day $/ \$ 114$ per month $/ \$ 1,370$ per year]

Write a sentence or two describing the energy meter that your neighbors see, including how much they typically spend on their home energy.

[open-ended response]

Suppose a neighbor is designing a flyer to tell other households in your neighborhood about the costs of various energy-related choices at home, similar to the yellow label you saw in the previous scenario.

Your neighbor wants to ensure that the costs are easy to understand, and asks for your suggestions on the following ways to describe the costs. Please rate each description below. 
[7-point Likert scale: Doesn't make any sense at all - Makes complete sense]

- “... costs $\$ 0.10$ per day"

- “... costs $\$ 3.10$ per month”

- “... costs $\$ 36.50$ per year”

Which description would you recommend that your neighbor use? [multiple choice selection]

- “... costs $\$ 0.10$ per day"

- “... costs $\$ 3.10$ per month"

- “... costs $\$ 36.50$ per year”

Preferred frame

Suppose you were designing a label like the yellow label you saw before. You want to convey the costs of various household activities and alternatives so that your neighbors understand the costs easily. To do this, you want to describe costs in a way that seems the most natural.

For example, you might say that eating at a restaurant instead of buying groceries costs $\$ 50$ more per week or $\$ 200$ more per month. Or you might say that leaving the lights on at home all day instead of turning them off costs $\$ 1$ more per day or $\$ 0.20$ more per lamp. 
Please select the description that you think makes the most sense for each activity below. There is no right or wrong answer - just select the choice that makes the most sense to you.

[multiple choice; frames include cost per day, cost per week, cost per month, cost per year, cost per trip, cost per load, cost per fill-up]

- My movie budget

- Using a space heater or window air conditioner

- Driving a gas-powered vehicle instead of an electric vehicle

- Using incandescent light bulbs instead of LED or CFL bulbs

- Going to the grocery store

- Taking public transportation to work instead of driving my own car

- My energy bill

- Washing laundry with hot water instead of cold water

- Using two refrigerators instead of one 